\title{
Environmental Geophysics, Offshore Bush River Peninsula, Aberdeen Proving Ground, Maryland
}

Energy Systems Division Argonne National Laboratory

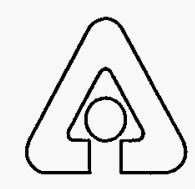

Operated by The University of Chicago, under Contract W-31-109-Eng-38, for the United States Department of Energy 


\section{Argonne National Laboratory}

Argonne National Laboratory, with facilities in the states of Illinois and Idaho, is owned by the United States Government, and operated by the University of Chicago under the provisions of a contract with the Department of Energy.

This technical memo is a product of Argonne's Energy Systems (ES) Division. For information on the division's scientific and engineering activities, contact:

Director, Energy Systems Division

Argonne National Laboratory

Argonne, Illinois 60439-4815

Telephone (708) 252-3724

Presented in this technical memo are preliminary results of ongoing work or work that is more limited in scope and depth than that described in formal reports issued by the ES Division.

Publishing support services were provided by Argonne's Information and Publishing Division (for more information, see IPD's home page: http://wuww.ipd.anl.gov/).

\section{Disclaimer.}

This report was prepared as an account of work sponsored by an agency of the United States Government. Neither the United States Government nor any agency thereof, nor any of their employees, makes any warranty, express or implied, or assumes any legal liability or responsibility for the accuracy, completeness, or usefulness of any information, apparatus, product, or process disclosed, or represents that its use would not infringe privately owned rights. Reference herein to any specific commercial product, process, or service by trade name, trademark, manufacturer, or otherwise, does not necessarily constitute or imply its endorsement, recommendation, or favoring by the United States Government or any agency thereof. The views and opinions of authors expressed herein do not necessarily state or reflect those of the United States Govermment or any agency thereof. 


\section{Environmental Geophysics, Offshore Bush River Peninsula, Aberdeen Proving Ground, Maryland}

by S.F. Miller, G.J. Kuecher, B.E. Davies, M.A. Benson, L.D. McGinnis, and C.A. Padar

Center for Environmental Restoration Systems, Energy Systems Division,

Argonne National Laboratory, 9700 South Cass Avenue, Argonne, Illinois 60439

November 1995

Work sponsored by United States Department of Defense, United States Army, Aberdeen Proving Ground, Maryland 
This report is printed on recycled paper. 


\section{Contents}

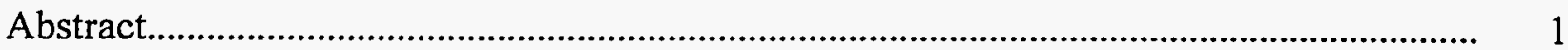

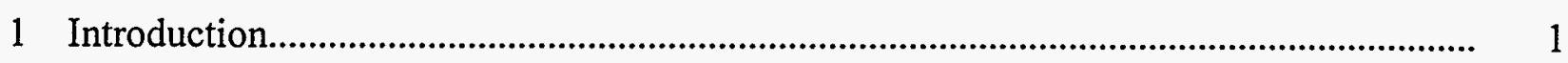

1.1 Regional Physiographic Setting and Site Survey .................................................. 3

1.2 Site Geology and Hydrogeology .................................................................. 5

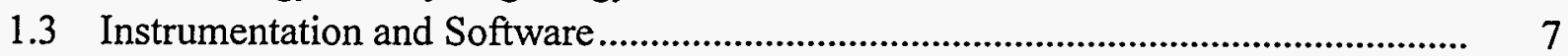

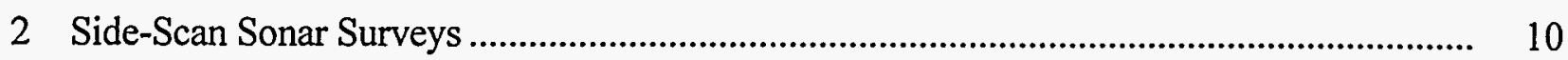

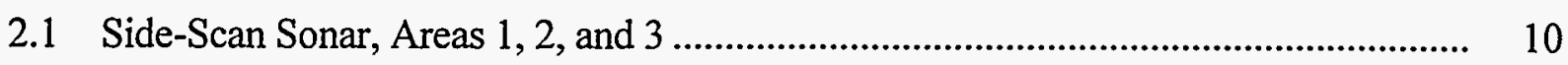

2.1.1 KC-1 Transect................................................................................... 10

2.1.2 KC-2 Transect................................................................................... 14

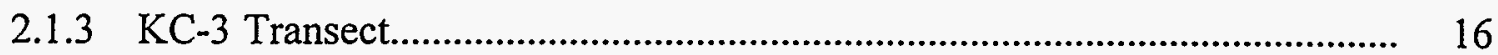

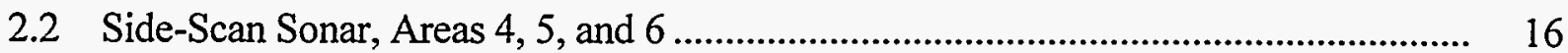

2.2.1 Transect Tapler Point-Eagle Point 1/4 f................................................... 16

2.2.2 Transect Tapler Point-Eagle Point 2/4 f................................................... 16

2.2.3 Transect Tapler Point-Eagle Point 3/4 ................................................... 19

2.2.4 Transect Tapler Point-Eagle Point 4/4 ..................................................... 19

3 Continuous Profiling Magnetometry ................................................................. 21

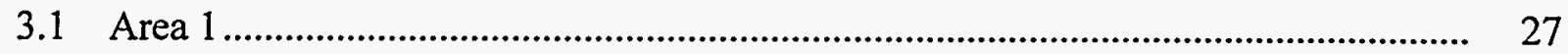

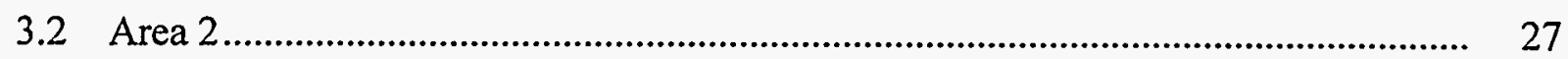

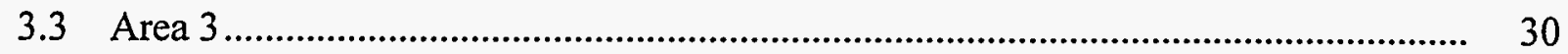

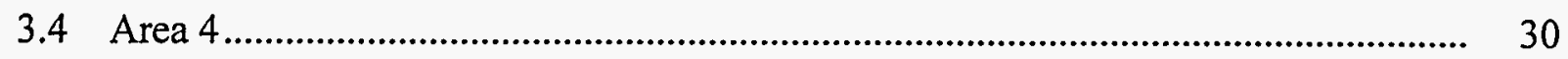

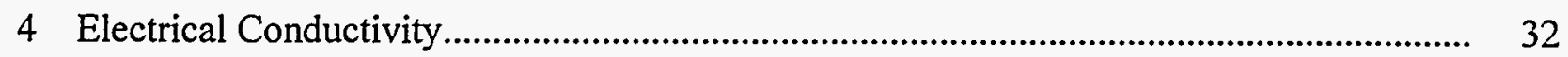

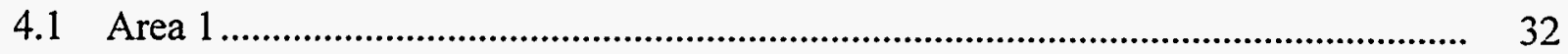

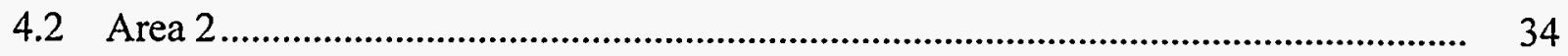

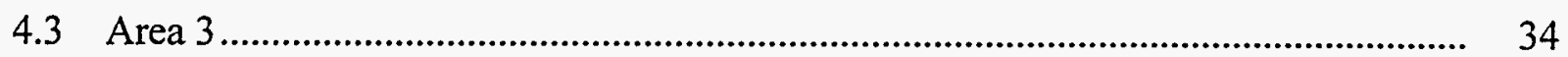

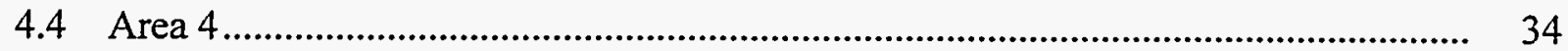

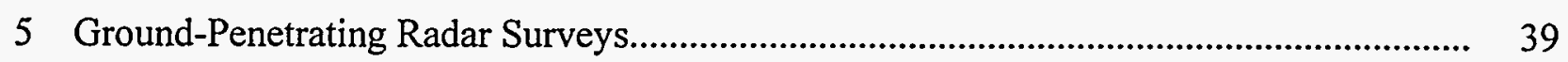

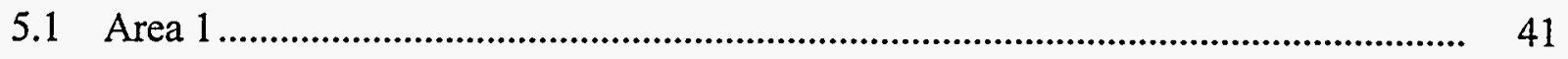

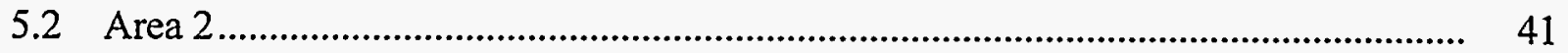

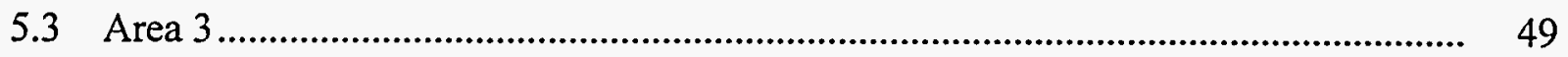

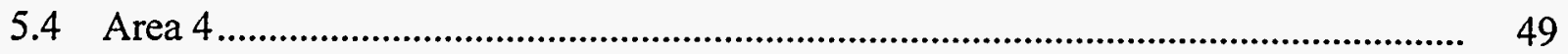

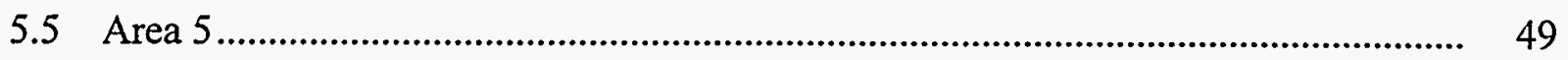

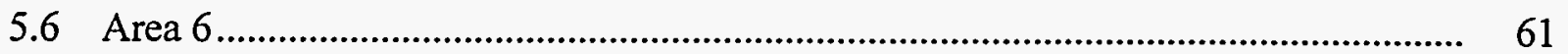




\section{Contents (Cont.)}

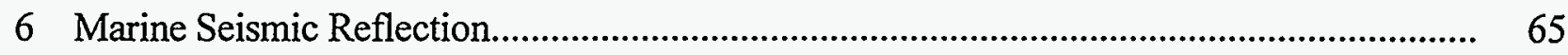

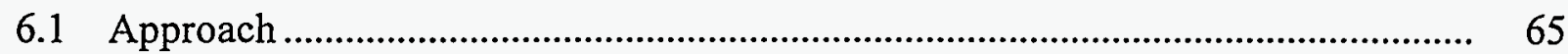

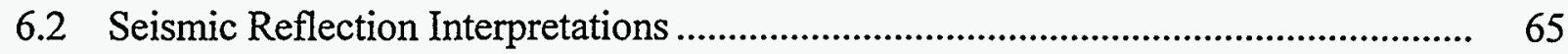

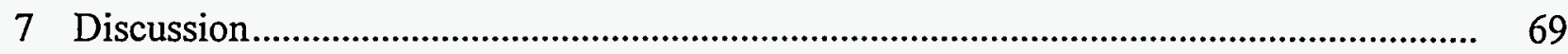

7.1 Synthesis of Anthropogenic Anomalies....................................................................... 69

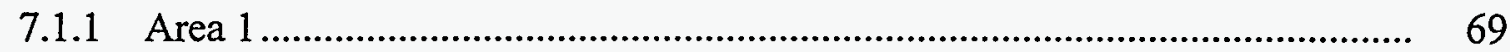

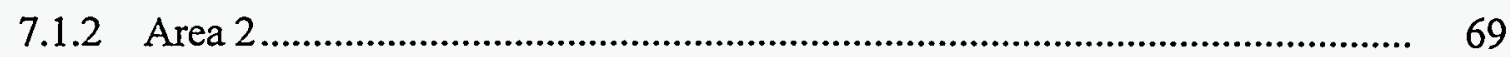

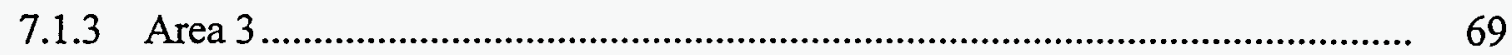

7.1.4 Area 4 ............................................................................................ 70

7.2 Paleochannel Synthesis ........................................................................................ 70

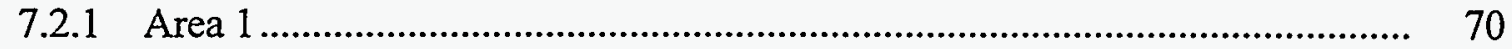

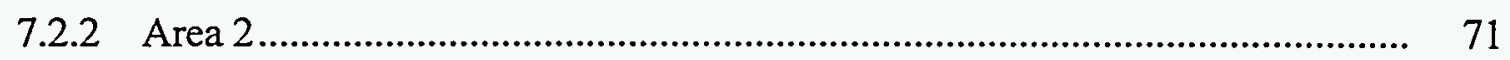

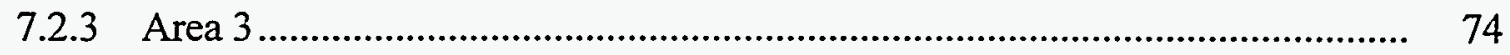

7.2.4 Area 4

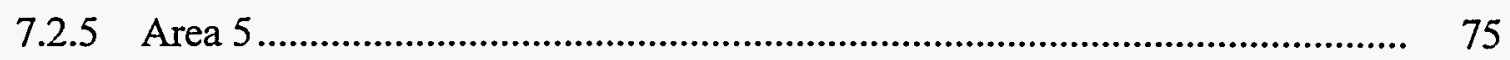

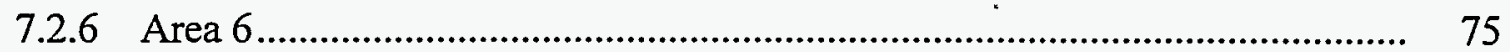

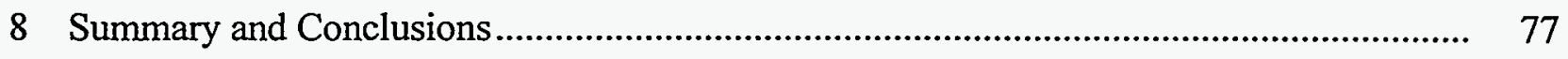

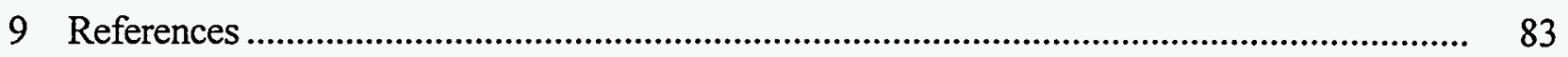

\section{Tables}

1 Locations and Descriptions of Magnetic Anomalies Detected Offshore of the BRP......... 28

\section{Figures}

1 Topography and Site Features of the Bush River Peninsula ................................................ 2

2 Offshore Geophysical Survey Areas around Bush River Peninsula..................................... 4

3 Geologic Cross Section of the Bush River Peninsula ............................................................ 6

4 Configuration of Magnetometer and EM-31 in Zodiac....................................................... 9 


\section{Figures (Cont.)}

5 Location of Side-Scan Sonar Profiles around Bush River Peninsula ................................. 11

6 Location of Side-Scan Sonar Profiles in Kings Creek ........................................................ 12

7 Side-Scan Profile near Fix 25 .................................................................................. 13

8 Side-Scan Profile near Fix 29 ................................................................................ 13

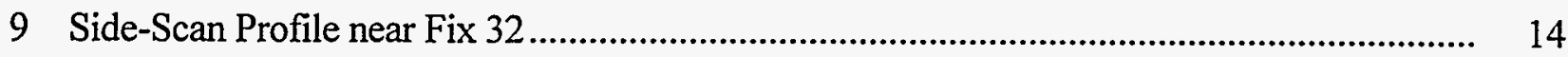

10 Side-Scan Profile near Fix 39 ................................................................................... 15

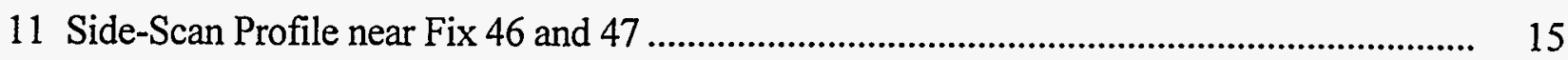

12 Location of Side-Scan Sonar Profiles in Bush River........................................................ 17

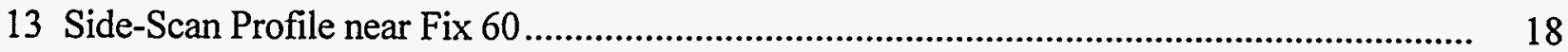

14 Side-Scan Profile near Fix 62 ................................................................................. 18

15 Side-Scan Profile near Fix 66 ........................................................................................ 19

16 Side-Scan Profile near Fix 86 ....................................................................................... 20

17 Location of Geophysical Survey Areas 1-4 around Bush River Peninsula......................... 22

18 Area 1, Total Field Magnetics Map............................................................................... 23

19 Area 2, Total Field Magnetics Map.............................................................................. 24

20 Area 3, Total Field Magnetics Map............................................................................ 25

21 Area 4, Total Field Magnetics Map............................................................................... 26

22 Area 1, EM-31 Electromagnetics Map ………………................................................. 33

23 Area 2, EM-31 Electromagnetics Map ....................................................................... 35

24 Area 3, EM-31 Electromagnetics Map ………………................................................. 36

25 Area 4, EM-31 Electromagnetics Map ........................................................................ 37

26 Location of Offshore GPR Profiles................................................................................ 40

27 A: Area 1 GPR Profile; B: Area 1 GPR Profile with Interpretation.................................... 42 


\section{Figures (Cont.)}

28 A: Area 1 GPR Profile; B: Area 1 GPR Profile with Interpretation.................................... 43

29 A: Area 1 GPR Profile; B: Area 1 GPR Profile with Interpretation.................................... 44

30 A: Area 2 GPR Profile; B: Area 2 GPR Profile with Interpretation.................................... 45

31 A: Area 2 GPR Profile; B: Area 2 GPR Profile with Interpretation.................................... 46

32 A: Area 2, Eastern Extension GPR Profile; B: Area 2, Eastern Extension GPR Profile with Interpretation ................................................................................... 47

33 A: Area 2, Eastern Extension GPR Profile; B: Area 2, Eastern Extension GPR Profile with Interpretation .................................................................................. 48

34 A: Area 3 GPR Profile; B: Area 3 GPR Profile with Interpretation................................... 50

35 A: Area 3 GPR Profile; B: Area 3 GPR Profile with Interpretation.................................... 51

36 A: Area 3 GPR Profile; B: Area 3 GPR Profile with Interpretation.................................... 52

37 A: Area 3 GPR Profile; B: Area 3 GPR Profile with Interpretation.................................... 53

38 A: Area 4 GPR Profile; B: Area 4 GPR Profile with Interpretation................................... 54

39 A: Area 4 GPR Profile; B: Area 4 GPR Profile with Interpretation.................................... 55

40 A: Area 4 GPR Profile; B: Area 4 GPR Profile with Interpretation................................... 56

41 A: Area 4 GPR Profile; B: Area 4 GPR Profile with Interpretation.................................... 57

42 A: Area 5 GPR Profile; B: Area 5 GPR Profile with Interpretation...................................... 58

43 A: Area 5 GPR Profile; B: Area 5 GPR Profile with Interpretation...................................... 59

44 A: Area 5 GPR Profile; B: Area 5 GPR Profile with Interpretation...................................... 60

45 A: Area 6 GPR Profile; B: Area 6 GPR Profile with Interpretation...................................... 62

46 A: Area 6 GPR Profile; B: Area 6 GPR Profile with Interpretation..................................... 63

47 A: Area 6 GPR Profile; B: Area 6 GPR Profile with Interpretation.................................... 64

48 Location of Marine Seismic Profile .................................................................................... 66

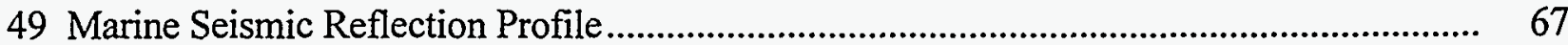


Figures (Cont.)

50 GPR and EM-31 Profile across Area 1 Paleochannel …...................................................... 72

51 Locations of Paleochannels on the Basis of Geophysical Surveying .................................. 73

52 Locations of Cross Section A-A'................................................................................ 79

53 Cross Section A-A' across Bush River Peninsula and Kings Creek................................... 80

54 GPR Depth Model \#1......................................................................................... 81

55 GPR Depth Model \#2........................................................................................... 81 


\title{
Environmental Geophysics, Offshore Bush River Peninsula, Aberdeen Proving Ground, Maryland
}

\author{
by \\ S.F. Miller, G.J. Kuecher, B.E. Davies, M.A. Benson, \\ L.D. McGinnis, and C.A. Padar
}

\begin{abstract}
Geophysical studies in shallow waters adjacent to the Bush River Peninsula, Edgewood Area of Aberdeen Proving Ground, Maryland, have delineated the extent of waste disposal sites and established a hydrogeologic framework, which may control contaminant transport offshore. These studies indicate that during the Pleistocene Epoch, alternating stands of high and low sea levels resulted in a complex pattern of shallow channel-fill deposits around the Bush River Peninsula. Ground-penetrating radar studies reveal paleochannels greater than $50 \mathrm{ft}$ deep. Some of the paleochannels are also imaged with marine seismic reflection. Conductivity highs measured with the EM-31 are also indicative of paleochannels. This paleochannel depositional system is environmentally significant because it may control the shallow groundwater flow regime beneath the peninsula. Magnetic, conductivity, and side-scan sonar anomalies outline anthropogenic anomalies in the study area. On the basis of geophysical data, underwater anthropogenic materials do exist in some isolated areas, but large-scale offshore dumping has not occurred in the area studied.
\end{abstract}

\section{Introduction}

An environmental geophysical study was conducted offshore from the Bush River Peninsula (BRP) in both Kings Creek and Bush River in the Edgewood Area of Aberdeen Proving Ground (APG), Maryland (Figure 1). The study area includes Kings Creek and the western shore of Bush River from Tapler Point to Eagle Point. Areas offshore from the Kings Creek Disposal Site, 30th Street Landfill, Chemical Munitions Burial Site 1 (CMBS-1), CMBS-2, CMBS-3, Tapler Point Dredge Material Site, and the 22nd Street Landfill are also included.

The objectives of the offshore geophysical investigations (as outlined in the workplan) are as follows:

1. Define the areal, offshore extent of waste disposal sites; 


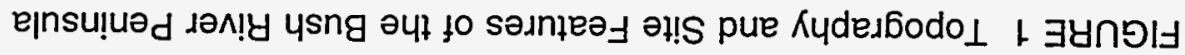

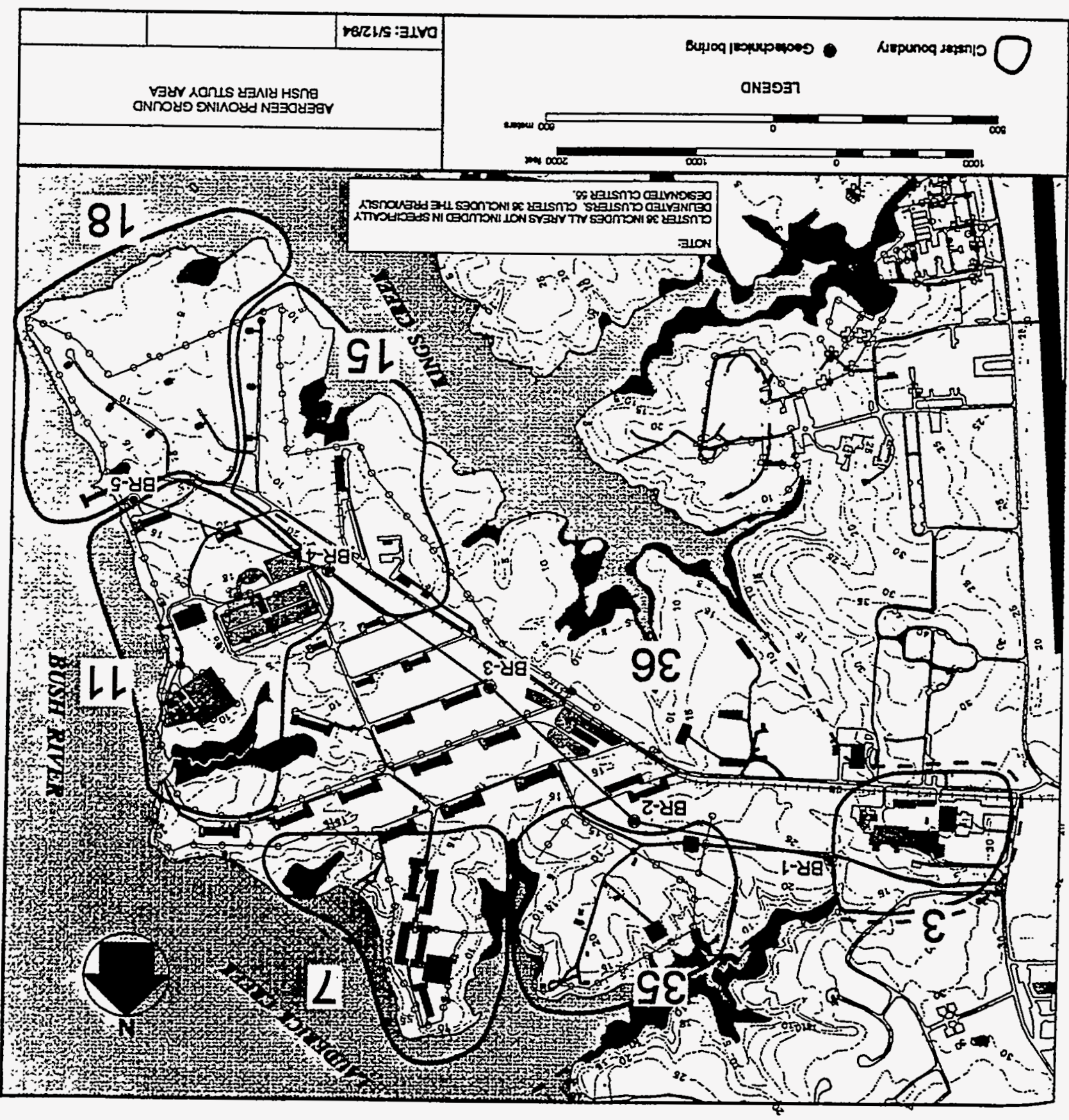


2. Determine the hydrogeologic framework offshore of the BRP, including the configuration of the angular unconformity separating Pleistocene sediment from Atlantic Coastal Plain sediments of Cretaceous age and the general structural configuration of the coastal plain sediments beneath the unconformity; and

3. Provide information on the geologic integrity and continuity of strata underlying the transition zone from land to offshore at the Kings Creek Disposal site and the 22nd Street Landfill.

Field activities were conducted during the summer and fall of 1994. Geophysical techniques used during this study include side-scan sonar, magnetics, electromagnetics, groundpenetrating radar (GPR), and marine seismic reflection. Magnetic, electromagnetic, and side-scan sonar surveys were performed to characterize the subbottom sediments and to approximate the offshore areal extent of possible landfill sites. The GPR, marine seismic reflection, and electromagnetic surveys were used to determine the hydrogeologic framework beneath the site.

\subsection{Regional Physiographic Setting and Site Survey}

The BRP lies within the Atlantic Coastal Plain physiographic province of Maryland. The study area is located in the waters around the BRP, which is bounded by Lauderick Creek to the north, Bush River to the east, and Kings Creek to the south (Figure 1). The BRP is a remnant of Pleistocene subareal erosion. Recent sediment bottom in Kings Creek, Lauderick Creek, and Bush River consists of sand, silt, and clay deposited following the most recent Pleistocene sea level low stand. Bush River is one of the major estuarine channels on the western shore of Chesapeake Bay.

A survey grid, with nodes spaced at 100 - $\mathrm{ft}$ intervals, was established offshore to guide the geophysical surveys. The survey area began south of a small inlet to Kings Creek, which marked the northwestern boundary of onshore geophysical surveys performed by ANL, and continued into the Bush River, around Tapler Point, north to the Bush River Dock, and finished at Eagle Point. The survey area extended a minimum of $200 \mathrm{ft}$ offshore.

The survey area was divided into six subareas around the BRP (Figure 2). Survey boundaries include indentations to the irregular shoreline. Stakes were placed at 100 -ft intervals within each subarea to fill out the survey grid. Upon completion of the geophysical surveys, Global Positioning System (GPS) measurements were made to obtain survey coordinates at the corners of each subarea. GPR and side-scan sonar data were collected in all six subareas, but ANL only collected electromagnetic and magnetic data in areas 1-4. Coordinate nomenclature in all discussions to follow refers to the $\mathrm{Y}$-direction as North and the $\mathrm{X}$-direction as East. 


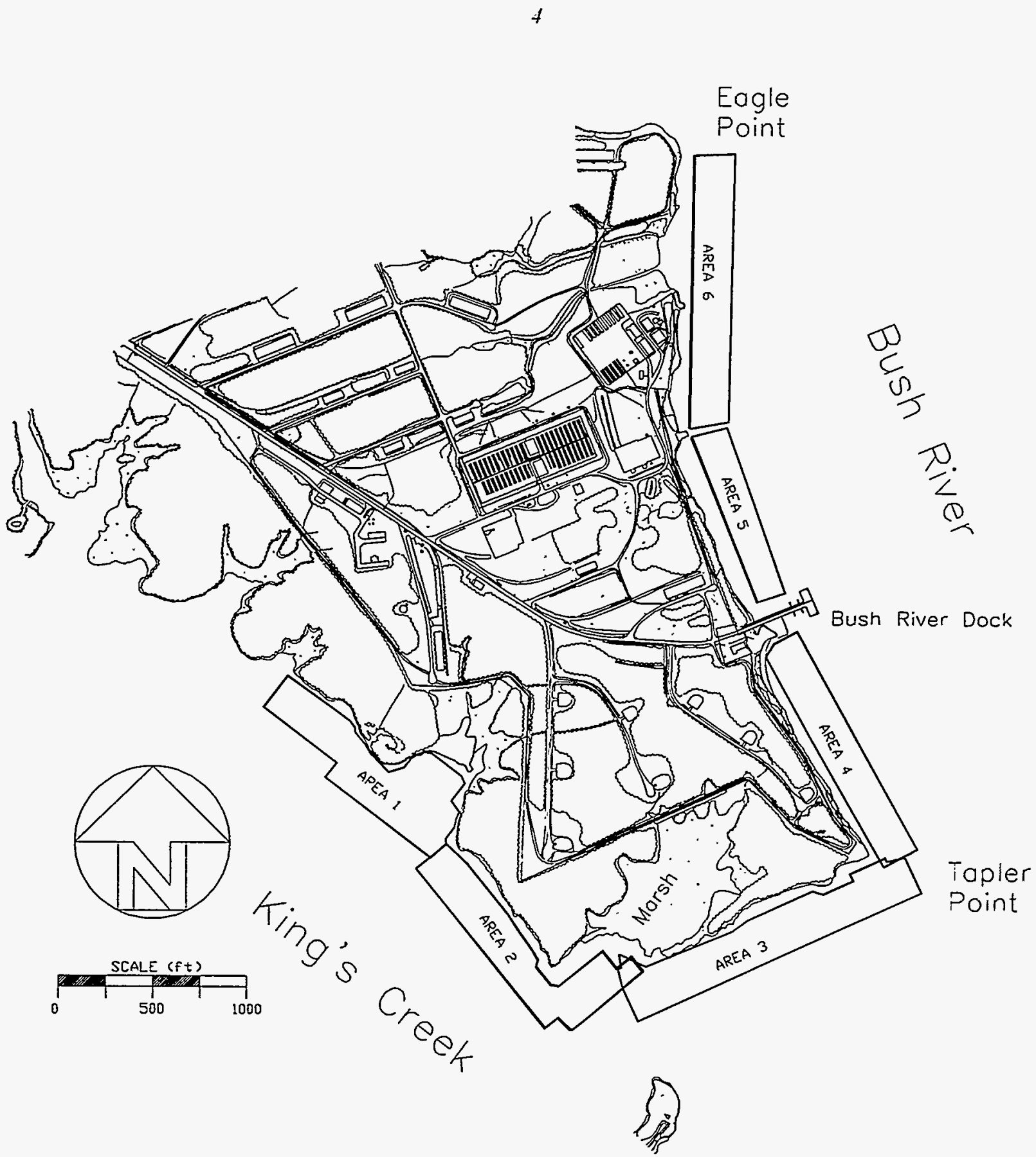

FIGURE 2 Offshore Geophysical Survey Areas around Bush River Peninsula 


\subsection{Site Geology and Hydrogeology}

On the basis of numerous deep borings in the area and seismic refraction profiles on Beach Point, approximately 2,000 ft south, a Precambrian-age crystalline basement is interpreted to lie at depths of approximately $450 \mathrm{ft}$ and approximately $650 \mathrm{ft}$ below mean sea level (MSL) beneath the BRP (Hansen 1978; Otton and Mandle 1984; Oliveros and Vroblesky 1989; McGinnis et al. 1994). The crystalline basement surface dips to the southeast at an angle of approximately one degree (Bennett and Meyer 1952; Dingman, Ferguson, and Martin 1956; Southwick, Owens, and Edwards 1969) to one and one-half degrees (Hansen 1978). East of the fall line, including all of the areas described in this report, unconsolidated Atlantic Coastal Plain sediments overlie Piedmont basement rocks.

Atlantic Coastal Plain sediments beneath the Edgewood Area of APG were deposited during the Mesozoic Cretaceous Period and the Cenozoic Pleistocene Epoch (Oliveros and Vroblesky 1989; Thurmond 1993). A thin cover of Holocene-age unconsolidated, estuarine sediments lies in wetland areas at APG. Unconsolidated to moderately consolidated sediments comprise the Potomac Group, which was deposited during the Lower Cretaceous. The gravelly sand, sand, clay, and interbedded sand and clay units are continental in origin and represent several subenvironments, namely fluviatile, channel-fill, and overbank deposits (Southwick, Owens, and Edwards 1969). Although the Potomac Group has been further subdivided into formations near Baltimore, they have not been differentiated beneath APG (Oliveros and Vroblesky 1989).

Resting unconformably on the Potomac Group is the Pleistocene-age Talbot Formation, with minor amounts of recent alluvium (Oliveros and Vroblesky 1989). The gravelly sand, sand, and silty clay deposits are marginal marine in origin and consist primarily of fluvial and estuarine deposits (Southwick, Owens, and Edwards 1969). During the Pleistocene Epoch, sea level fell periodically, and three main channels were cut into the Cretaceous sediments. The Talbot Formation is commonly found as paleochannel-fill complexes deposited during subsequent sea level rises (Kerhin et al. 1988). Beneath the BRP, the Talbot Formation is thickest in paleochannel-fill complexes, although thin overbank and estuarine deposits are found outside of these paleochannels.

A hydrogeologic cross section, running northwest to southeast along the BRP (adapted from Thurmond 1993), is presented in Figure 3. The location of the cross section is shown in Figure 1. The sediments beneath the BRP are a complex of clays, silts, sands, and gravels. Lorah and Vroblesky (1989) describe a similar section as follows: "Hydrogeologic units were defined partly on the basis of hydrogeologic characteristics of the units; therefore, the boundaries between the hydrogeologic units do not necessarily correspond with the contacts between geologic units." The surficial aquifer sediments are primarily contained in the Talbot Formation and appear to pinch-out in the northwestern end of the cross section (Figure 3). Aquifers beneath the surficial aquifer consist of Potomac Group sediments. Pleistocene and Cretaceous sands appear lithologically indistinguishable. 

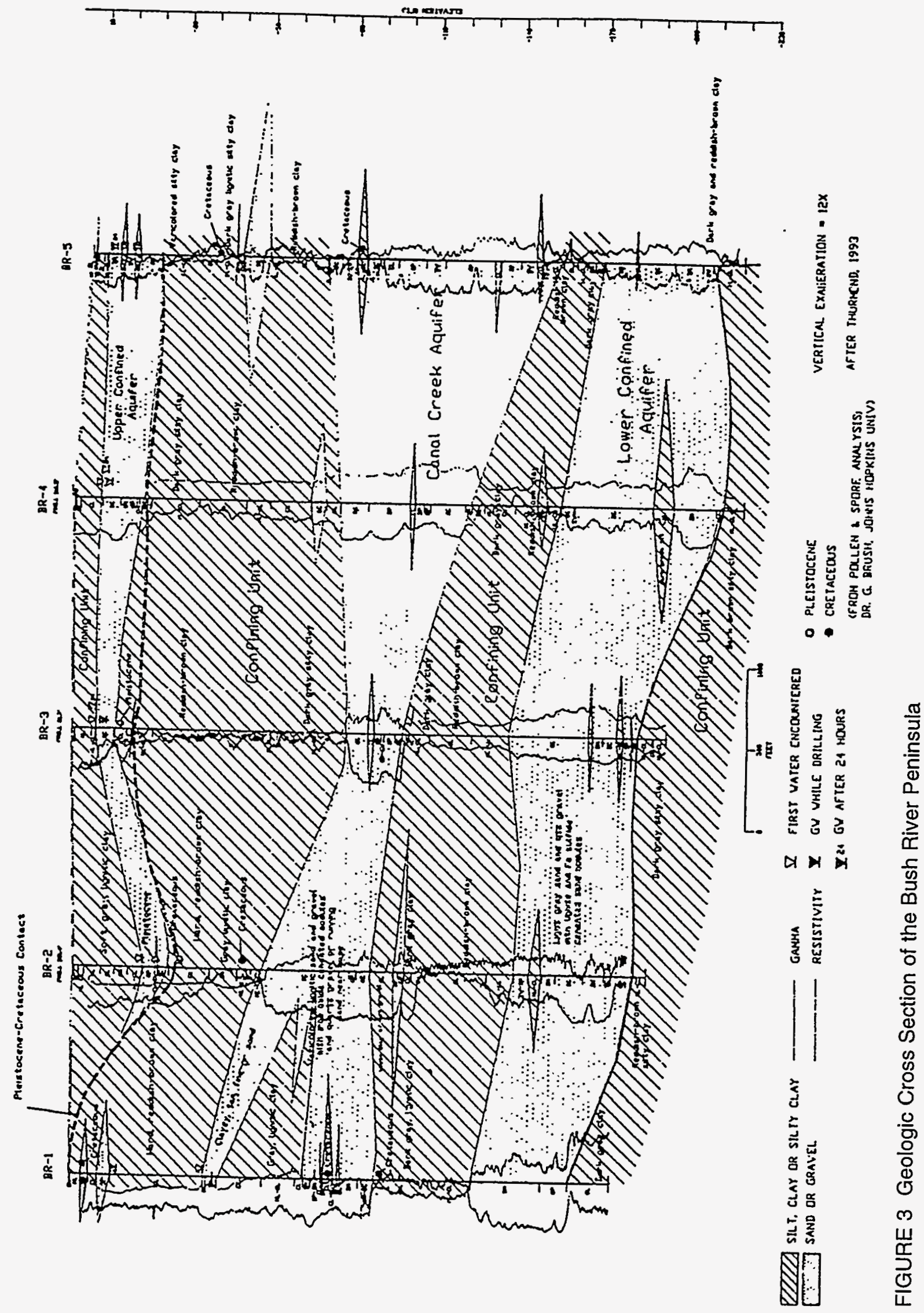
The Quaternary Talbot Formation unconformably overlies a local clay aquitard member of the Potomac Group sediments. The unconformity is not readily discernible in drill core or geophysical logs where the base of the Pleistocene also consists of clay.

From observations at the BRP study area and from studies elsewhere in the Edgewood Area, including Beach Point (McGinnis et al. 1994) and Canal Creek (Lorah and Vroblesky 1989 and McGinnis et al. 1994b), it is evident that a tributary system of Pleistocene-age was locally incised into Potomac Group sediments. Paleochannel fill sequences provide the conduit for shallow groundwater flow beneath the Bush River, and these sequences permit juxtaposition with Potomac Group aquifers for local recharge.

\subsection{Instrumentation and Software}

Instruments used to collect data at the site included the following:

- Side-scan sonar,

- Cesium vapor magnetometer,

- EM-31 electrical conductivity instrument,

- $\quad$ SIR-2 GPR, and

- Marine seismic reflection.

The following paragraphs describe each of these instruments and the software (if applicable) used to reduce the side-scan sonar data and the electromagnetic data; process the magnetic, GPR, and seismic reflection data; and produce contour maps.

Side-scan sonar surveys were performed by using an EG\&G Model 272 towfish operating at $100 \mathrm{kHz}$ under tow speeds of 3-3.5 knots. Data were recorded with an EG\&G Model 260 analog recorder. The side-scan sonar data were collected by using ANL's ERDA-1 research vessel prior to the establishment of the survey grids. On-board navigation used the Trimble NavGraphic XL GPS system (nondifferentially corrected). Some manual shifting in the position of survey way points relative to known range poles was required.

Total-field magnetic data were acquired by using the Model G-822L cesium vapor magnetometer manufactured by EG\&G Gecmetrics. The magnetometer is a continuous-recording (10 readings per second), total-field, microprocessor-based instrument capable of resolving anomalies to one nanotesla $(1 \mathrm{nT})$. 
Electrical conductivity measurements were made with a Model EM-31, an electromagnetic instrument manufactured by Geonics Limited, which provides mean values of conductivity, in millisiemens per meter $(\mathrm{mS} / \mathrm{m})$, for soils ranging from 0 to approximately $18 \mathrm{ft}$ in depth. Apparent conductivities measured by the EM-31 are weighted mean values measured over the entire depth range, with greater weights applied to shallower depths.

Magnetic and electromagnetic data were collected simultaneously from an inflatable Zodiac boat. The magnetometer was mounted on the port side of the boat, while the EM-31 was positioned on the starboard side; approximately $10 \mathrm{ft}$ separated the two instruments. The instrument configuration is shown in Figure 4. Tests were performed prior to surveying to determine the required separation between the instruments to avoid interference from each other and from the electric trolling motor.

Initial reduction of the electromagnetic and total-field magnetic data was completed by using DAT 31 software provided by Geonics Limited. The United States Geological Survey (USGS) minimum curvature program MINC (Cordell, Philips, and Godsen 1992) was used for gridding. Color contour maps presenting the electromagnetic and total-field magnetic data were produced by using COLORMAP software developed by Argonne National Laboratory (ANL) (Thompson 1994).

GPR surveying was accomplished with a model SIR-2, manufactured by Geophysical Survey Systems, Inc. (GSSI). Data from the SIR-2 system were downloaded directly to a personal computer. Continuous profiling was performed by using 100 -megahertz (MHz) frequency antennae in the bistatic mode. The antennae rested directly on the bottom of an inflated rubber boat, with a separation of $4 \mathrm{ft}$. The rubber boat was towed approximately $15 \mathrm{ft}$ behind a small aluminum bass boat. Profiles were collected as the boat traveled at 1-2 knots. An IBM-compatible processing computer was located in a field office to download and check the radar profiles and to allow preliminary data processing in the field. Radan III computer software, written by GSSI, was used for processing the GPR data.

The marine seismic-reflection system consisted of a sound source, hydrophone streamer, amplifier, filter, and graphic recorder. The Bubble Pulser ${ }^{\mathrm{TM}}$ (model BPV-520), manufactured by Datasonics, was used as the low-frequency sound source $(365-1030 \mathrm{~Hz})$. The system was controlled by an EPC thermal graphic recorder (model 9800), and hydrophones were contained in a custom-built hydrophone streamer. The Bubble Pulser used a Krohn-Hite (model 3988) amplifier. Seismic reflection data were collected by using ANL's ERDA-1 research vessel. Bubble Pulser reflection records were recorded as analogue data and printed with respect to time and known way-point fixes. 


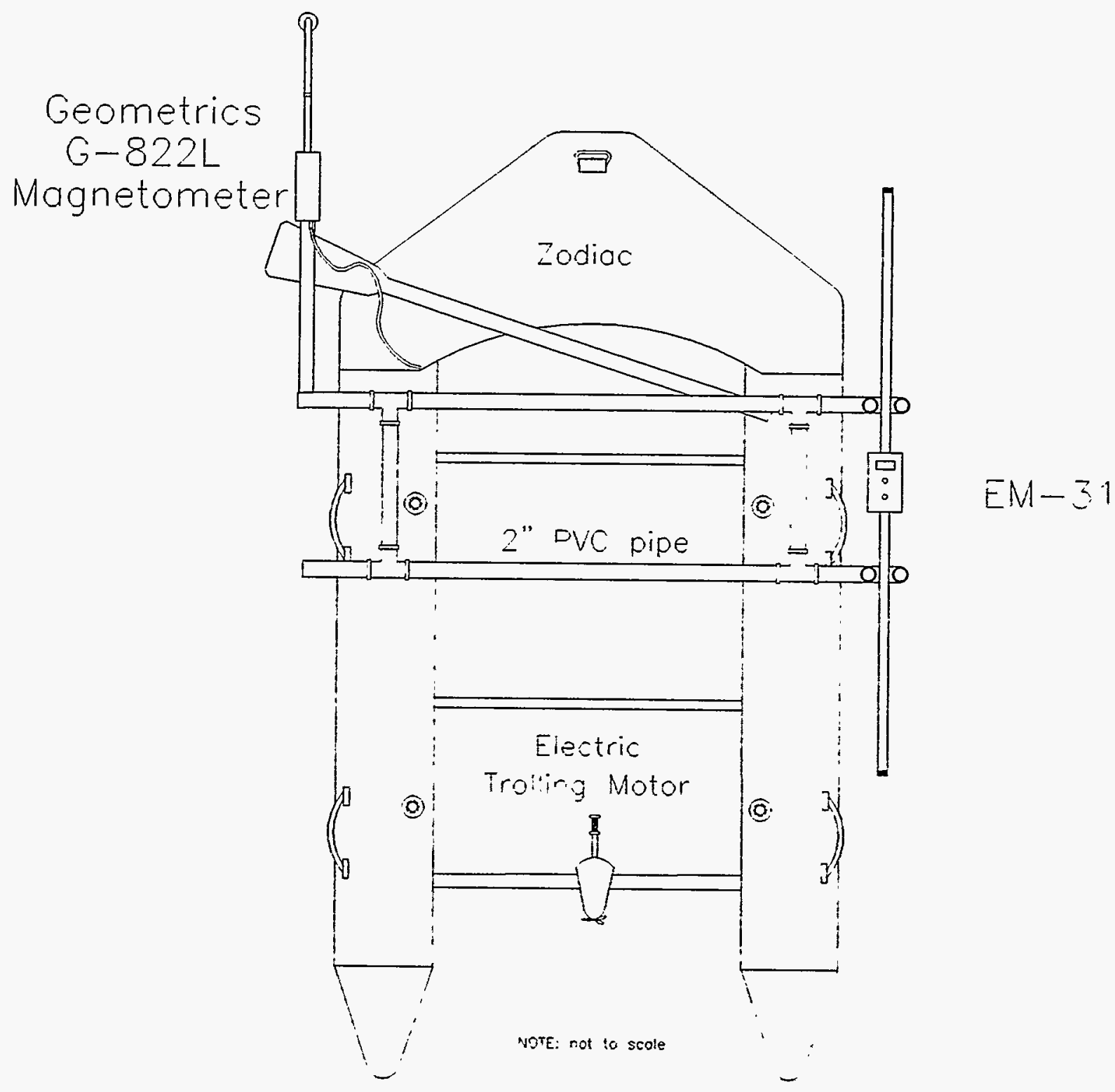

FIGURE 4 Configuration of Magnetometer and EM-31 in Zodiac 


\section{Side-Scan Sonar Surveys}

Side-scan sonar data were acquired in shallow water areas bordering the BRP between July 13 and July 16, 1994. The objective of this study was to locate debris push-outs, drums, unexploded ordnance, or other unidentified objects in bottom sediments of Kings Creek, Lauderick Creek, and in the offshore area east of the BRP. A base map of adjusted side-scan coverage in relation to Areas $1-6$ is provided in Figure 5.

Each side-scan transect provides approximately $100 \mathrm{~m}$ lateral coverage and $50 \mathrm{~m}$ along the starboard and port sides of the tow fish. The shoreline scarp is clearly visible on side-scan records when the tow fish approaches within $50 \mathrm{~m}$ of shore. Time is periodically annotated on the starboard record; each annotation often coincides with way point and range pole fixes. Gain was manually adjusted in an attempt to balance the brightness between starboard and port records. Complete balance could not be achieved in the field.

All side-scan figures presented in this discussion were balanced for brightness by photographic methods. Each figure shows 100 -m lateral coverage by approximately $90 \mathrm{~m}$ alongcourse. At least one registering way-point fix is included within each figure for reference.

Anthropogenic contributions to bottom images include pier footings, pilings, buildings, ERDA prop wash marks on water bottom, debris push-outs, drums, unexploded ordnance, scrap metal, sunken ships, and other unidentifiable objects. Natural contributions to bottom images include reflectivity change due to bottom grain size, sunken logs, branches, slumping shore escarpments, and fallen trees.

\subsection{Side-Scan Sonar, Areas 1, 2, and 3 (Kings Creek Transects)}

Three shore-parallel transects were conducted in the Kings Creek area (Figure 6). These transects are delimited as follows: (1) $\mathrm{KC}-1$ originates at WP 24 and terminates at WP 38, (2) $\mathrm{KC}-2$ originates at WP 39 and terminates at WP 52, and (3) KC-3 originates at WP 53 and terminates at WP 65. Along these transects, five areas are illustrated (Figure 6), which represent coverage provided in Figures 7-11. Figures will be presented in the discussion of each respective transect.

\subsubsection{KC-1 Transect}

The $\mathrm{KC}-1$ transect includes the area surveyed by EM-31, magnetics, and GPR in Areas 1 , 2 , and 3 (see Figure 5). The KC-1 transect commenced in the vicinity of Tapler Point and proceeded westerly along the north shore of Kings Creek. Distance from shore was less than 


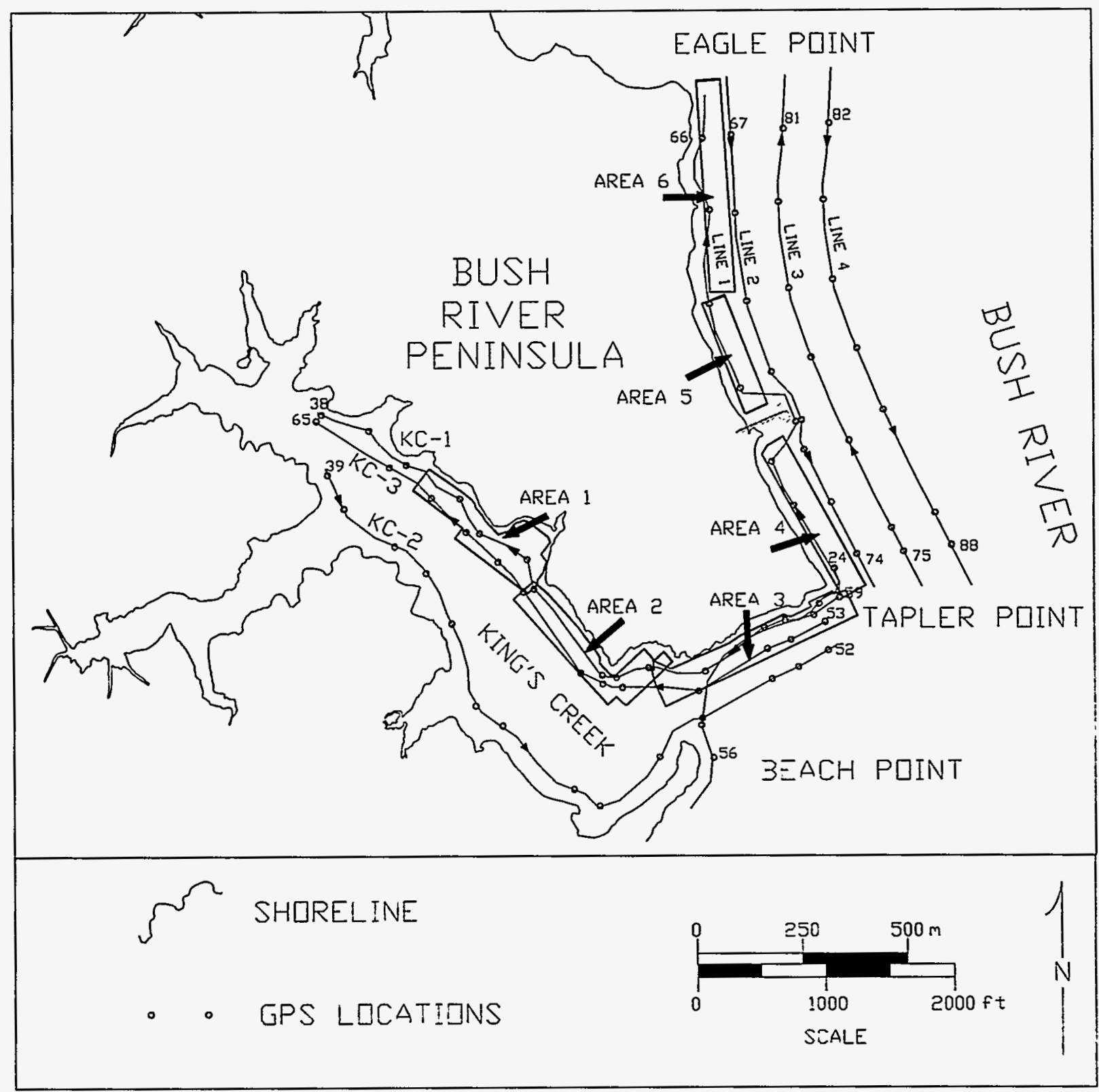

FIGURE 5 Location of Side-Scan Sonar Profiles around Bush River Peninsuia

$50 \mathrm{~m}$ over most of the transect, as determined by the presence of a shore scarp in most of the starboard record. Three side-scan figures are provided in the $\mathrm{KC}-1$ discussion, each illustrating features of concern along this transect.

Near the start of KC-1 on the record's starboard side, a polygonal shape of probable anthropogenic origins is evident (Figure 7) in the vicinity of Fix 25 . The feature, delimited by arrows on the starboard record, measures approximately $32 \mathrm{~m}$ along shore and projects approximately $25 \mathrm{~m}$ offshore. Polygonal and circular patterns are evident within the feature. Historical records at APG do not indicate the former existence of a building or a fence line, 


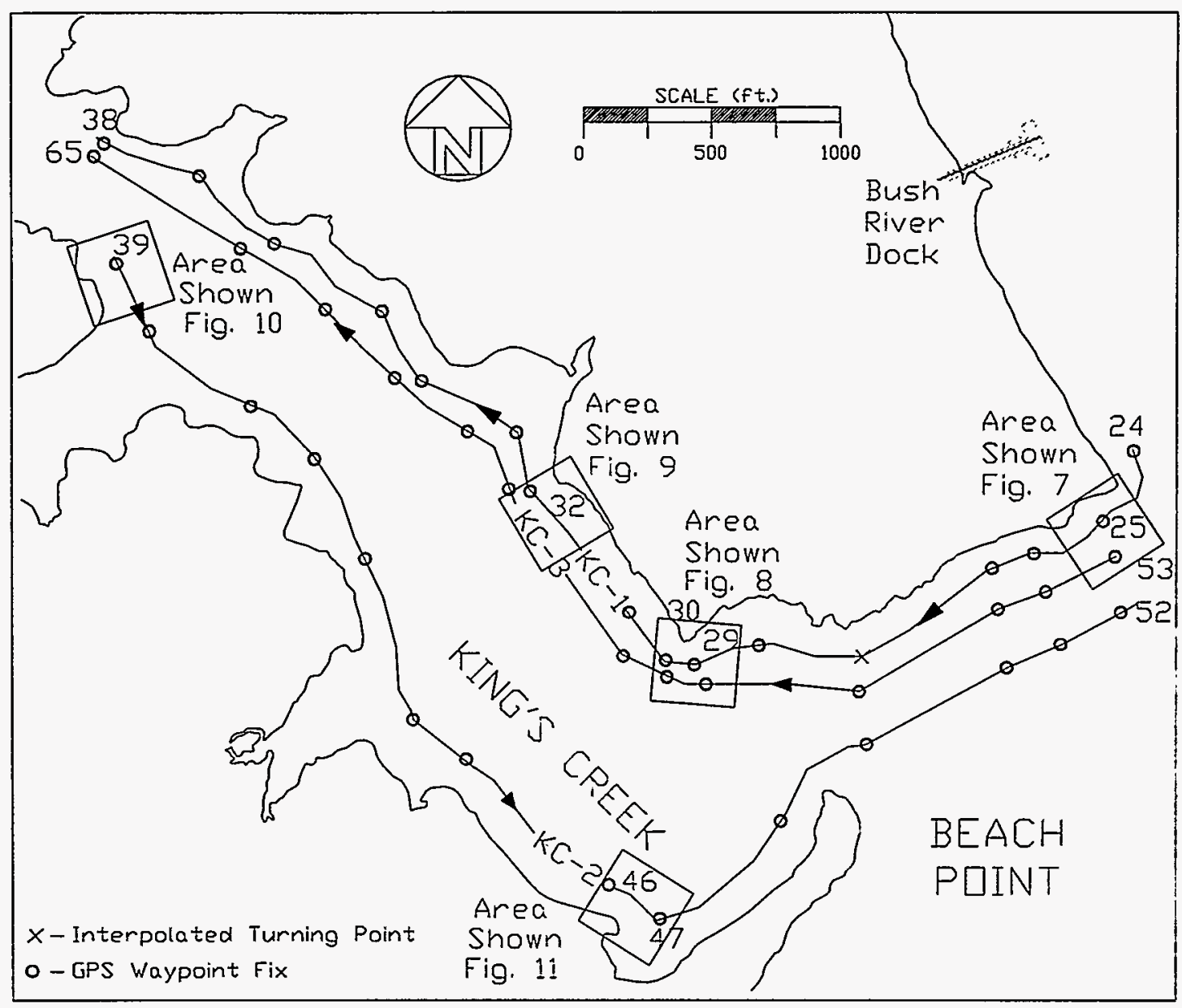

FIGURE 6 Location of Side-Scan Sonar Profiles in Kings Creek

leaving the possibility of a structure that pre-dates APG. On the $\mathrm{KC}-1 \mathrm{~A}$ port record, approximately $35 \mathrm{~m}$ offshore from the seaward margin of the previously described feature, lies two small, rectangular shapes that may be related to the feature seen on the starboard record.

On the KC-1B starboard record (Figure 8), in the vicinity of Fix 29, the shore scarp has experienced bank failure, or this may be a debris push-out area.

On the KC-1C starboard record (Figure 9), in the vicinity of Fix 32, a shore-parallel assemblage of scattered rectangular features is seen. The largest of these features is approximately $4 \mathrm{~m}$ in length, and the smallest resolvable object is approximately $1 \mathrm{~m}$ in length. In addition, a long, shore-parallel, polygonal feature, which may be a submerged fence line, is revealed. 


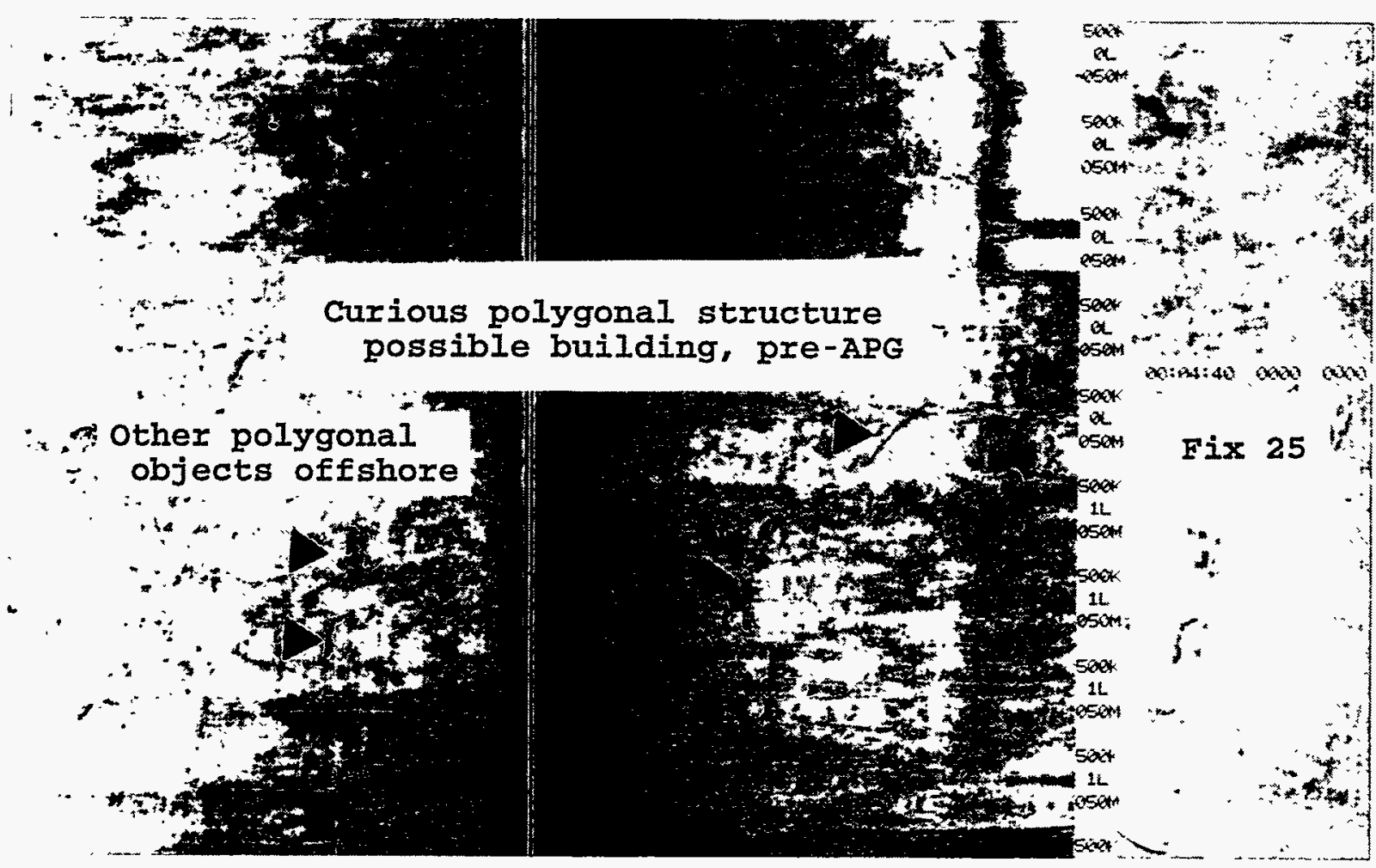

FIGURE 7 Side-Scan Profile near Fix 25

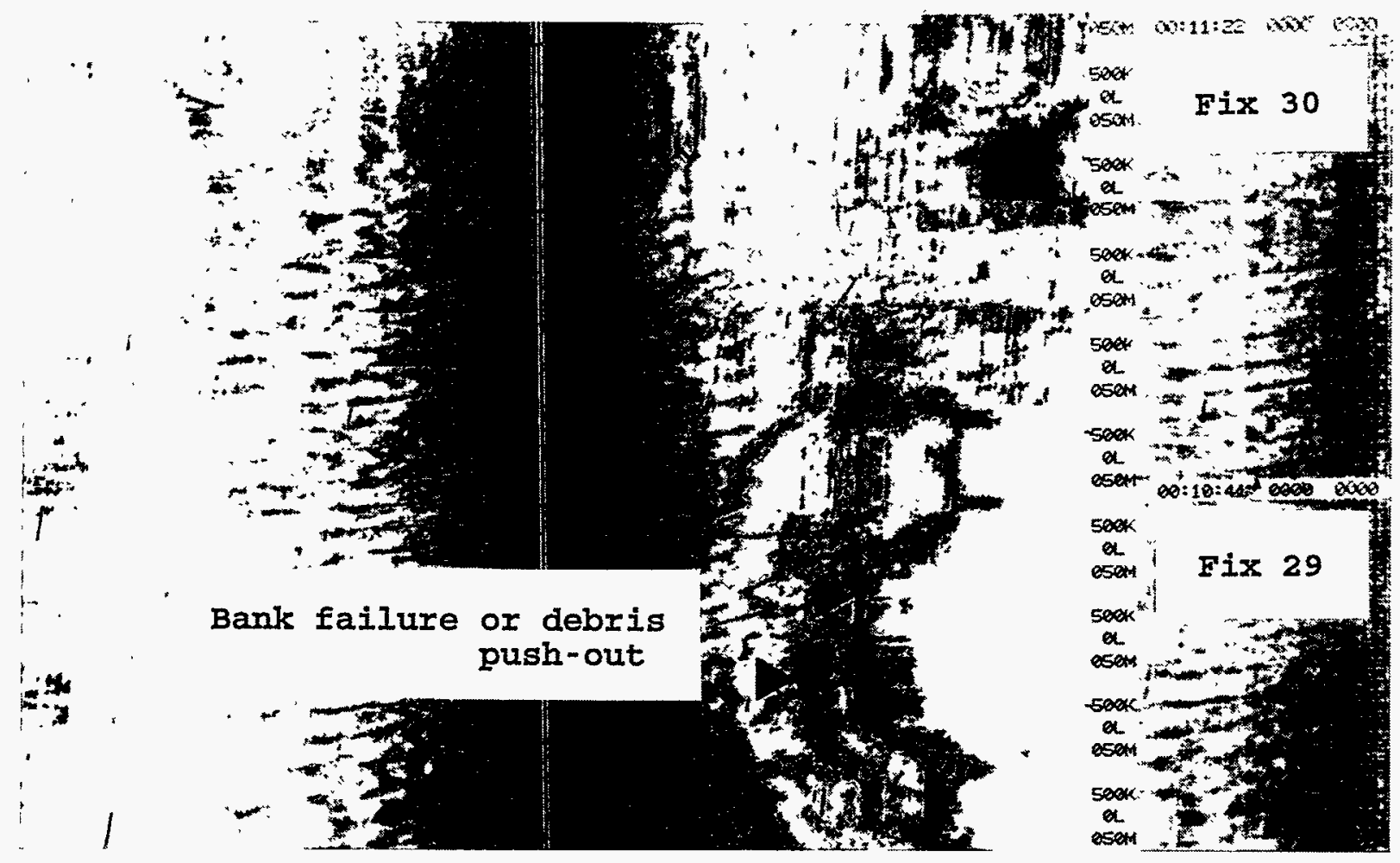

FIGURE 8 Side-Scan Profile near Fix 29 


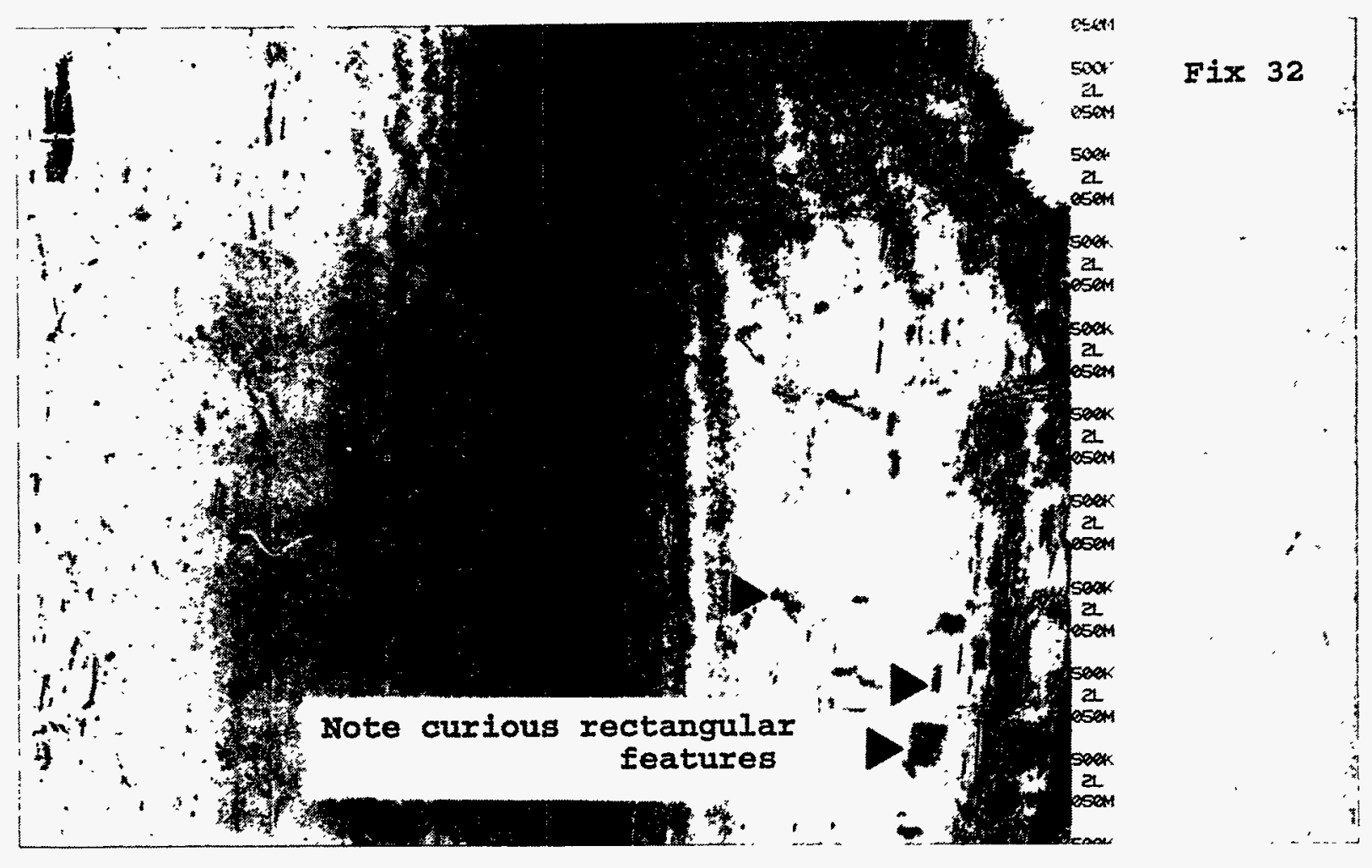

FIGURE 9 Side-Scan Profile near Fix 32

\subsubsection{KC-2 Transect}

The KC-2 transect investigated the southern shore of Kings Creek (Figure 5); it is entirely outside Areas 1,2, and 3. The transect commenced on the northwestern shore of Kings Creek and proceeded toward the southeast, roughly parallel to the shore.

A side-scan sonar image of a large tree that has fallen out into the river is shown on the $\mathrm{KC}-2 \mathrm{~A}$ starboard record in the vicinity of Fix 39 (Figure 10). Trees often fall into the river when the bank is either undercut by headward erosion or the bank slumps following heavy rains.

Along the KC-2 transect, circular depressions are seen on both the port and starboard records variously between Fix 46 and 47 (Figure 11). Similar depressions can be seen along this transect to Fix 60 . The depressions range from 1.5 to $5.5 \mathrm{~m}$ in diameter. The depressions may have been caused by a blast crater or by the impact of a heavy object (e.g., unexploded ordnance, drums, or canisters) on the soft bay-bottom sediments. The shore scarp is found on the starboard side. A terrace, which may have been exhumed through localized channel scour, is also evident on the starboard record. 


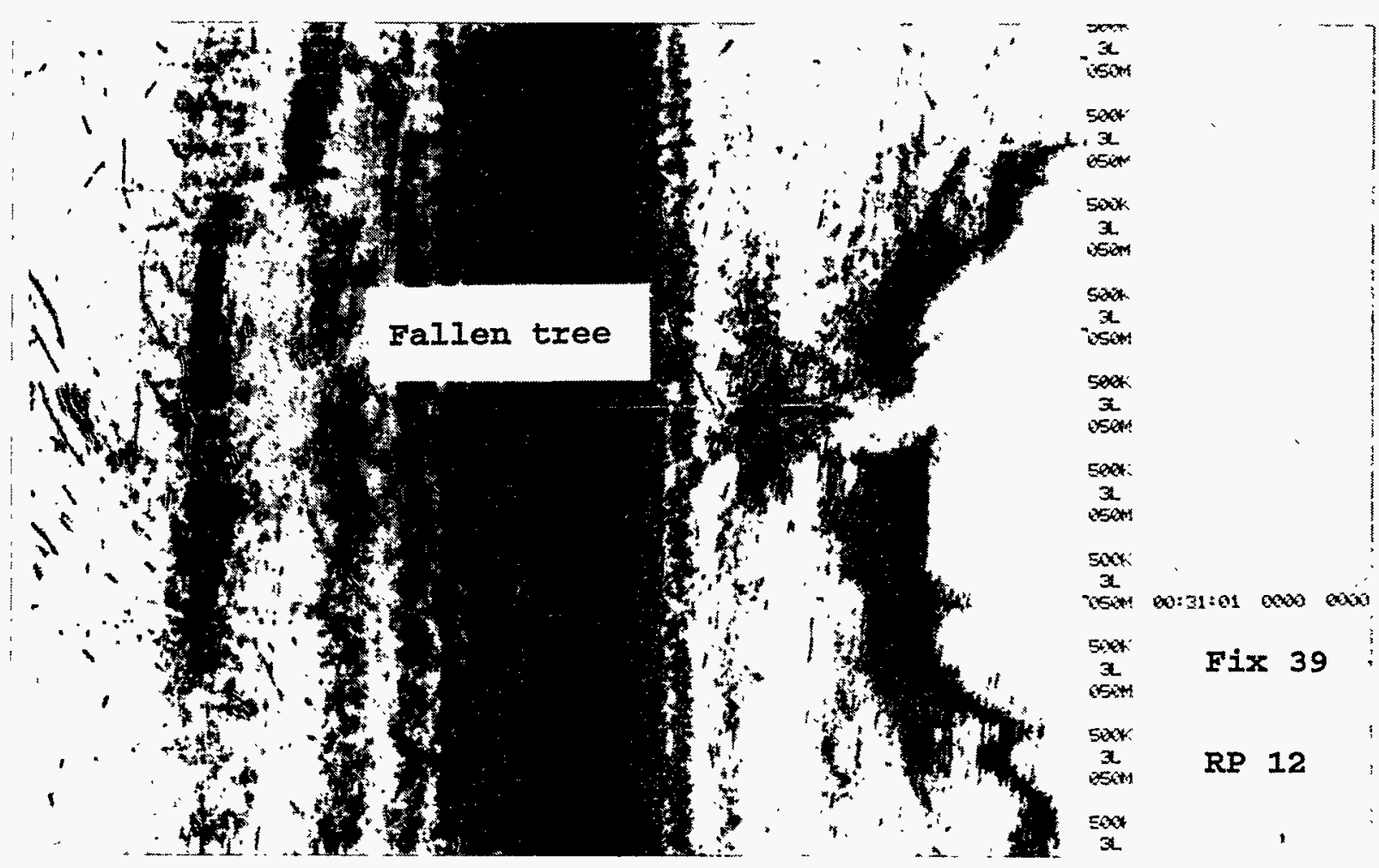

FIGURE 10 Side-Scan Profile near Fix 39

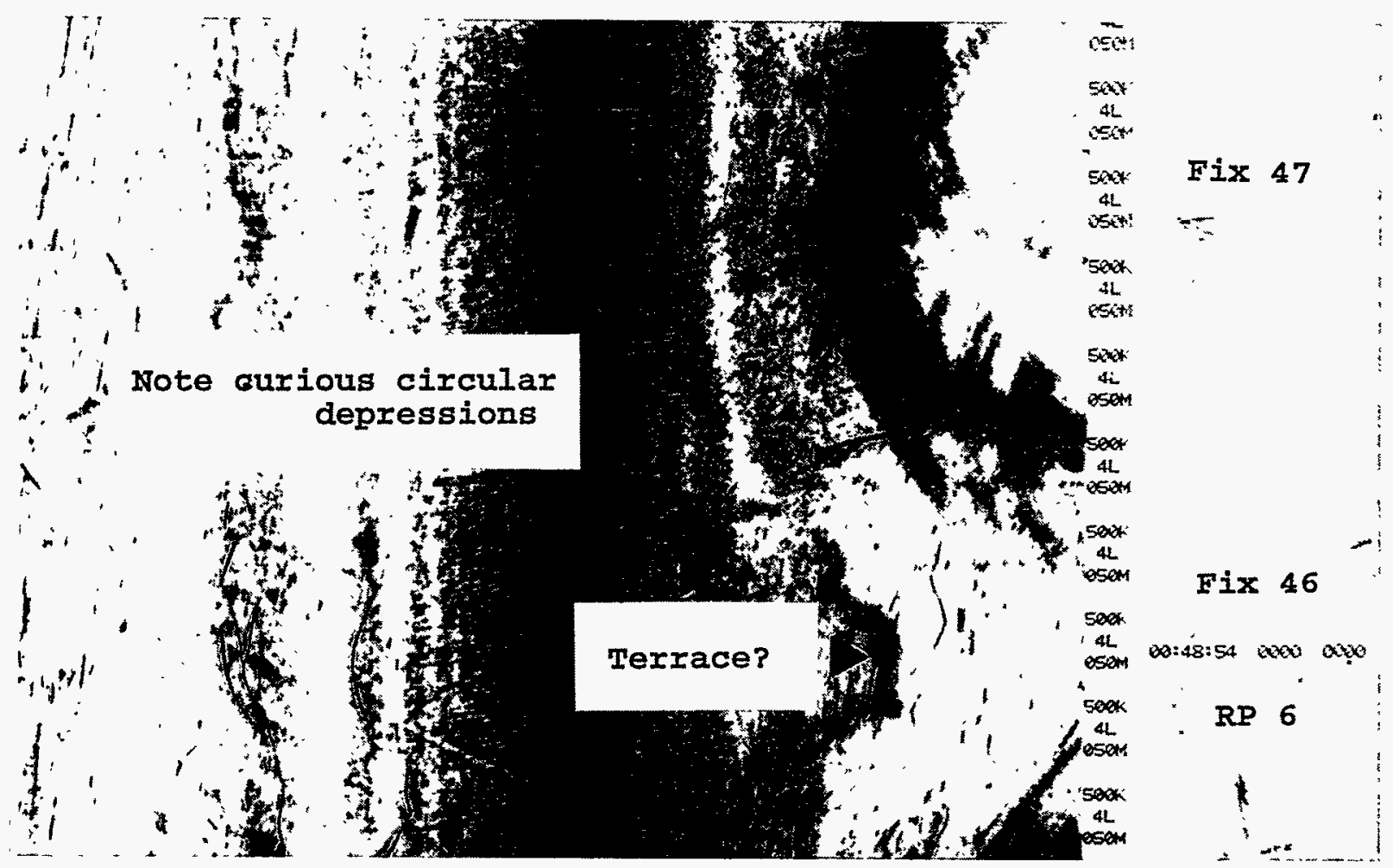

FIGURE 11 Side-Scan Profile near Fix 46 and 47 


\subsubsection{KC-3 Transect}

The KC-3 transect investigated the Kings Creek bottom approximately $50 \mathrm{~m}$ offshore from the KC-1 transect, and it provides some side-scan coverage in Areas 1, 2, and 3 (Figure 6). The transect commenced in the southeast and proceeded northwesterly into shallow water at the head of the Kings Creek embayment. No features were identified that were not previously identified in transects $\mathrm{KC}-1$ or $\mathrm{KC}-2$.

\subsection{Side-Scan Sonar, Areas 4, 5, and 6 (Tapler Point to Eagle Point Transects)}

\subsubsection{Transect Tapler Point-Eagle Point 1/4}

Transect Tapler Point-Eagle Point 1/4 (TP-EP 1/4) was acquired in a northerly direction; a distance of approximately $200 \mathrm{ft}$ was maintained from the eastern shore of the BRP (Figures 5 and 12). The line commences east of Beach Point, crosses the Kings Creek Pass, and then proceeds northward. The shore scarp is identified on the port record. The bottom surface surveyed in this transect covers most of Areas 4, 5, and 6.

The TP-EP 1/4A record in the vicinity of Fix 60 (Figure 13) shows a circular feature on the starboard record. This feature has high reflectivity toward the sonar transmitter (i.e., it is dark) and casts a shadow of no data behind. Observers on ERDA-1 suggest this feature could be a large piling or footing. If so, it would be approximately $8 \mathrm{~m}$ in diameter.

The TP-EP 1/4B record in the vicinity of Fix 62 (Figure 14) illustrates the side-scan response to the concrete loading pier or pier footing on the port-side record. A shadow is cast behind the feature, indicating its vertical disposition.

The TP-EP 1/4C record (Figure 15) displays the chaotic nature of a debris push-out immediately south of Fix 66.

\subsubsection{Transect Tapler Point-Eagle Point 2/4}

Transect Tapler Point-Eagle Point 2/4 was acquired in a southerly direction; a distance of approximately $400 \mathrm{ft}$ was maintained from the eastern shore of the BRP (see Figure 12). No unusual features were identified. 


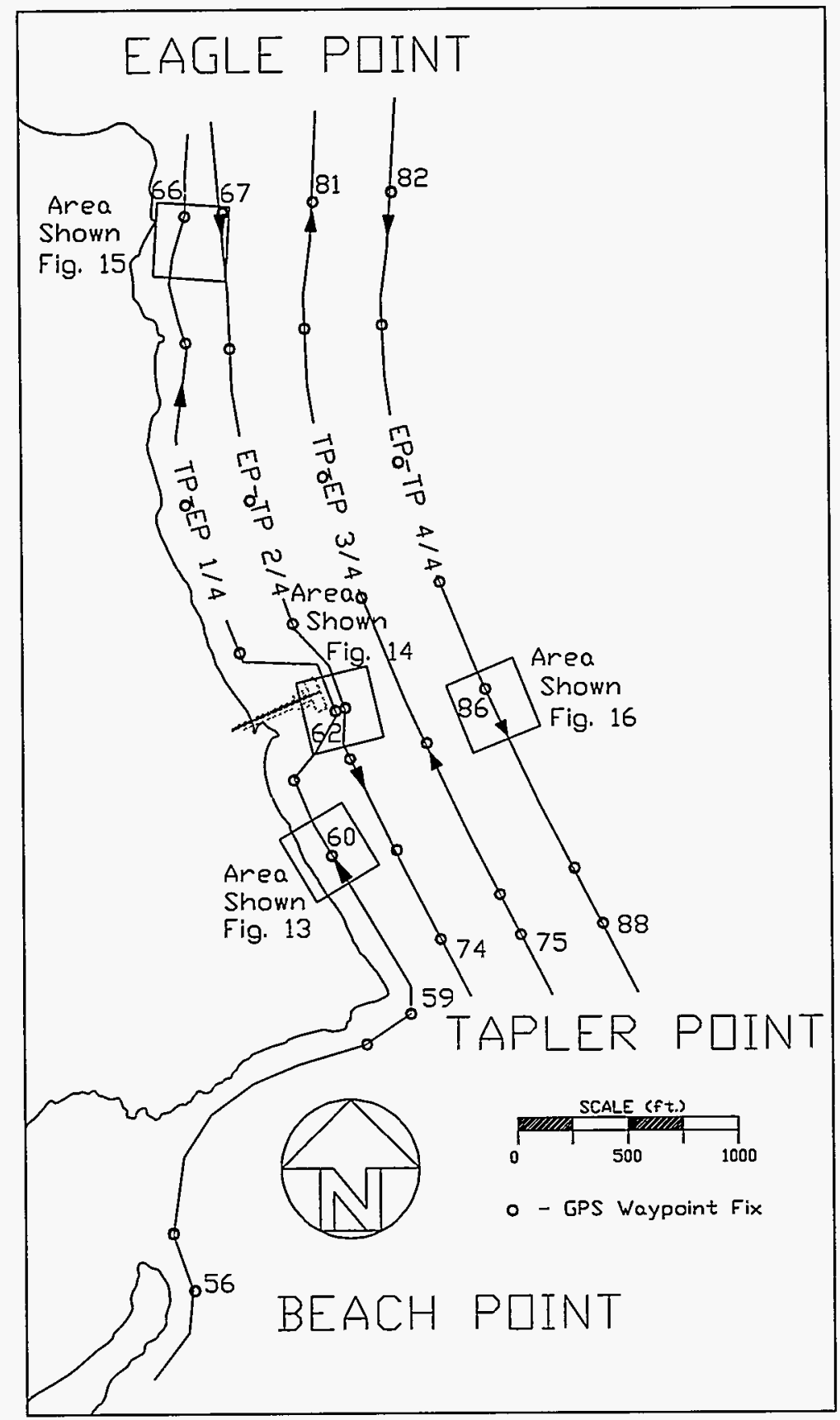

FIGURE 12 Location of Side-Scan Sonar Profiles in Bush River 


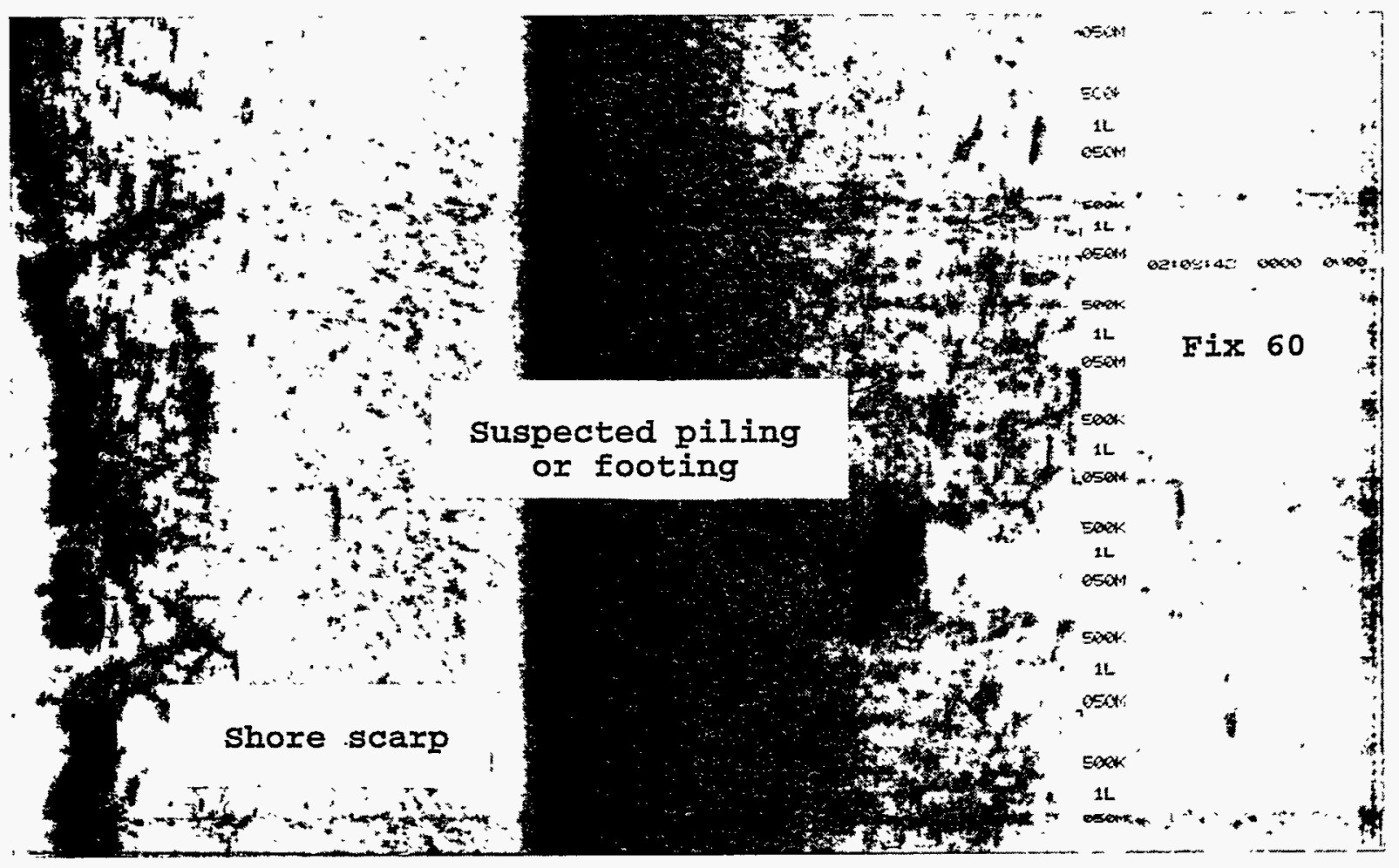

FIGURE 13 Side-Scan Profile near Fix 60

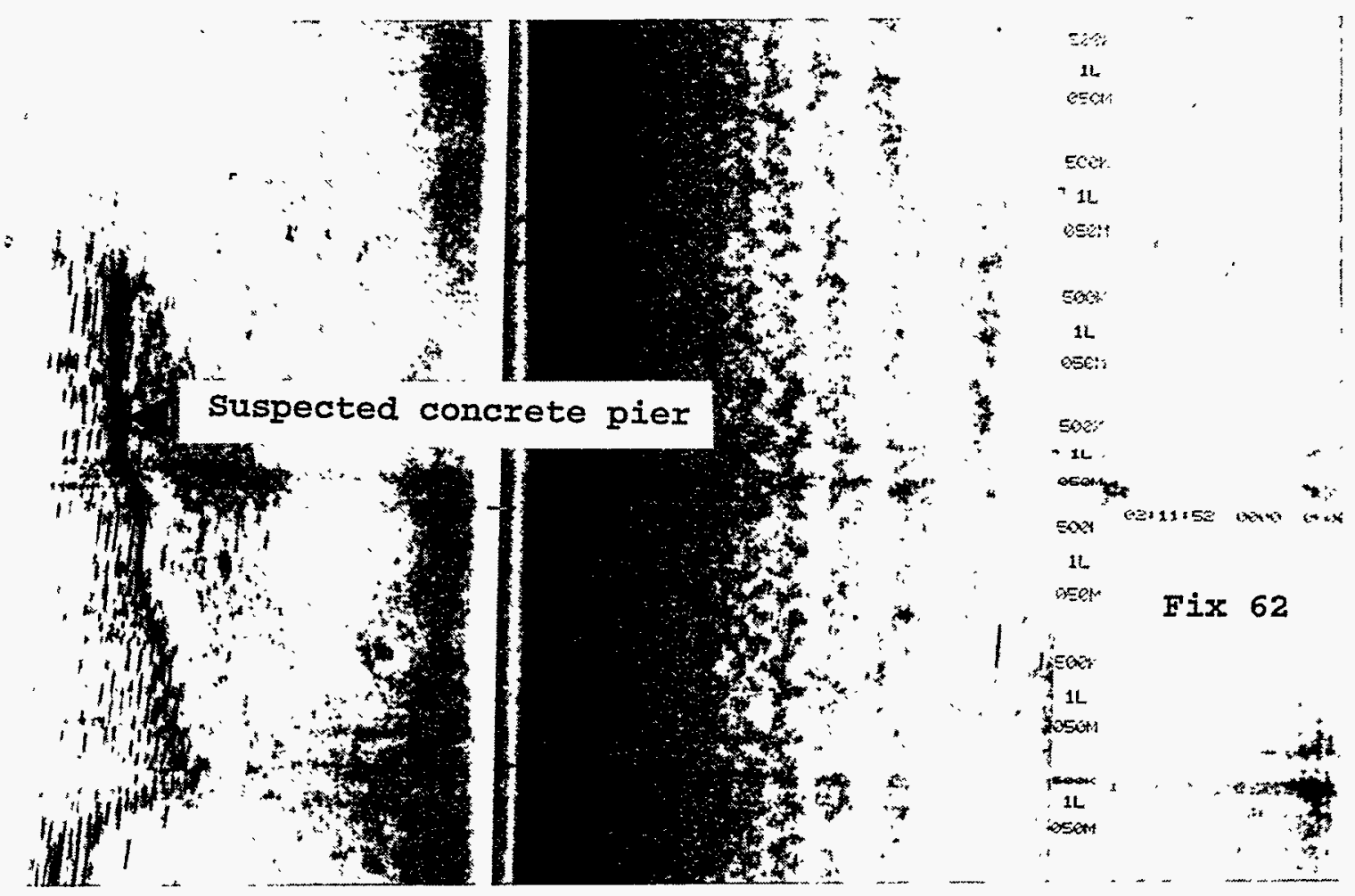

FIGURE 14 Side-Scan Profile near Fix 62 


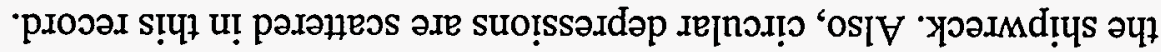

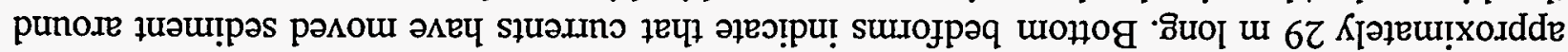

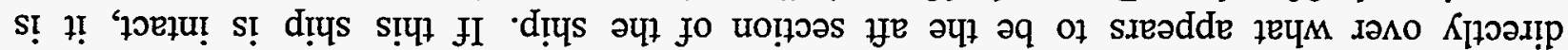

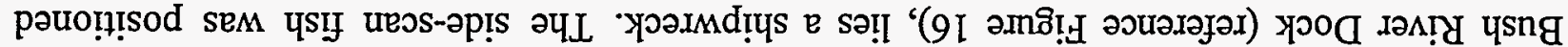

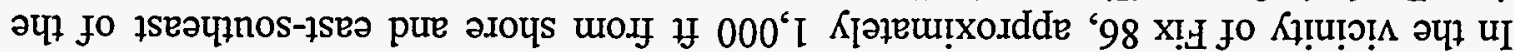

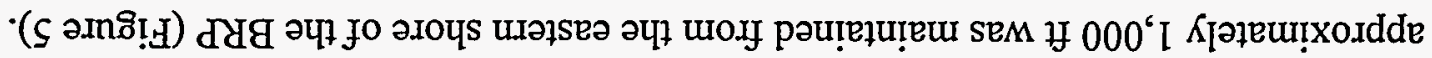

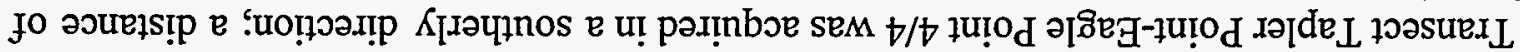

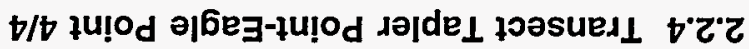

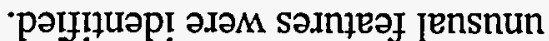
oN (ZI әmఠิ!

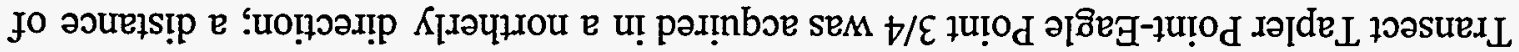

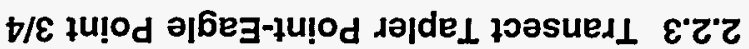

99 x!

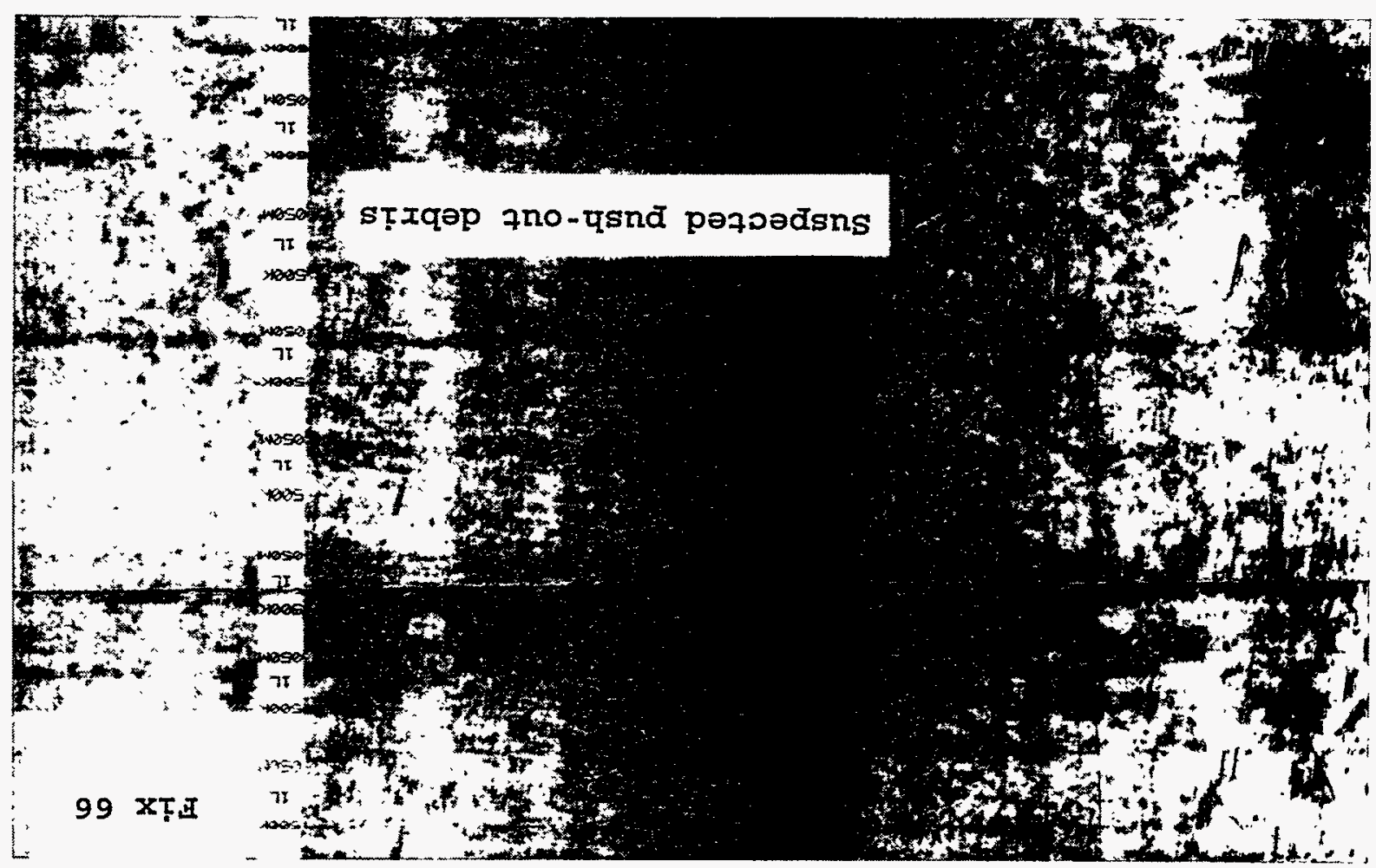




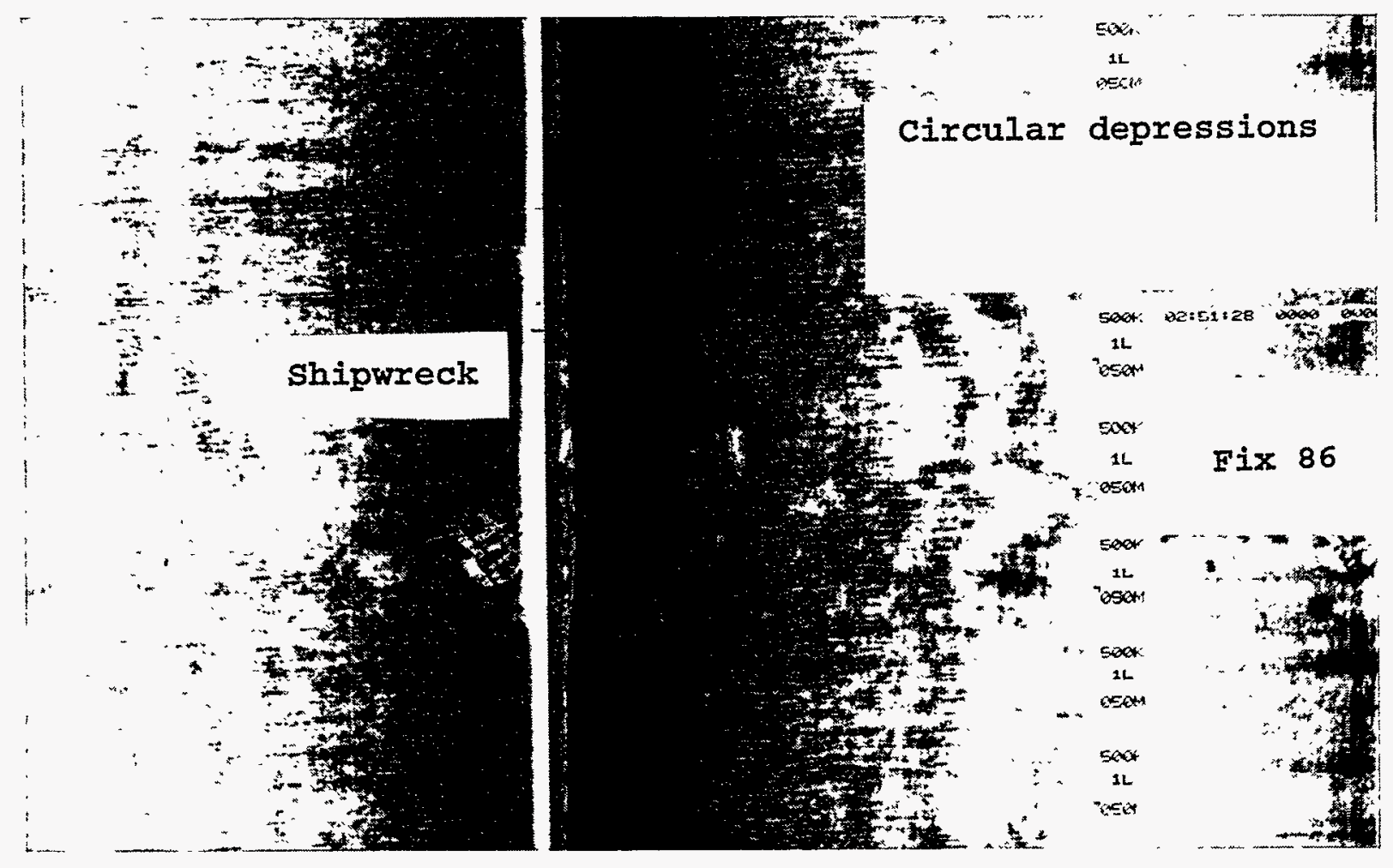

FIGURE 16 Side-Scan Profile near Fix 86 


\section{Continuous Profiling Magnetometry}

The objectives of the total field magnetic surveys performed offshore from BRP were to (1) approximate the areal, offshore extent of possible landfill sites and (2) delineate the boundaries of miscellaneous ferromagnetic debris. As previously discussed, the offshore area between the former Kings Creek Disposal Site and the Bush River Dock was subdivided into four survey sections (Areas 1-4; see Figure 17). The sections follow the irregularly shaped shoreline and extend from as close as possible to the shoreline with the shallow-draft Zodiac to a minimum of $200 \mathrm{ft}$ out into Kings Creek and the Bush River. Magnetic profiles were collected at $20-\mathrm{ft}$ intervals parallel to the shore. Tie-line profiles were collected perpendicular to the shore every $100 \mathrm{ft}$. Marks were annotated on the data at $100-\mathrm{ft}$ intervals and the beginning and end of each survey line. Digital and graphic data readouts are included with the data-logging computer. If significant errors were noted while the survey was conducted, the profile was redone. Careful control of data acquisition and processing procedures kept errors to a minimum.

Relatively small (10-100 nT) diurnal variations in the earth's magnetic field are caused by the interaction of fluctuating solar radiation and the ionosphere. Larger changes occur during solar storm events. Data were corrected for diurnal variations by the following methodology: (1) base station readings were collected at one- to two-hour intervals before and after data collection of subsections within the larger main areas and (2) data were corrected under the assumption of a linear diurnal variation during the time between base station readings. Linear corrections help reduce the error introduced by diurnal variation, but they do not totally eliminate it. Errors introduced into the magnetic data as a result of uncorrected diurnal variations and insufficient response speed to changing signals were small compared to the amplitude of the anomalies detected in the offshore surveys. The anomalies displayed on the magnetic maps are therefore qualitatively significant. Other factors affecting the offshore magnetic readings include varying water depth, which has the effect of raising or lowering the instrument above the "ground" surface, and mineralogic variations of the silt and clay sediments deposited offshore.

The offshore magnetic data representing Areas 1 through 4 are presented on Figures 18-21, respectively. Compared to the magnetic surveys performed on land at the BRP (see Davies et al. 1995a and 1995b), the offshore magnetic maps are relatively free of anomalies. As a result, the color-contour intervals used for the magnetic maps are relatively low, ranging from $4.5 \mathrm{nT}$ to $9.5 \mathrm{nT}$. The low-contour intervals used for the magnetic maps readily distinguish significant magnetic anomalies from background readings. These contour intervals, however, also highlight uncorrected diurnal variations and, potentially, subtle mineralogic and depth variations within the large area encompassed by each map. The variations appear on the maps as trends and tie line mismatches rather than as point-source anomalies due to ferromagnetic objects. The following sections describe the magnetic anomalies for each of the four survey areas. 


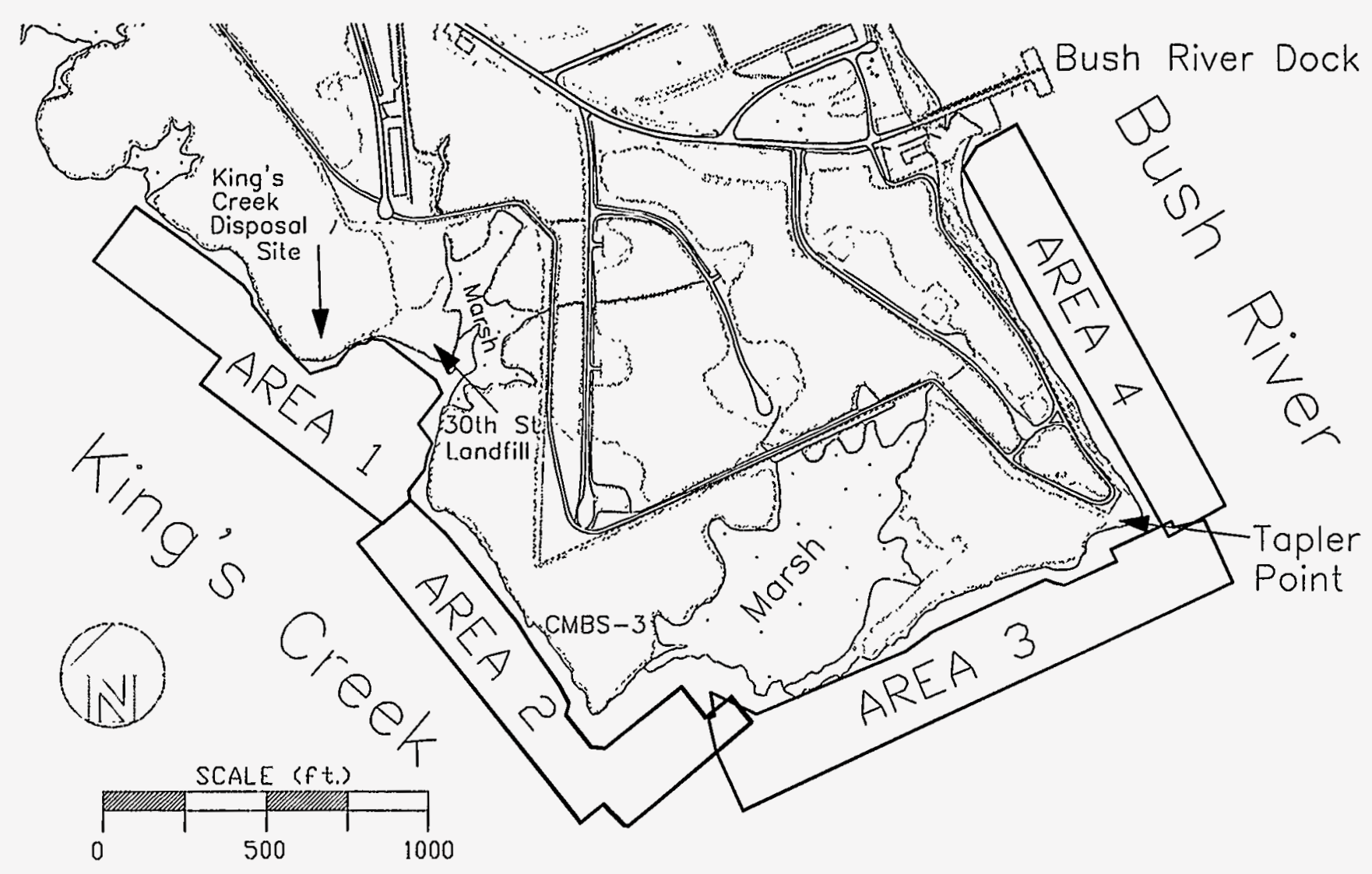

FIGURE 17 Location of Geophysical Survey Areas 1-4 around Bush River Peninsula 
30th Street

Landfill

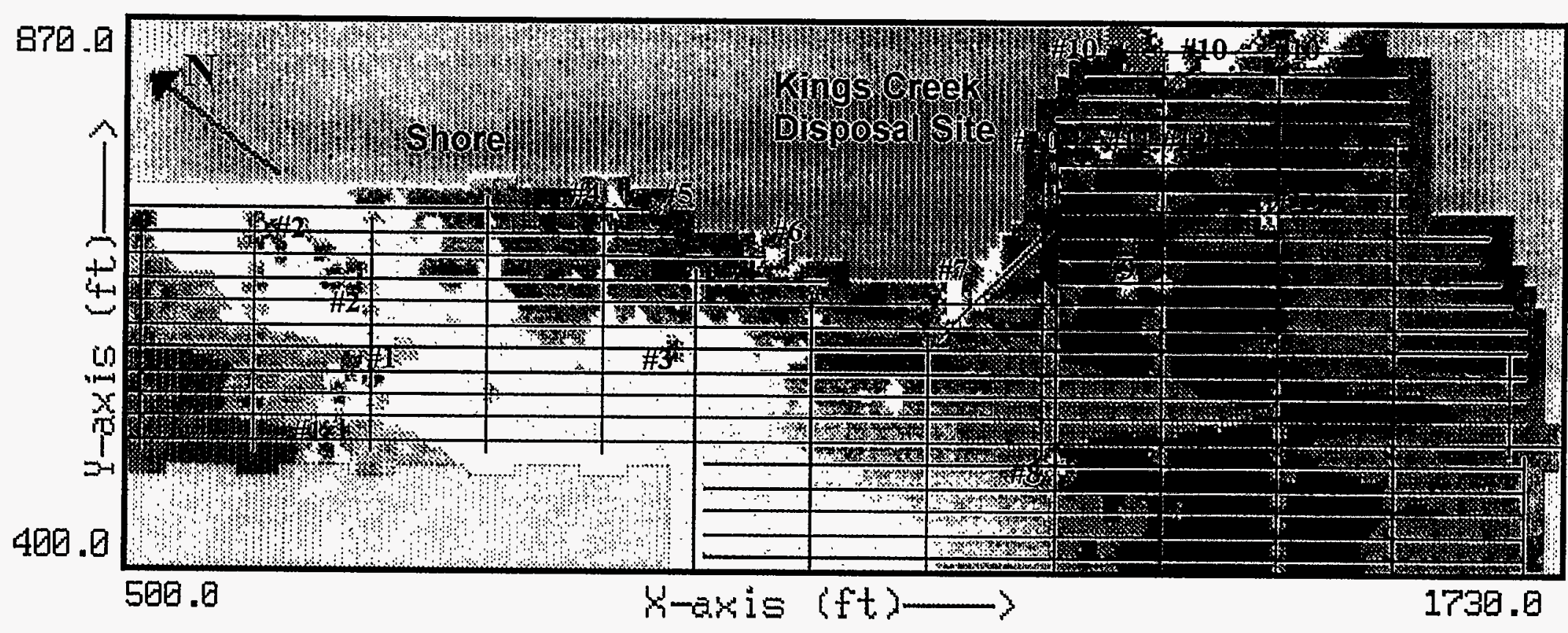

Area 1 Offshore: Magnetics

\begin{tabular}{|c|c|c|}
\hline $53,825 \mathrm{nT}$ & Color Contour Interval = $9.5 \mathrm{nT}$ & $54,100 \mathrm{nT}$ \\
\hline 顽 & $\mathrm{D}$ - W & W \\
\hline
\end{tabular}

FIGURE 18 Area 1, Total Field Magnetics Map 


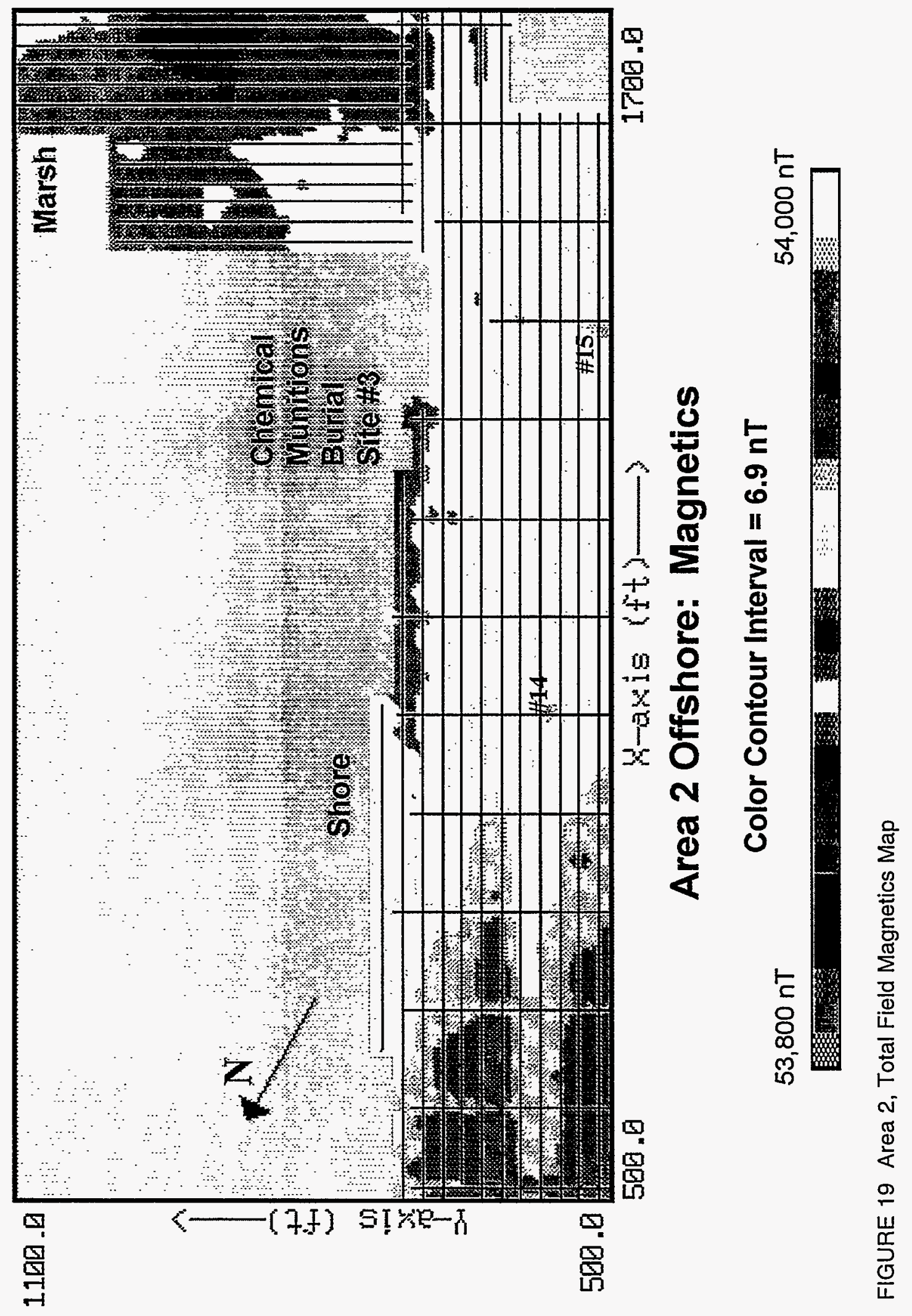




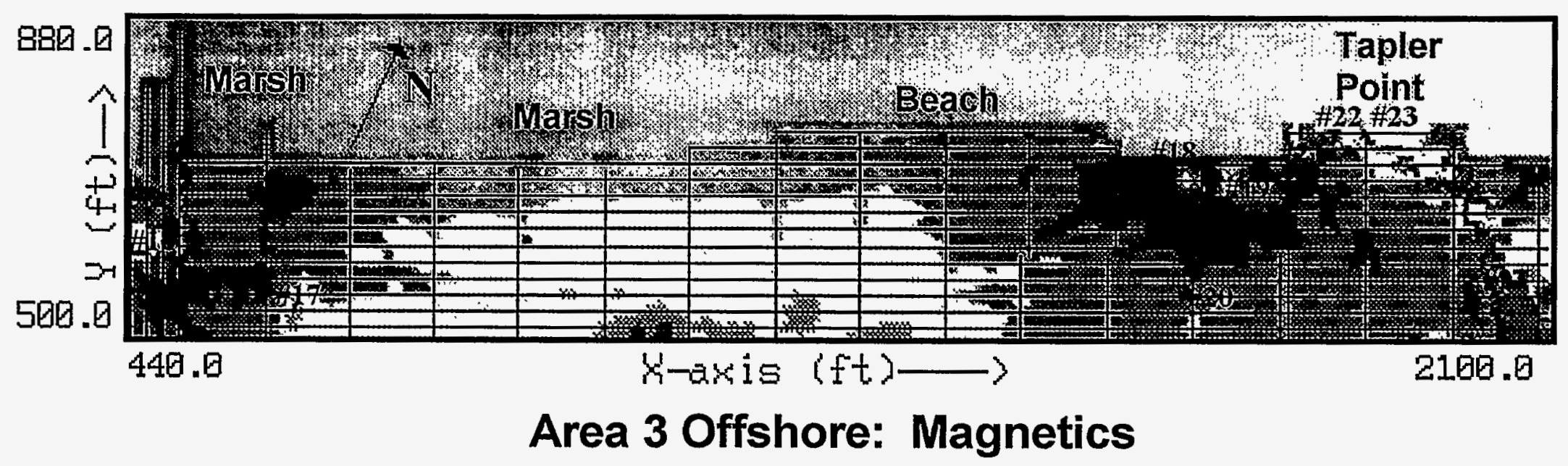

$53,800 \mathrm{nT} \quad$ Color Contour Interval $=4.5 \mathrm{nT}$

$53,930 \mathrm{nT}$

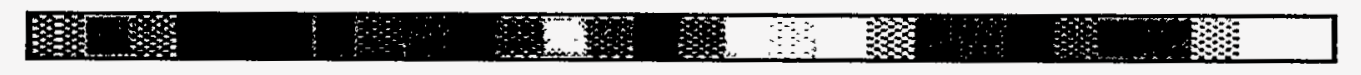

FIGURE 20 Area 3, Total Field Magnetics Map 


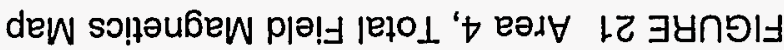
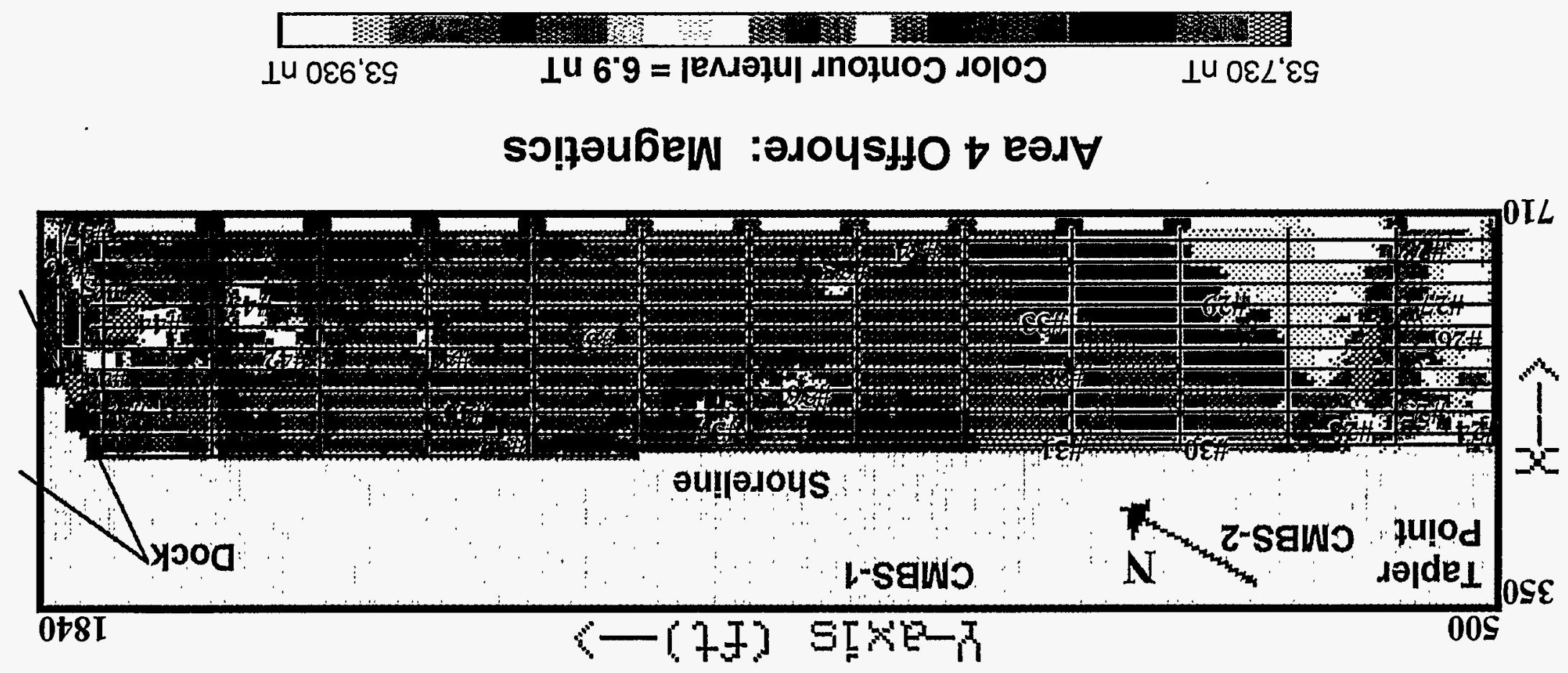


\subsection{Area 1}

Area 1 is located in Kings Creek and extends approximately $1,200 \mathrm{ft}$ southeast of a small embayment north of the former Kings Creek Disposal Site. The area encompasses the shoreline off of the former Kings Creek Disposal Site and includes a larger embayment off of the 30th Street Landfill (see Figure 18). A color-contour total field magnetic map for Area 1 is presented as Figure 18. The contour interval for Figure 18 is $9.5 \mathrm{nT}$. The X-axis is oriented northwest to southeast, and the Y-axis is oriented southwest to northeast. The grid orientation for each area was established to generally follow the shoreline.

Table 1 lists 13 magnetic anomalies detected in Area 1 and gives a general description of each listing. Some listed anomalies refer to anomalous groups or areas, while others are point sources. Numbers representing the listed anomalies are plotted on the magnetic map (Figure 18). Three zones contain the majority of the magnetic anomalies within Area 1. Anomalies \#1 and \#2 represent groups of anomalies located offshore, just north of the former Chemical Munitions Disposal Site. Subsequent to the magnetic survey, buried munitions were discovered by U.S. Navy demolition experts, and some munitions were removed by the Navy. Anomalies \#4 through \#7 comprise the near-shore area adjacent to the former Chemical Munitions Disposal Site. Some partially buried metal munitions parts extend offshore in this area. Anomaly \#10 represents the anomalous area of shoreline adjacent to the 30th Street Landfill. Again, some visible metal debris is present in this area. Some of this debris also extends offshore. Other isolated anomalies are also present in Area 1.

Table 1 lists positively identified ferromagnetic anomalies; it is not meant to list all potential anomalies visible in Figure 18. Uncorrected diurnal variations of the earth's magnetic field are largely responsible for the lower magnetic field toward the east, as indicated by the trend to colder colors on the map. On the basis of the magnetic data collected at the base station, a diurnal correction of approximately $37 \mathrm{nT}$ was made to the data. One obvious diurnal feature is represented by the sinuous color changes along some of the tie lines collected perpendicular to the shoreline. Rapid changes to the earth's magnetic field caused by magnetic "storms" were not always measured by the periodic base station readings and, hence, were not correctable. Varying water depths and sediment mineralogy may also subtly influence the magnetic data.

\subsection{Area 2}

Area 2 is located primarily within Kings Creek and extends $1,200 \mathrm{ft}$ in a northwest to southwest trend (Figure 17). Area 2 begins at the southeast end of Area 1, continues toward the southeast in Kings Creek, and includes the offshore area surrounding the site designated as Chemical Munitions Burial Site 3. A color-contour total field magnetics map for Area 2 is presented as Figure 19. The contour interval for Figure 19 is $6.9 \mathrm{nT}$. As in Area 1, the X-axis is oriented northwest to southeast, and the Y-axis is oriented southwest to northeast. 
TABLE 1 Locations and Descriptions of Magnetic Anomalies Detected Offshore of the BRP

\begin{tabular}{|c|c|c|c|}
\hline \multirow{2}{*}{$\begin{array}{l}\text { Anomaly } \\
\text { Number }\end{array}$} & \multicolumn{2}{|c|}{ Coordinates } & \multirow[b]{2}{*}{ Description } \\
\hline & $\mathrm{X}$-Axis & $Y$-Axis & \\
\hline \multicolumn{4}{|c|}{ Area 1} \\
\hline 1 & $660-710$ & $510-570$ & Linear trend of anomalies \\
\hline 2 & $610-680$ & $650-700$ & Linear trend of anomalies \\
\hline 3 & 970 & 590 & Point source \\
\hline 4 & 920 & 710 & Near-shore anomaly \\
\hline 5 & 950 & 710 & $\begin{array}{l}\text { Onshore anomaly - former chemical munitions } \\
\text { disposal site }\end{array}$ \\
\hline 6 & 1050 & 670 & $\begin{array}{l}\text { Onshore anomaly - former chemical munitions } \\
\text { disposal site }\end{array}$ \\
\hline 7 & $1190-1220$ & 630 & $\begin{array}{l}\text { Near-shore anomaly - former chemical munitions } \\
\text { disposal site }\end{array}$ \\
\hline 8 & 1300 & 490 & Point source \\
\hline 9 & 1370 & 660 & Point source between two profiles \\
\hline 10 & $1290-1450$ & $730-830$ & $\begin{array}{l}\text { Anomalous shoreline of } 30 \text { th Street landfill, some } \\
\text { metal debris (pipes, reinforced concrete, etc.) } \\
\text { visible. Anomalies extend into water. }\end{array}$ \\
\hline 11 & 1340 & 770 & Point source; off 30th Street landfill \\
\hline 12 & 1390 & 760 & Point source; off 30 th Street landfill \\
\hline 13 & 1480 & 710 & Point source; off 30th Street landfill \\
\hline \multicolumn{4}{|c|}{ Area 2} \\
\hline 14 & 990 & 560 & Point source \\
\hline 15 & 1380 & 510 & Point source \\
\hline \multicolumn{4}{|c|}{ Area 3} \\
\hline 16 & $440-480$ & $600-700$ & Large ferrous object(s) \\
\hline 17 & 630 & $510-530$ & Point source \\
\hline 18 & 1680 & 690 & Point source \\
\hline 19 & 1730 & 690 & Point source \\
\hline 20 & 1690 & 510 & Point source \\
\hline 21 & $1800-1830$ & 750 & Near-shore at Tapler Point \\
\hline 22 & $1850-1890$ & 750 & Near-shore at Tapler Point \\
\hline 23 & $1900-2100$ & $500-750$ & $\begin{array}{l}\text { Linear source extending offshore; underwater } \\
\text { cable? }\end{array}$ \\
\hline \multicolumn{4}{|c|}{ Area 4} \\
\hline 24 & $500-550$ & $500-580$ & $\begin{array}{l}\text { Linear source extending offshore; underwater } \\
\text { cable? }\end{array}$ \\
\hline 25 & 530 & 560 & Point source \\
\hline 26 & 590 & 560 & Point source \\
\hline 27 & 630 & 570 & Point source \\
\hline
\end{tabular}




\begin{tabular}{|c|c|c|c|}
\hline \multirow{2}{*}{$\begin{array}{l}\text { Anomaly } \\
\text { Number }\end{array}$} & \multicolumn{2}{|c|}{ Coordinates } & \multirow[b]{2}{*}{ Description } \\
\hline & $X$-Axis & Y-Axis & \\
\hline & Area 4 & & \\
\hline 28 & $500-700$ & $580-620$ & $\begin{array}{l}\text { Linear source extending offshore; underwater } \\
\text { cable? }\end{array}$ \\
\hline 29 & 620 & 730 & Point source between profiles \\
\hline 30 & 500 & 760 & Near shore point source \\
\hline 31 & 500 & 900 & Near shore point source \\
\hline 32 & 570 & 900 & Point source \\
\hline 33 & 610 & 890 & Point source \\
\hline 34 & 670 & 1040 & Point source(s) \\
\hline 35 & 660 & 1110 & Point source between profiles \\
\hline 36 & $530-550$ & 1150 & Point source; larger anomaly \\
\hline 37 & 530 & 1220 & Point source \\
\hline 38 & 610 & 1350 & Point source \\
\hline 39 & 510 & 1430 & Point source \\
\hline 40 & 530 & 1460 & Point source \\
\hline 41 & 600 & 1490 & Point source \\
\hline 42 & 590 & $1600-1630$ & Point source; larger anomaly \\
\hline 43 & $630-650$ & $1630-1665$ & Large anomaly(ies) \\
\hline 44 & $490-640$ & $1730-1830$ & $\begin{array}{l}\text { Anomalous area extending onshore at the Bush } \\
\text { River Dock }\end{array}$ \\
\hline 45 & 650 & 1810 & Point source \\
\hline 46 & 660 & 1830 & Point source; near dock \\
\hline 47 & 700 & 1810 & Point source? only view beginning \\
\hline
\end{tabular}

Area 2 was found to be magnetically quiet. Table 1 lists two small point-source anomalies for Area 2. These anomalies (\#14 and \#15) are plotted on Figure 19.

Uncorrected diurnal variations are evident on the magnetic map for Area 2. On the basis of the magnetic data from the base station, diurnal corrections within a range of $48 \mathrm{nT}$ were made to the data. After making these corrections, the total range for the Area 2 magnetic data was only $56 \mathrm{nT}$. This range is very small for an area of this size and indicates an area clear of ferromagnetic objects. The majority of the change in magnetic values is attributed to uncorrected diurnal variations, especially in the western section of Area 2. Evidence for this phenomenon can be seen in the mismatched tie line data. 


\subsection{Area 3}

Area 3 extends 1,660 ft in an approximate east-west direction along the southern portion of the BRP to slightly beyond Tapler Point (Figure 17). A color-contour total field magnetics map for Area 3 is presented as Figure 20. The contour interval for Figure 20 is $4.5 \mathrm{nT}$.

Large magnetic anomalies were detected in both the western and eastern ends of Area 3 , as were some scattered small point anomalies. Table 1 lists eight magnetic anomalies (\#16 through \#23) detected in Area 3. These anomalies are plotted in Figure 20. A large ferrous object(s) is in the western end of the survey grid (Anomaly \#16, Figure 20). The middle portion of Area 3 is devoid of magnetic anomalies, thus indicating the absence of ferromagnetic objects. Significant magnetic anomalies are present near the shore at Tapler Point (Anomalies \#21, \#22, and \#23). This section onshore has been designated as CMBS-2. Previous magnetic surveys performed onshore indicate this area contains materials that generate positive magnetic anomalies. Visible metallic debris is present at the surface (see Davies et al. 1995b). The linear feature labeled \#23 in Figure 20 is thought to represent an underwater cable. Three small point source anomalies (\#18, $\# 19$, and \#20) are also present in the eastern portion of Area 3.

Uncorrected diurnal variations are evident on the magnetic map for Area 3. On the basis of base station readings, diurnal corrections within a range of $18 \mathrm{nT}$ were made to the data. This range is substantially less than corrections made to the data from Areas 1 and 2. Evidence for the uncorrected diurnal variations can be seen in the mismatched tie line data, especially in the center of Area 3. The small contour interval $(4.5 \mathrm{nT})$ may also highlight changes in water depth and sediment mineralogy.

\subsection{Area 4}

Area 4 extends $1,330 \mathrm{ft}$ in a north-northwesterly direction along the eastern shore of the BRP from Tapler Point to the Bush River Dock (Figure 17). A color-contour total field magnetics map for Area 4 is presented as Figure 21. The contour interval for Figure 21 is $6.9 \mathrm{nT}$. On the basis of base station readings, diurnal corrections within a range of $10 \mathrm{nT}$ were made to the data set. Excess diurnal variation is not evident in the magnetic map for Area 4 as indicated by the relatively quiet magnetic background present during the survey.

Large magnetic anomalies were detected near Tapler Point and near the Bush River Dock. Scattered point source anomalies were prevalent between these portions of Area 4. Table 1 lists 24 magnetic anomalies detected in Area 4. These anomalies are plotted on the magnetic map (Anomalies \#24 \#47, Figure 21). Two linear anomalies (\#24 and \#28) extending offshore to beyond the survey boundary are thought to represent underwater cables. Anomalies \#25, \#26, and \#27 appear as point sources on the magnetic map, but they may represent a predominately nonferrous cable (see discussion in Section 4). Point source anomalies, some with relatively large signatures, are scattered throughout the survey area (see Anomalies \#29-\#41, Figure 21). Anomalies \#42 and \#43 have relatively large magnetic signatures, which are indicative of large 
ferrous objects or multiple objects. These two anomalies are located approximately $200 \mathrm{ft}$ south of the Bush River Dock. The entire area within approximately $100 \mathrm{ft}$ of the dock is also anomalous, especially near the shore. Scattered anomalies are present near the dock, farther offshore (Anomalies \#45, \#46, and \#47). 


\section{Electrical Conductivity (EM-31)}

Shore-parallel EM-31 transects, spaced $20 \mathrm{ft}$ apart, were run around the perimeter of BRP in Areas 1-4 (Figure 17). The EM-31 was operated from a rubber Zodiac, with the sensor boom oriented parallel to the transect direction. Surveys were run from 10 to $40 \mathrm{ft}$ offshore to a maximum of $200 \mathrm{ft}$ offshore. Tie lines perpendicular to the shore were spaced at $100 \mathrm{ft}$ intervals. The offshore surveys were divided into four areas to aid in the processing and interpretation of data. Water depths ranged from approximately two to five feet. Conductivity data acquired with the EM-31 represent weighted mean values from the surface to depths of $18 \mathrm{ft}$, with greatest weights attributed to surficial layers. The water column, therefore, exhibits a disproportionately large effect on apparent conductivities.

Conductivities in millisiemens/meter $(\mathrm{mS} / \mathrm{m})$ generally increase uniformly from onshore to offshore. Minimum onshore conductivities are less than $5 \mathrm{mS} / \mathrm{m}$, whereas maximum values reach $50 \mathrm{mS} / \mathrm{m}$. Offshore conductivities range from 30 to $200 \mathrm{mS} / \mathrm{m}$. Increasing conductivities from onshore to offshore results from greater concentrations of total dissolved solids in the surface water and subbottom waters offshore relative to fresh groundwater onshore. Exceptions to the uniform gradients occur where headward erosion of paleochannels crosses the shoreline and where waste of anthropogenic origins has been dumped offshore. Conductivities are higher in both cases.

\subsection{Area 1}

The Area 1 EM-31 survey (Figure 22) was conducted offshore the Kings Creek Disposal Site and 30th Street Landfill (see Davies et al. 1995a). Conductivities generally decrease uniformly shoreward, except for the offshore extension of a paleochannel underlying the wetland between 30th and 29th Streets (Davies et al. 1995a). The conductivity gradient in undisturbed areas of Area 1 is $0.46 \mathrm{~ms} / \mathrm{m}$ per foot. Deeper water values are generally greater than $170 \mathrm{mS} / \mathrm{m}$, whereas near-shore values average about $60-70 \mathrm{mS} / \mathrm{m}$. The dominant conductivity feature in Area 1, other than the onshore-to-offshore conductivity increases, is a positive lineament that trends southwest to northeast and may be associated with a paleochannel. Greater clay thicknesses along the western flank of the offshore paleochannel extension provide one explanation for the high conductivity signature.

High-intensity conductivity anomalies located between the coordinates $670 \mathrm{X}$ and $700 \mathrm{X}$ and extending from the coordinates $500 \mathrm{Y}$ to $580 \mathrm{Y}$ in the northwestern region of the survey area are sourced by waste debris in an area where extensive buried munitions were discovered by U.S. Navy demolition experts. During field operations associated with this study, a Navy team extracted miscellaneous munitions debris from this area following the ANL study. 
30th Street

Landfill

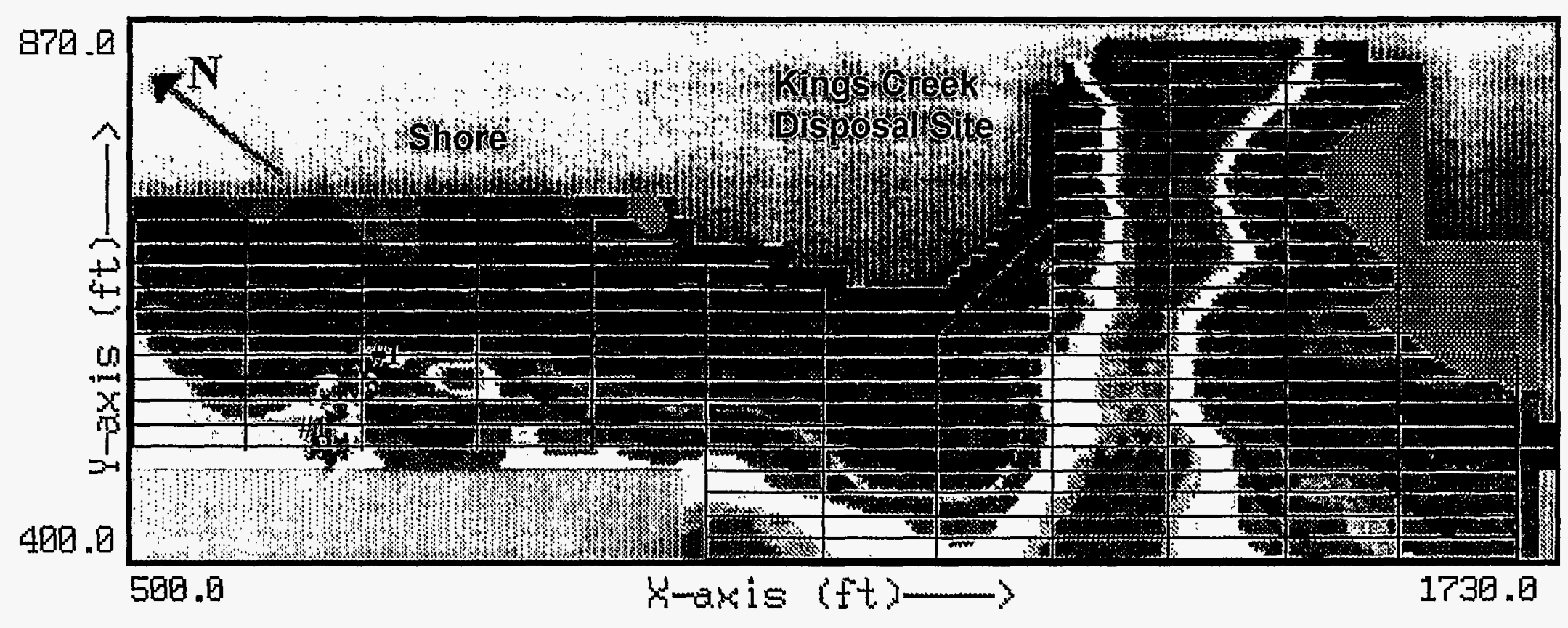

Area 1 Offshore: EM-31

\begin{tabular}{|c|c|c|}
\hline $50 \mathrm{mS} / \mathrm{m}$ & Color Contour Interval $=7.1 \mathrm{mS} / \mathrm{m}$ & $250 \mathrm{mS} / \mathrm{m}$ \\
\hline 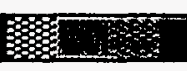 & 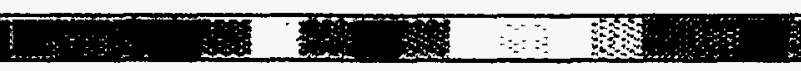 & 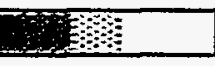 \\
\hline
\end{tabular}

FIGURE 22 Area 1, EM-31 Electromagnetics Map 


\subsection{Area 2}

Area 2 extends southeastward from Area 1 and rounds the corner of the southwest corner of CMBS-3 (Figure 23). This area displays offshore conductive gradients similar to those described in Area 1. Conductivities in Area 2 range from 50 to $250 \mathrm{mS} / \mathrm{m}$. Two high-conductivity zones mark the sites of headward erosion of valleys toward BRP. From the shape of the conductivity anomalies, it appears that the westernmost anomaly in Area 2 does not extend onshore, but it probably represents a valley wall that ends in a steep gradient near shore.

The easternmost zone of high conductivity may connect an offshore paleochannel to an onshore wetland. The eastern portion of Area 2 and the southwest end of Area 3 may represent the onshore extension of a paleochannel. Although geophysical data have not been collected in the wetland, paleochannels have been mapped onshore in the southern BRP by Davies et al. (1995a) and are likely connected to this feature.

\subsection{Area 3}

Conductivities in Area 3 (Figure 24) range from approximately 50 to $250 \mathrm{mS} / \mathrm{m}$. The southwestern limits of Area 3 overlap the southeastern part of Area 2 and contain a broad, positive conductivity anomaly. This mapped anomaly is associated with a conductivity lineament that probably represents a paleochannel and an associated tributary trending eastnortheast in the eastern half of Area 3. The tributary parallels the southeast limits of BRP. The sharpness of the northwest face of the anomaly suggests that BRP is shaped in its southeast limits by offshore channel cutting.

A series of large, positive conductivity anomalies trends northwesterly in the eastern 50 $\mathrm{ft}$ of Area 3. These anomalies are attributed to a buried cable that extends across Bush River (see map NOAA 1992). The cable type is unknown. Similar anomalies are observed in the southern limits of Area 4.

\subsection{Area 4}

The northern terminus of Area 4 is five feet south of the Bush River Dock, whereas the southern terminus is at the northeast end of Area 3 (see Figure 17). Conductivities in Area 4 (Figure 25) range from approximately 50 to $250 \mathrm{mS} / \mathrm{m}$.

Conductivities in Area 4 generally do not reach the minimum values observed in the preceding three areas; however, maximum values are about the same. This finding suggests that water depths do not decrease in a shoreward direction in Area 4 to the degree that they do in the other areas. The major anomalies in Area 4 are located in the extreme south near Tapler Point 


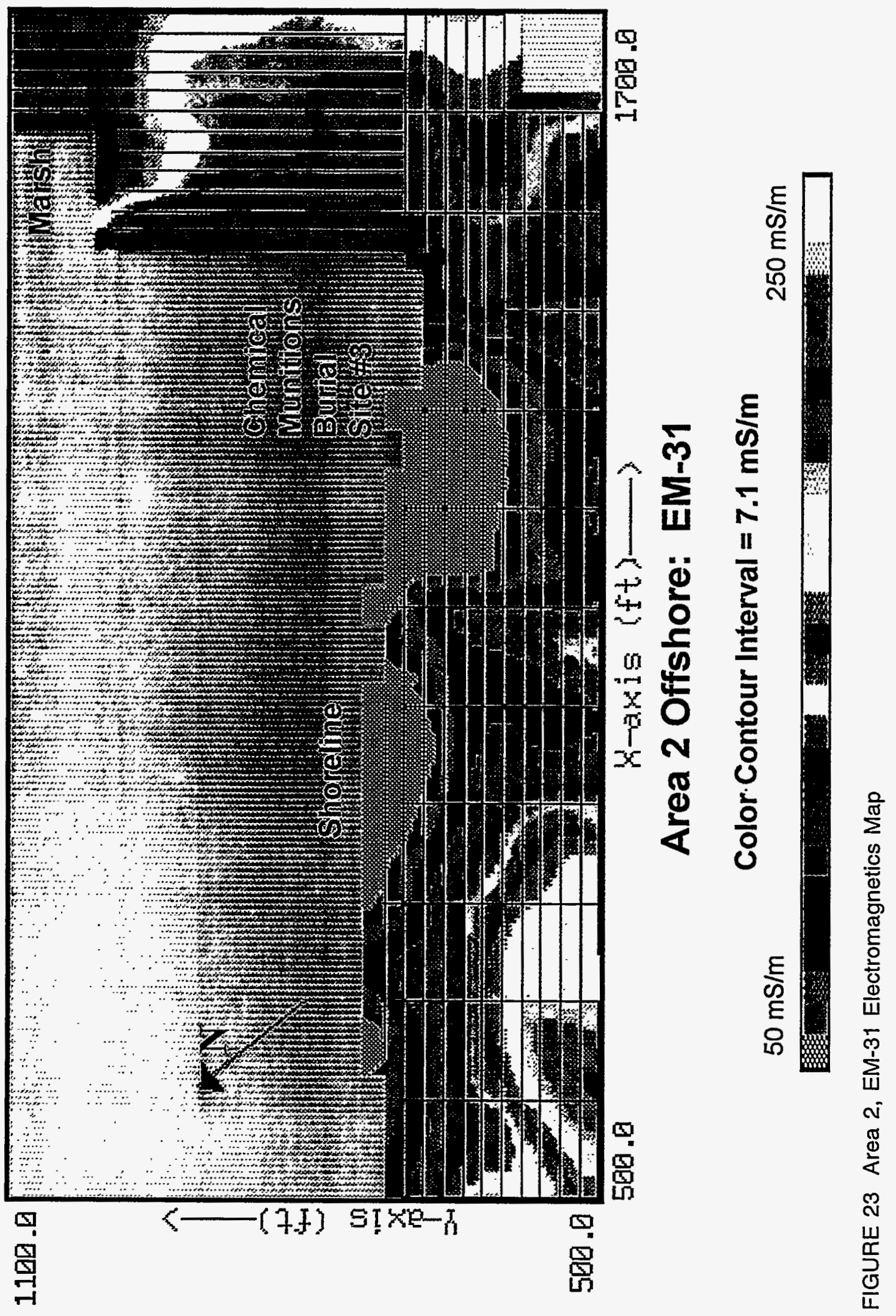




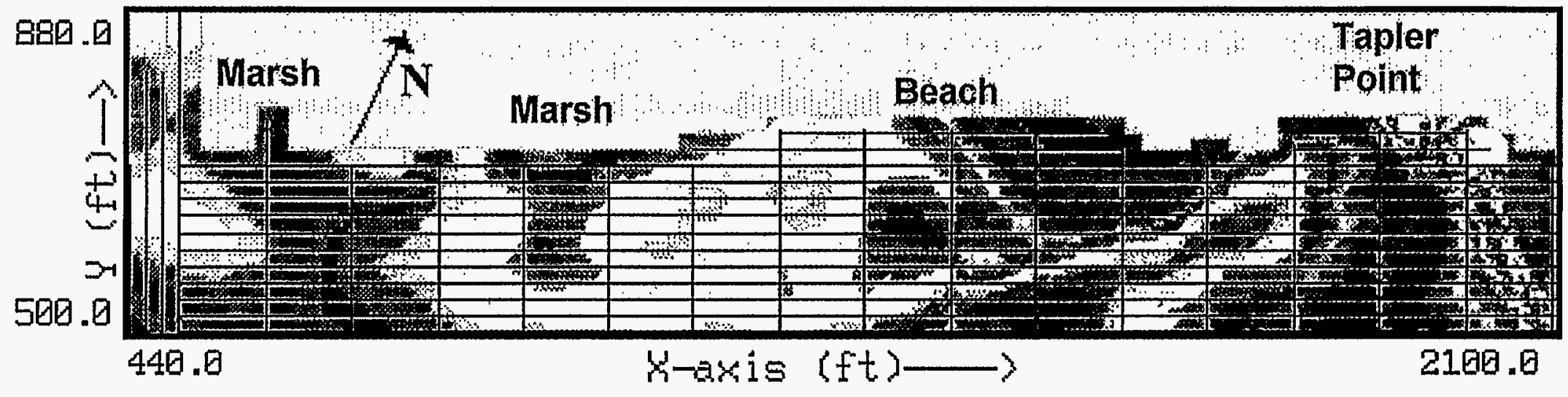

Area 3 Offshore: EM-31

\begin{tabular}{|c|c|c|}
\hline $50 \mathrm{~ms} / \mathrm{m}$ & Color Contour Interval = $7.1 \mathrm{~ms} / \mathrm{m}$ & $250 \mathrm{mS} / \mathrm{m}$ \\
\hline
\end{tabular}

FIGURE 24 Area 3, EM-31 Electromagnetics Map 


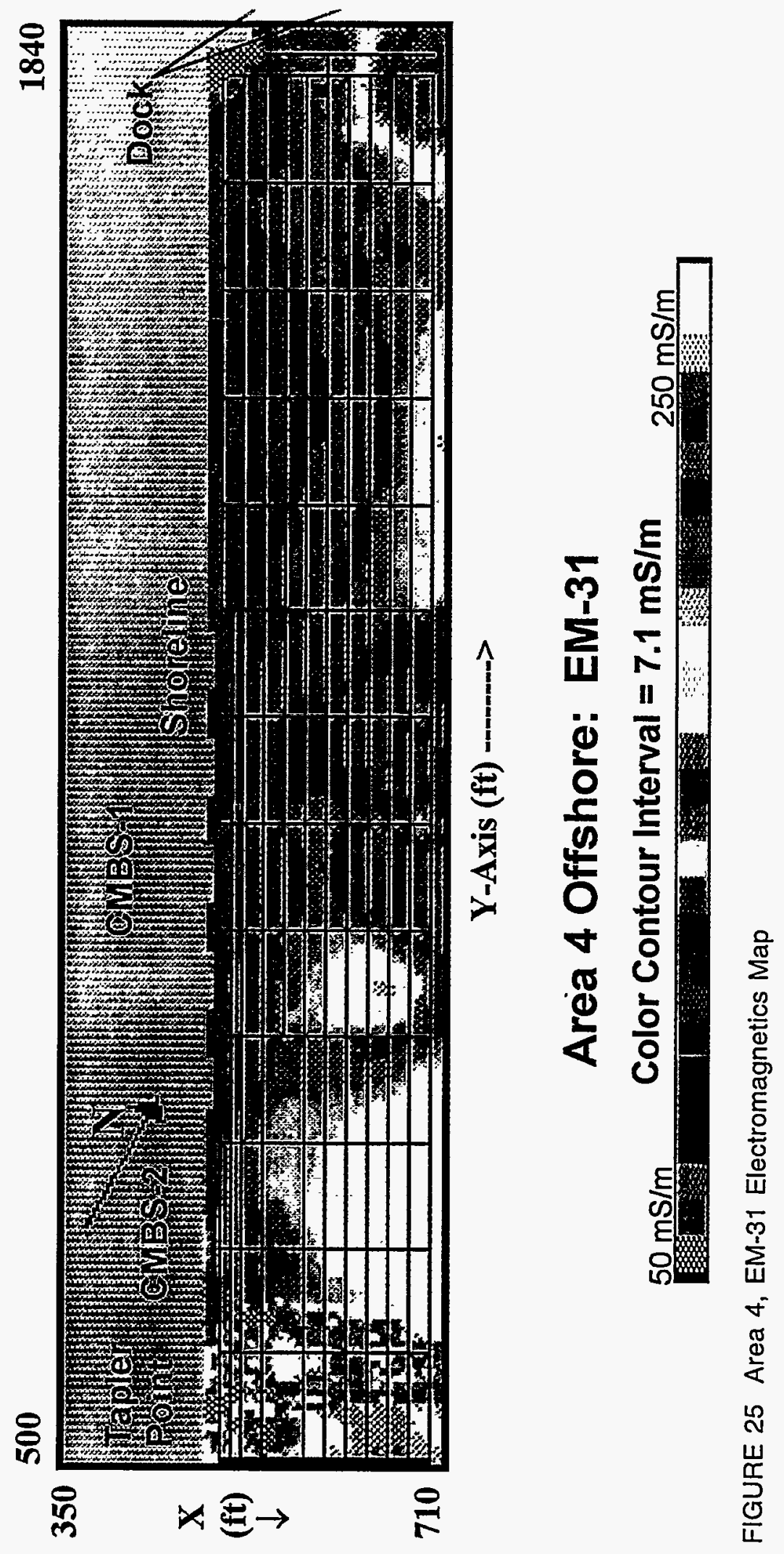


and in the north immediately south of the Bush River Dock. The anomaly complex in the south is caused by two buried cables trending northeast and converging to a single cable about $200 \mathrm{ft}$ offshore. The source or sources of the conductive feature in the northeast corner of Area 4 is unknown. Its proximity to the pier, however, suggests that it is caused by former activities associated with the dock.

There are no lineaments indicating the presence of tightly constrained buried valleys in Area 4. 


\section{Ground-Penetrating Radar Surveys}

The primary objective of GPR surveys was to provide a better understanding of the shallow stratigraphy in waters adjacent to the BRP. In some isolated areas, GPR was also used to help locate buried anthropogenic objects. Profiles were collected parallel to the shoreline and roughly $20-40 \mathrm{ft}$ offshore. The location of these GPR profiles is shown in Figure 26.

The GPR system was operated in a bistatic configuration by using two $100-\mathrm{MHz}$ antennae separated by $4.5 \mathrm{ft}$. A small bass boat served as the towing platform, while the antennae were located on the bottom of an inflatable rubber boat towed approximately $30 \mathrm{ft}$ behind the bass boat. A range setting of 500 nanoseconds (ns) was used in the acquisition of all GPR profiles. All of the profiles shown have been computer processed with a boxcar filter, and some have had adjustments made in the gains. This processing helps remove high-frequency noise and enhances structure at depth.

The interpretation of stratigraphy in GPR data follows procedures outlined in seismic stratigraphic studies (Mitchum, Vail, and Thompson 1977). Boundaries between distinct stratal assemblages are identified on the basis of reflector parallelism, or lack of it, between the strata and the boundary surface itself. The Top Quaternary section and a strong reflector that is, as we interpret, the unconformity between the Quaternary and the lower Cretaceous sections are the two boundaries that are mapped in this report. The Quaternary section largely consists of Pleistocene-age sediments.

The Top Quaternary boundary marks the interface between the base of the water column and the top of Quaternary sediments. Radar wave amplitudes within the water column plot are higher amplitude reds and whites, whereas the return signals from the bottom muds are of lower amplitude (purple, blue, or black). The Top Quaternary boundary is mappable as a single reflector over the greater part of the study area, but there are aberrations where debris is scattered atop these bottom muds. Dark reflector areas within the Quaternary record may represent areas with either higher clay content or biogenic gas (Daniels 1990 and Daniels, Roberts, and Vendl 1995). Mounded features atop the Top Quaternary surface show areas in which woody debris has accumulated. Thin mud wedges are apparent in areas in which the Top Quaternary lies beneath deeper water (i.e., $8 \mathrm{ft}$ or more).

The unconformity between the Quaternary Talbot Formation and the Lower Cretaceous Potomac Group (P-K boundary) is defined by varying reflector geometries from discordant to concordant reflectors. Geometries vary along profiles and from region to region. As indicated in this study, the Lower Cretaceous Potomac Group was deposited as a series of overlapping lobate, haystack-shaped depositional units. Post-depositional processes, namely compaction, have reduced each depositional lobe to a maximum vertical relief of approximately $15 \mathrm{ft}$ and maximum width of perhaps $300 \mathrm{ft}$, as determined by GPR measurements. Discordant reflectors (i.e., those in which strata above or below a surface terminate) are useful in mapping individual depositional lobes within the Potomac Group and the P-K unconformity itself. Potomac 


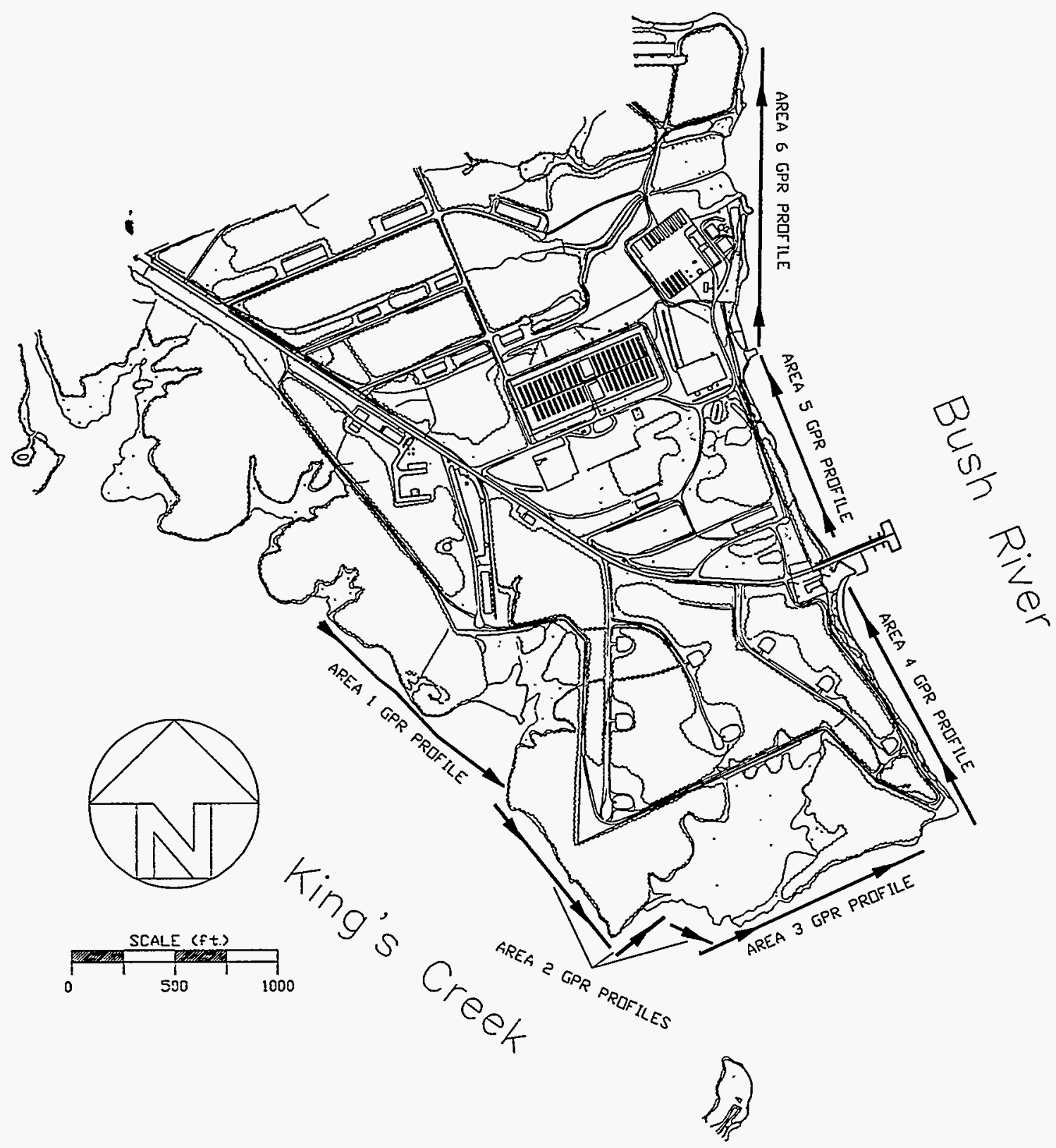

FIGURE 26 Location of Offshore GPR Profiles

reflectors subcropping this unconformity are commonly discordant beneath lobate highs and concordant on the flanks, providing an unconformity that is readily mapped atop lobate highs but is mapped only with the aid of color displays in interlobe areas. The interpreted P-K unconformity is identified on GPR color sections in this report. However, without adequate palynological data, it is possible that the mapped reflector could be a Holocene-Pleistocene boundary or an intra-Pleistocene contact.

Lower Cretaceous highs and lows reflect subsurface depositional control. In regions where thick depositional lobes subcrop the surface, the Cretaceous is high, overlying Quaternary sediments are thin, and the water depth is shallow. Conversely, in interlobe areas where the 
Cretaceous is interpreted to be deeper, overlying Quaternary sediments are thick and water is also somewhat deeper.

\subsection{Area 1}

Ground-penetrating radar in Area 1 (Figures 27-29) indicates the P-K unconformity is distinctive and mappable. The dominant features of Area 1 GPR, described in reference to the survey grid, include the following: (1) a localized Cretaceous high / Pleistocene thin between grid values 500X, 500Y and 780X,650Y; (2) a localized, Cretaceous low / Pleistocene thick between grid values 780X, 650Y and 1070X, 700Y; a localized Cretaceous high / Pleistocene thin between grid values 1070X, 700Y and 1450X, 780Y; and (4) an incised paleochannel between grid values $1450 \mathrm{X}, 780 \mathrm{Y}$ and $1700 \mathrm{X}, 600 \mathrm{Y}$. A portion of the southern valley wall of the paleochannel is seen in Area 1 GPR.

Boundaries between depositional lobes, or sequences, in the Lower Cretaceous Potomac Group are illustrated. The depositional style of the Lower Cretaceous is markedly different from the layer-cake, low-amplitude stratigraphy of the overlying Pleistocene, and it is this difference that makes the $\mathrm{P}-\mathrm{K}$ unconformity mappable with a fair degree of confidence.

\subsection{Area 2}

Ground-penetrating radar in Area 2 (Figures 30 and 31) reveals considerable relief at the P-K unconformity. The dominant features include the following: (1) the southern margin of the paleochannel, identified previously on Area 1 data, between Area 2 grid values 500X, 500Y and $500 \mathrm{X}, 700 \mathrm{Y}$; (2) a very localized Cretaceous high / Pleistocene thin between grid values 500X, $700 Y$ and $700 X, 700 Y$; (3) a broad area in which the Cretaceous is deep and the Pleistocene is thick between grid values $700 \mathrm{X}, 700 \mathrm{Y}$ and $1100 \mathrm{X}, 700 \mathrm{Y}$; and (4) a localized Cretaceous high / Pleistocene thin between grid values 1100X, 700Y and 1450X, 1000Y.

The eastern extensions of Area 2 GPR data consist of an orthogonal line (Figure 32) and a sub-parallel line to the greater Area 2 line (Figure 33). The following features have been mapped from this extension data: (1) a localized Cretaceous high / Pleistocene thin between grid values $1450 \mathrm{X}, 700 \mathrm{Y}$ and 1450X, 880Y and (2) a rather substantial Cretaceous low / Pleistocene thick between grid values $1450 \mathrm{X}, 880 \mathrm{Y}$ and the end of the line. A paleochannel is interpreted at the easternmost end of this line extension, on the basis of the following lines of evidence: (1) increasing depth to the Top Cretaceous reflector, (2) a rapidly thickening Pleistocene section, and (3) an EM-31 conductivity lineament.

Boundaries between depositional lobes in the Lower Cretaceous Potomac Group are provided in both Area 2 and Area 2 extension figures. 


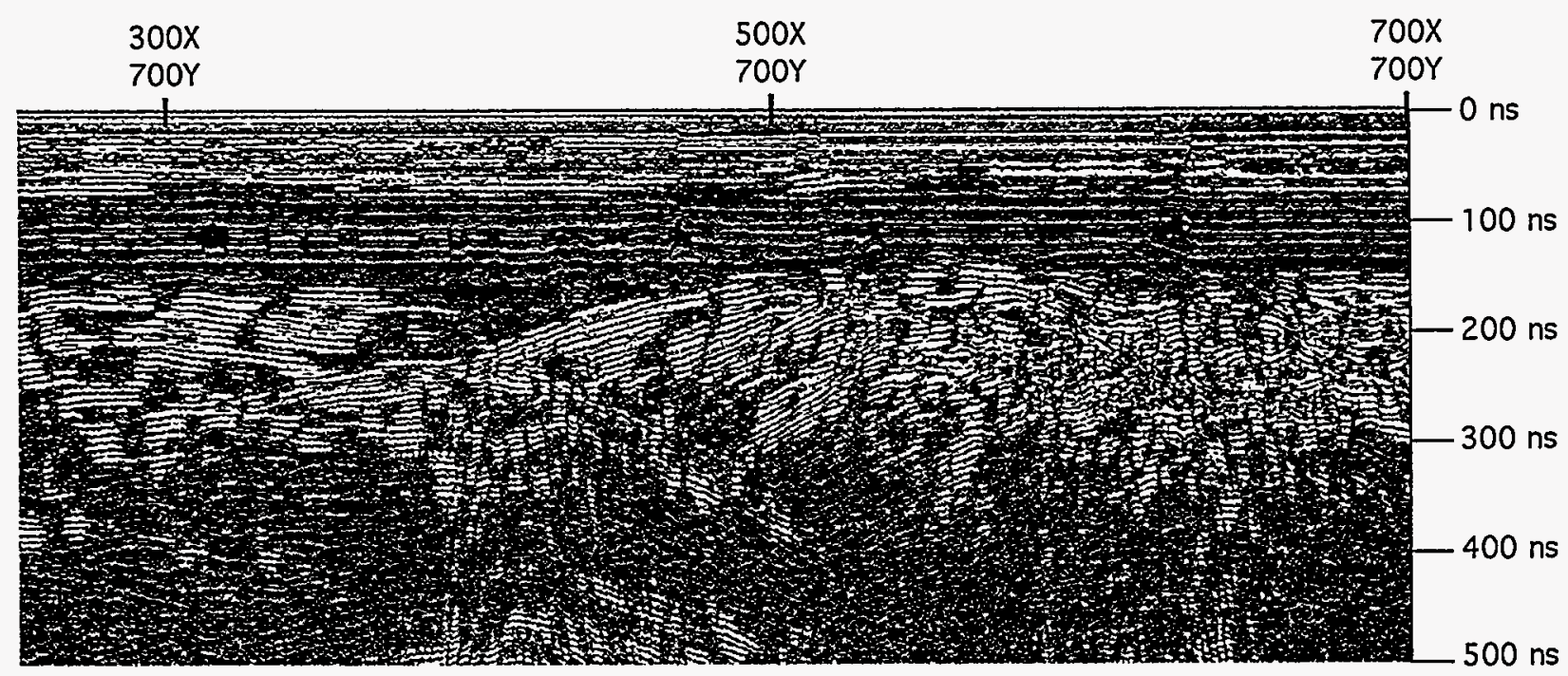

$27 \mathrm{~A}$

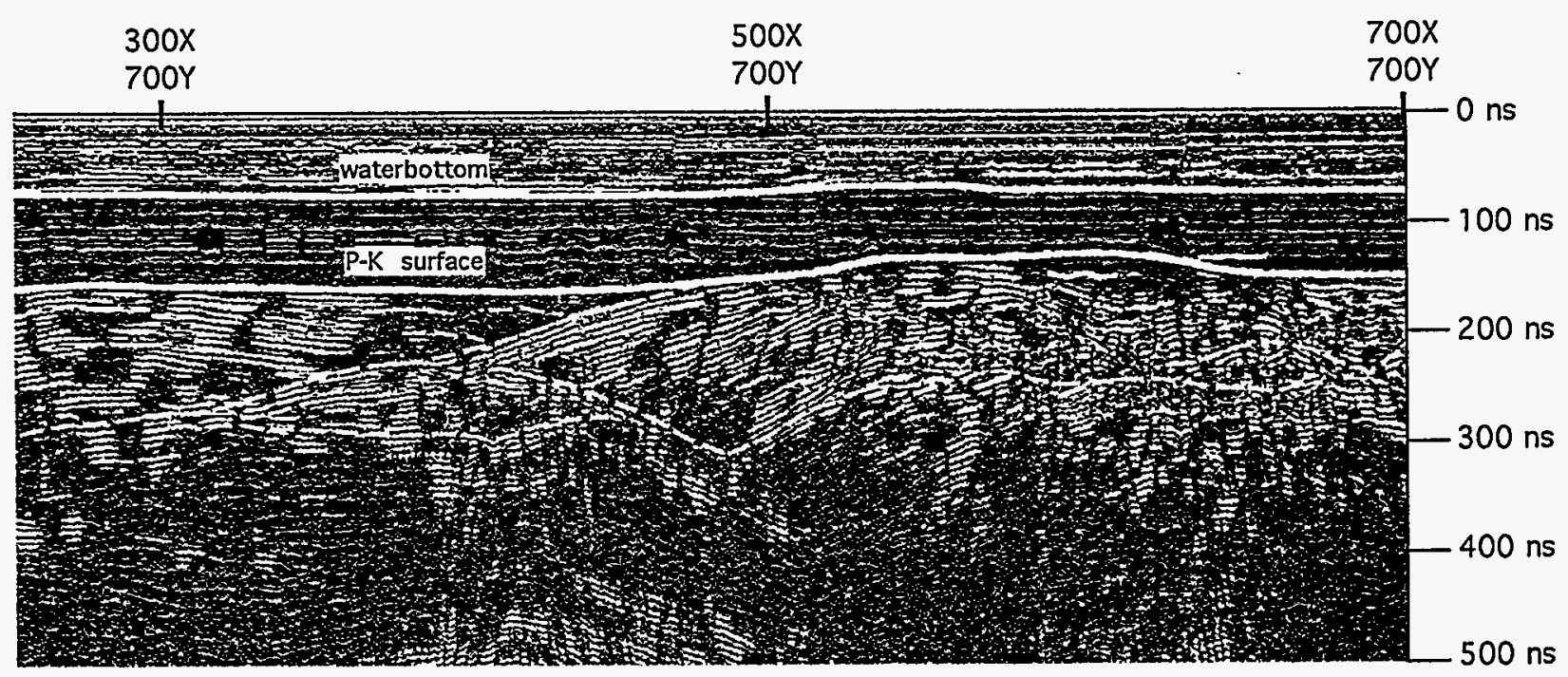

\section{B}

FIGURE 27 A: Area 1 GPR Profile; B: Area 1 GPR Profile with Interpretation 


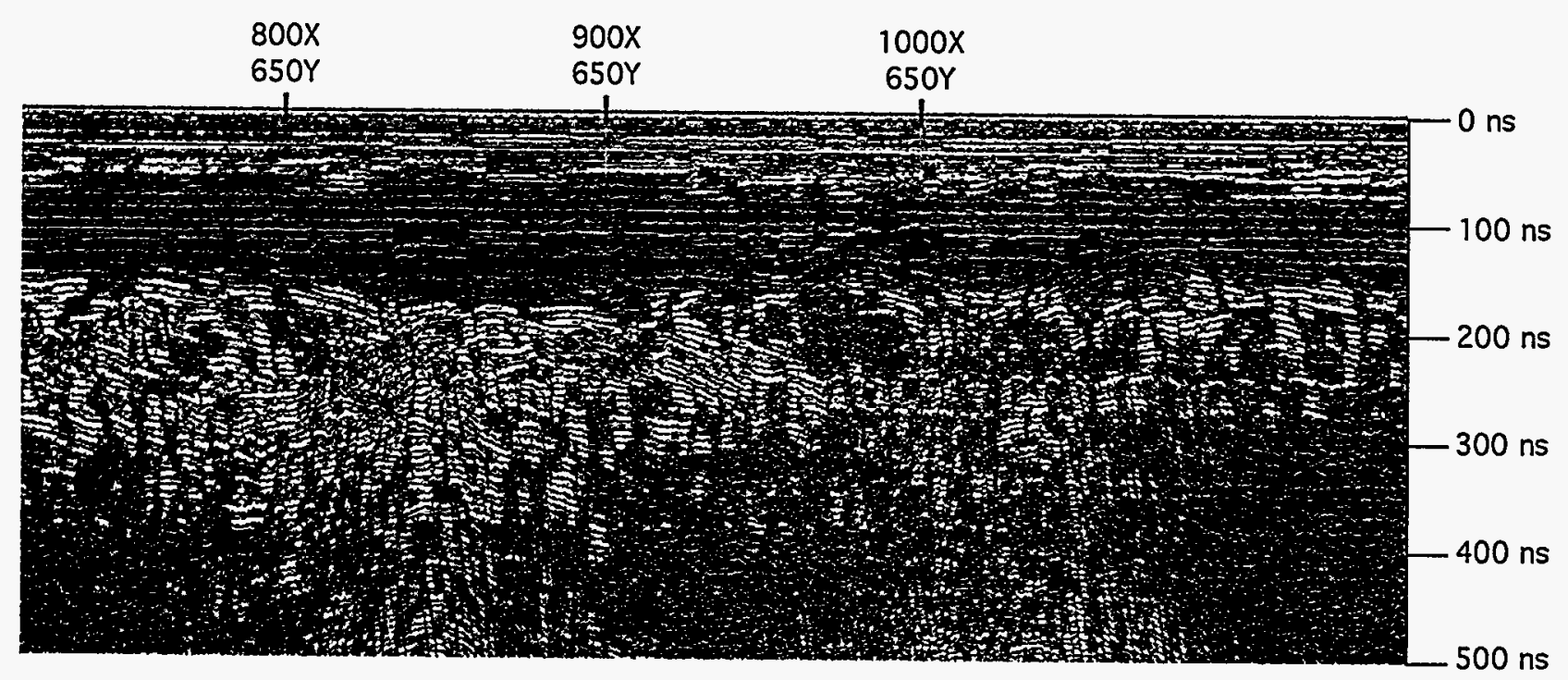

$28 \mathrm{~A}$

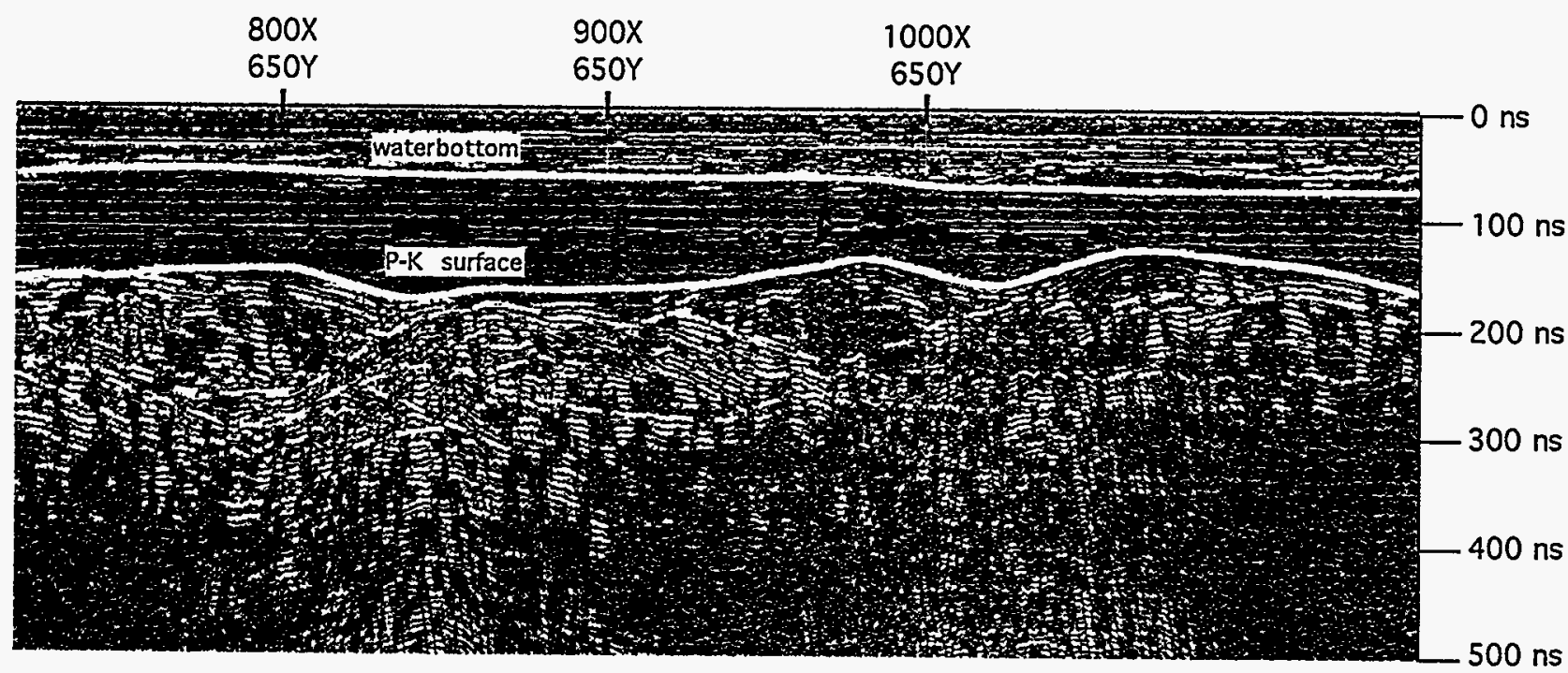

$28 \mathrm{~B}$

FIGURE 28 A: Area 1 GPR Profile; B: Area 1 GPR Profile with Interpretation 


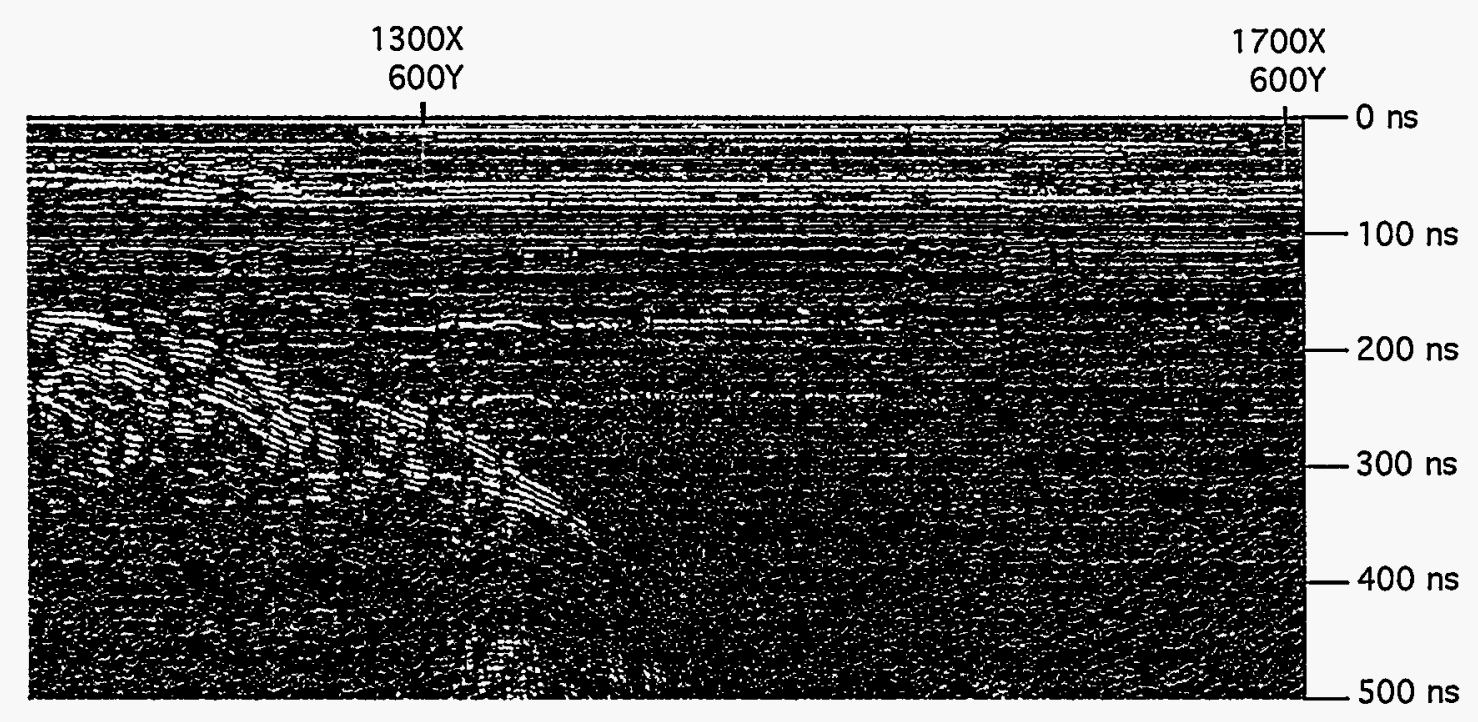

$29 A$

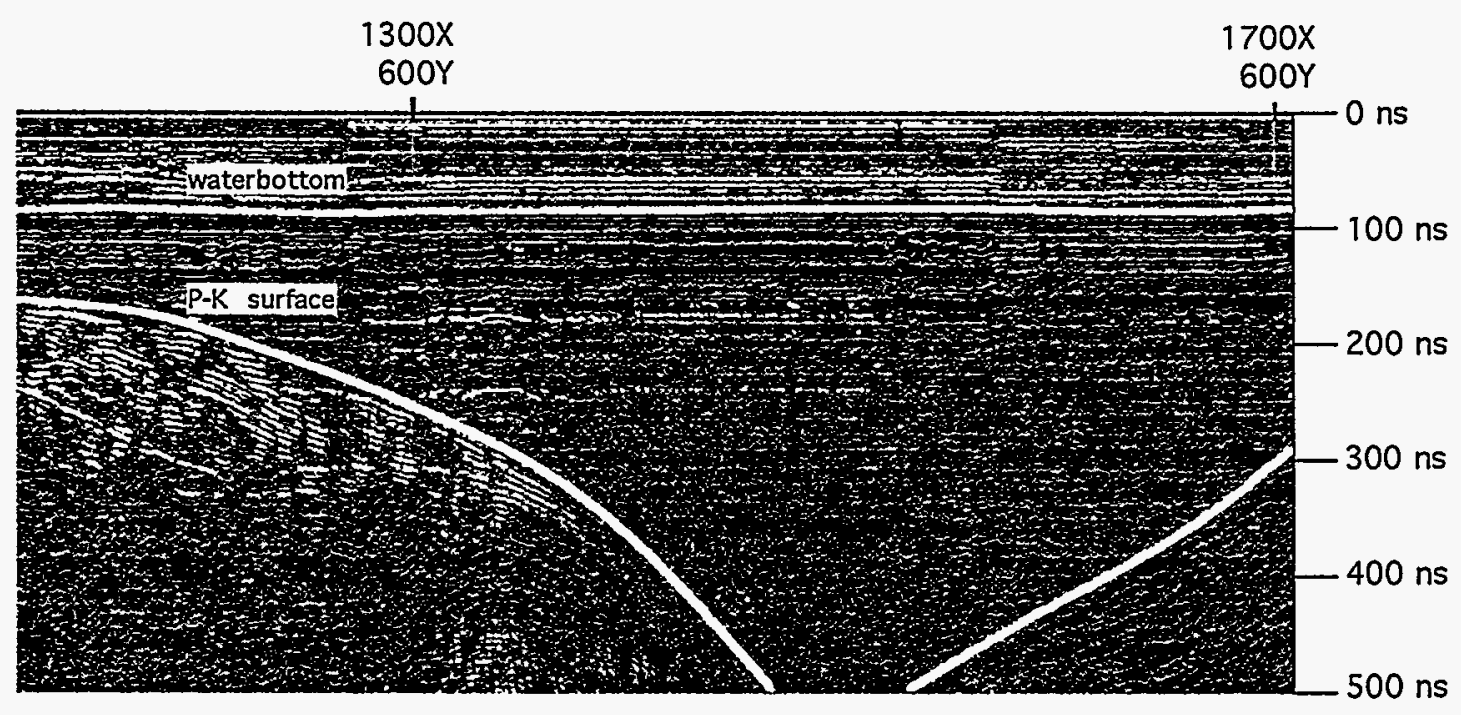

\section{$29 B$}

FIGURE 29 A: Area 1 GPR Profile; B: Area 1 GPR Profile with Interpretation 


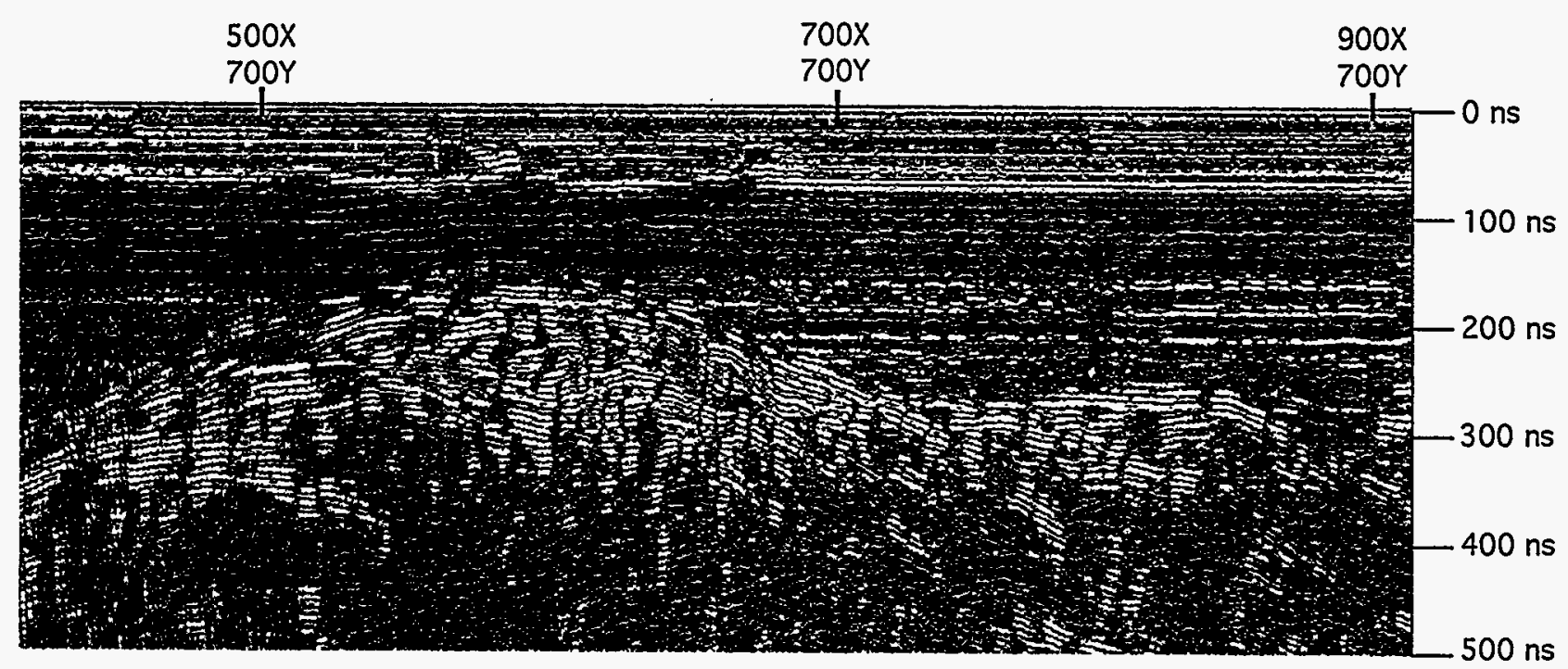

$30 \mathrm{~A}$

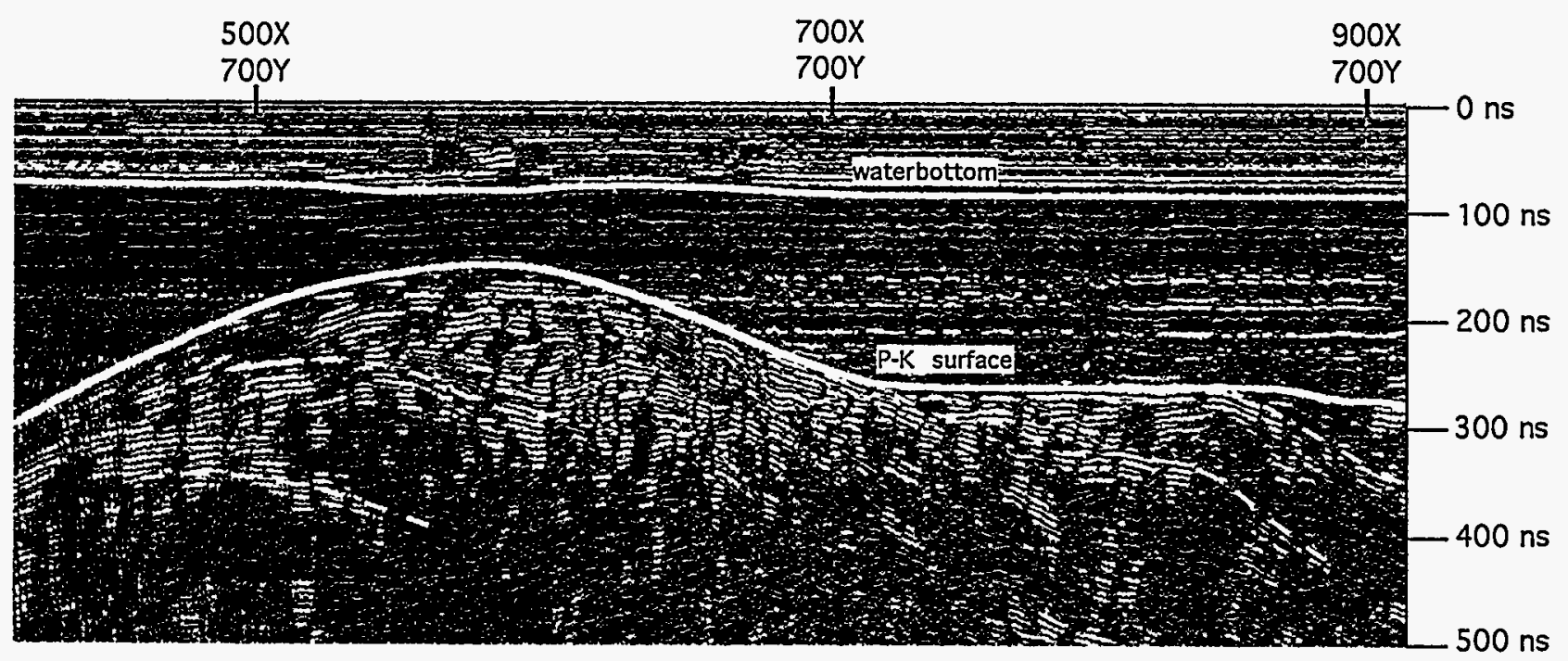

308

FIGURE 30 A: Area 2 GPR Profile; B: Area 2 GPR Profile with Interpretation 


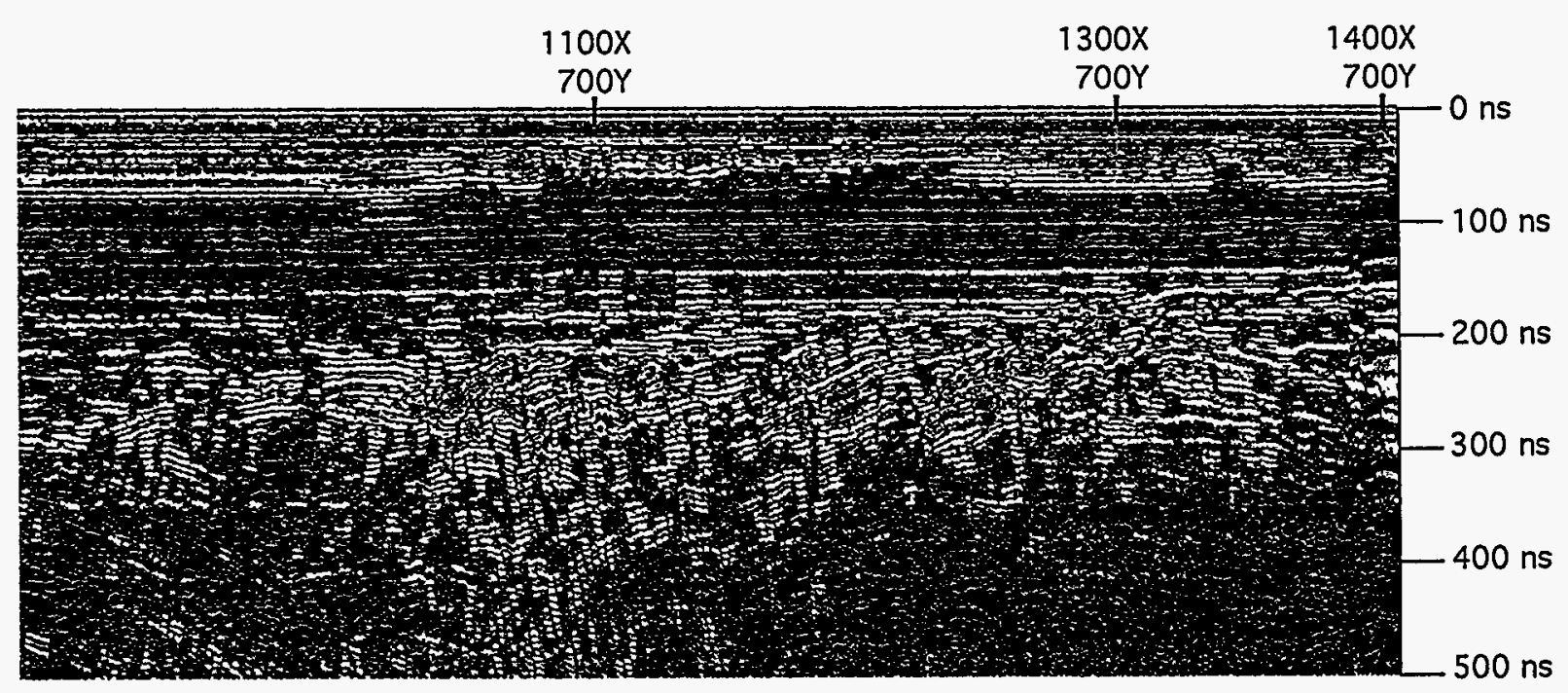

$31 \mathrm{~A}$

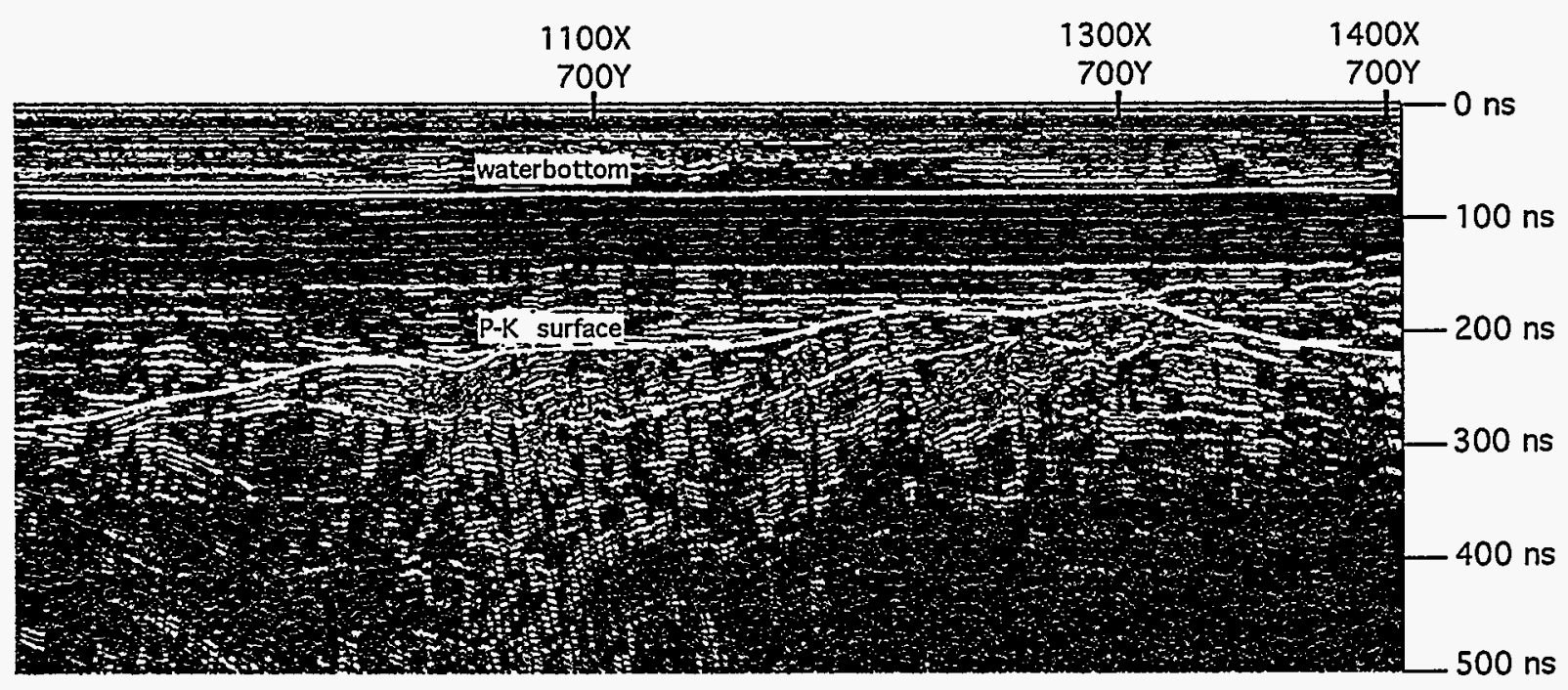

$31 \mathrm{~B}$

FIGURE 31 A: Area 2 GPR Profile; B: Area 2 GPR Profile with Interpretation 


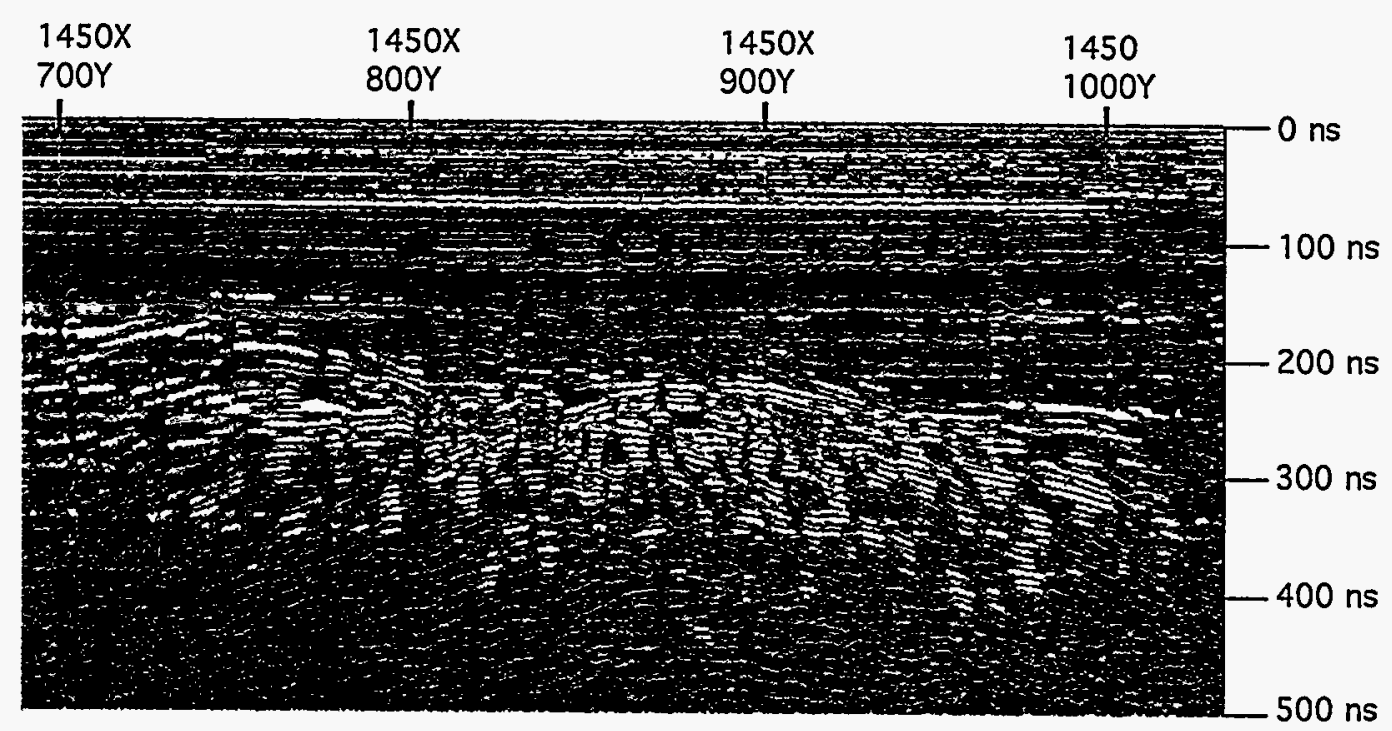

$32 \mathrm{~A}$

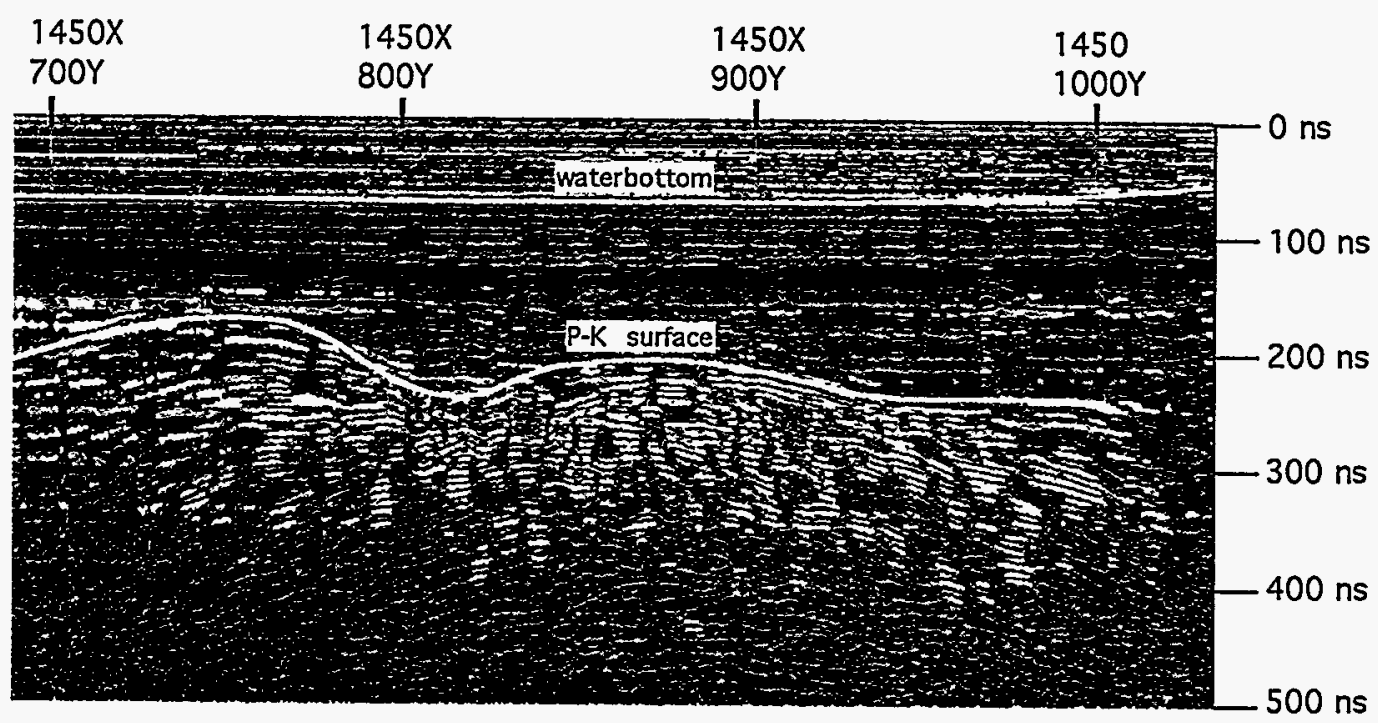

$32 B$

FIGURE 32 A: Area 2, Eastern Extension GPR Profile; B: Area 2, Eastern Extension GPR Profile with Interpretation 


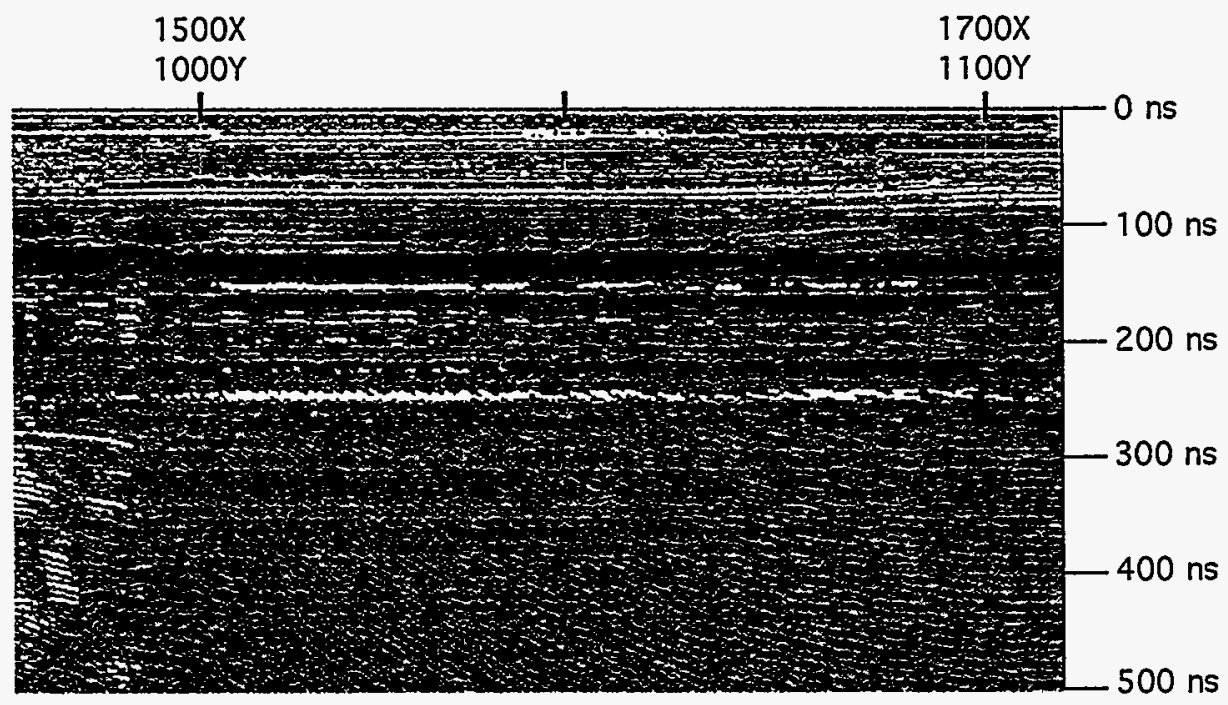

33A

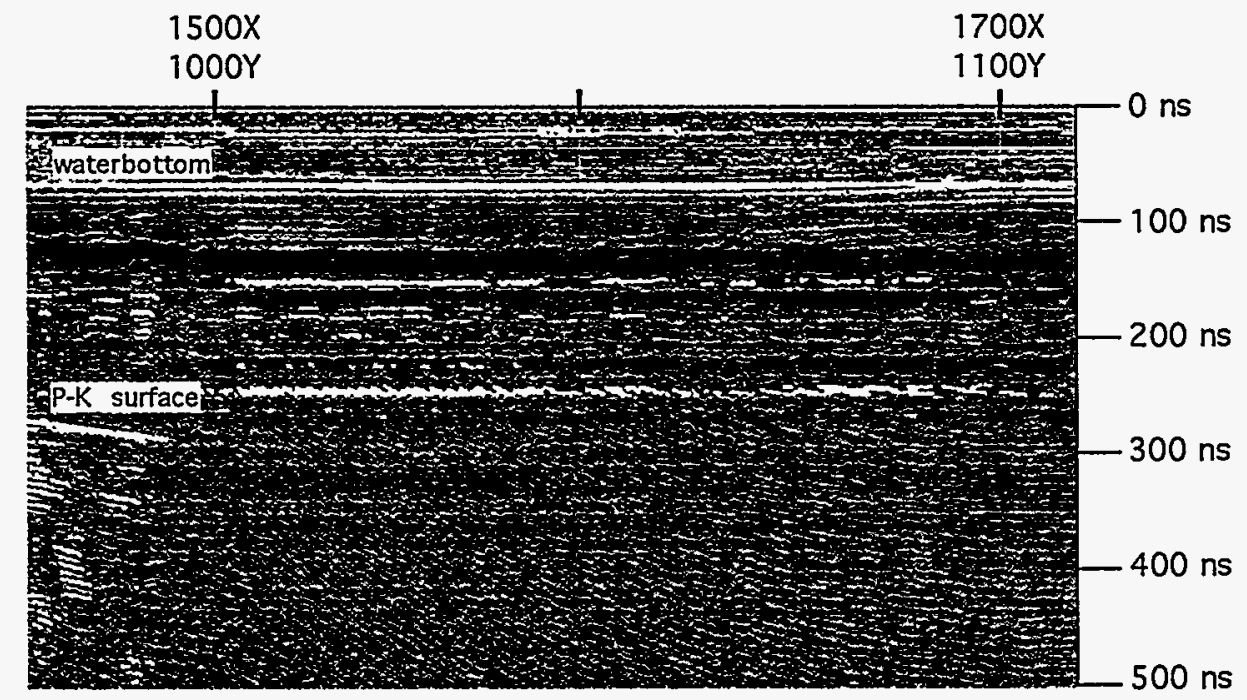

$33 B$

FIGURE 33 A: Area 2, Eastern Extension GPR Profile; B: Area 2, Eastern Extension GPR Profile with Interpretation 


\subsection{Area 3}

Ground-penetrating radar in Area 3 (Figures 34-37) indicates the P-K unconformity is not identifiable in the western part of Area 3 , specifically between grid values $500 \mathrm{X}, 700 \mathrm{Y}$ and 700X, 700Y. This same general region is where GPR from Area 2 detected a Pleistocene paleochannel. The eastern valley wall is identified by Pleistocene onlap to the Cretaceous in the vicinity of grid value $700 \mathrm{X}, 700 \mathrm{Y}$. This area is characterized by a substantial Cretaceous low / Pleistocene thick.

To the east, the P-K unconformity remains at a shallow depth between grid values $700 \mathrm{X}$, $700 \mathrm{Y}$ and near the end of the line at approximately $1700 \mathrm{X}, 700 \mathrm{Y}$. This area is characterized by a Cretaceous high in which numerous coeval haystack-shaped depositional lobes are mapped. Woody debris is scattered in various areas on the water bottom.

\subsection{Area 4}

Ground-penetrating radar in Area 4 (Figures 38-41) indicates that the P-K unconformity is poorly defined at the southern end of Area 4 between grid values $500 \mathrm{X}, 500 \mathrm{Y}$ and $500 \mathrm{X}$, $680 \mathrm{Y}$. Color displays were not helpful in establishing the P-K unconformity in this area. However, a small single point reflector appears to be at the beginning of the profile $500 \mathrm{X}, 470 \mathrm{Y}$; it may be a buried cable. The cable appears to have a few feet of sediment covering it. Starting approximately at grid value $500 \mathrm{X}, 680 \mathrm{Y}$, the $\mathrm{P}-\mathrm{K}$ unconformity is interpreted to dip to the south. This dipping reflector may be the northern valley wall of a paleochannel located southeast of Tapler Point.

To the north, a clearly definable P-K unconformity remains high, and the Pleistocene remains thin between grid values $500 \mathrm{X}, 700 \mathrm{Y}$ and $500 \mathrm{X}, 940 \mathrm{Y}$. Between grid values $500 \mathrm{X}, 940 \mathrm{Y}$ and $500 \mathrm{X}, 1330 \mathrm{Y}$, the P-K unconformity defines a broad sag, in which the Pleistocene is intermediate in thickness. A localized high at the level of the P-K unconformity is mapped between grid values $500 \mathrm{X}, 1330 \mathrm{Y}$ and $500 \mathrm{X}, 1770 \mathrm{Y}$, and aside from minor aberrations, the Pleistocene section is thin. Near the end of Area 4, between grid values 500X, 1770Y and the Bush River Dock, a sag develops at the level of the P-K unconformity and a localized Pleistocene thick ensues. The complex nature of the Lower Cretaceous depositional lobes is illustrated in Figures 38-41. Haystack-shaped depositional lobes are clearly delimited here, and major boundaries between lobe sequences are indicated by dashed lines.

\subsection{Area 5}

Ground-penetrating radar in Area 5 (Figures 42-44) indicates an area where the P-K unconformity is deep and the Pleistocene is thick between grid values $500 \mathrm{X}, 450 \mathrm{Y}$ and $500 \mathrm{X}$, 


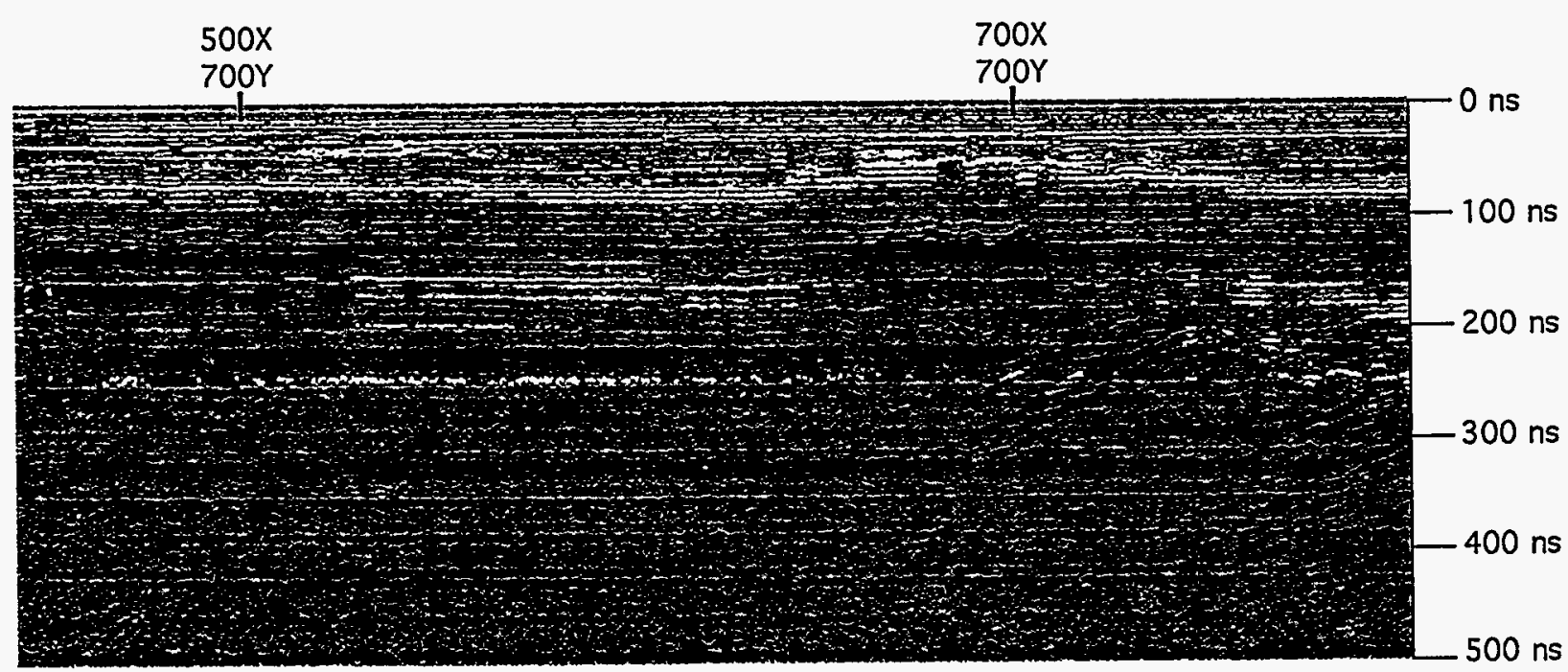

$34 \mathrm{~A}$

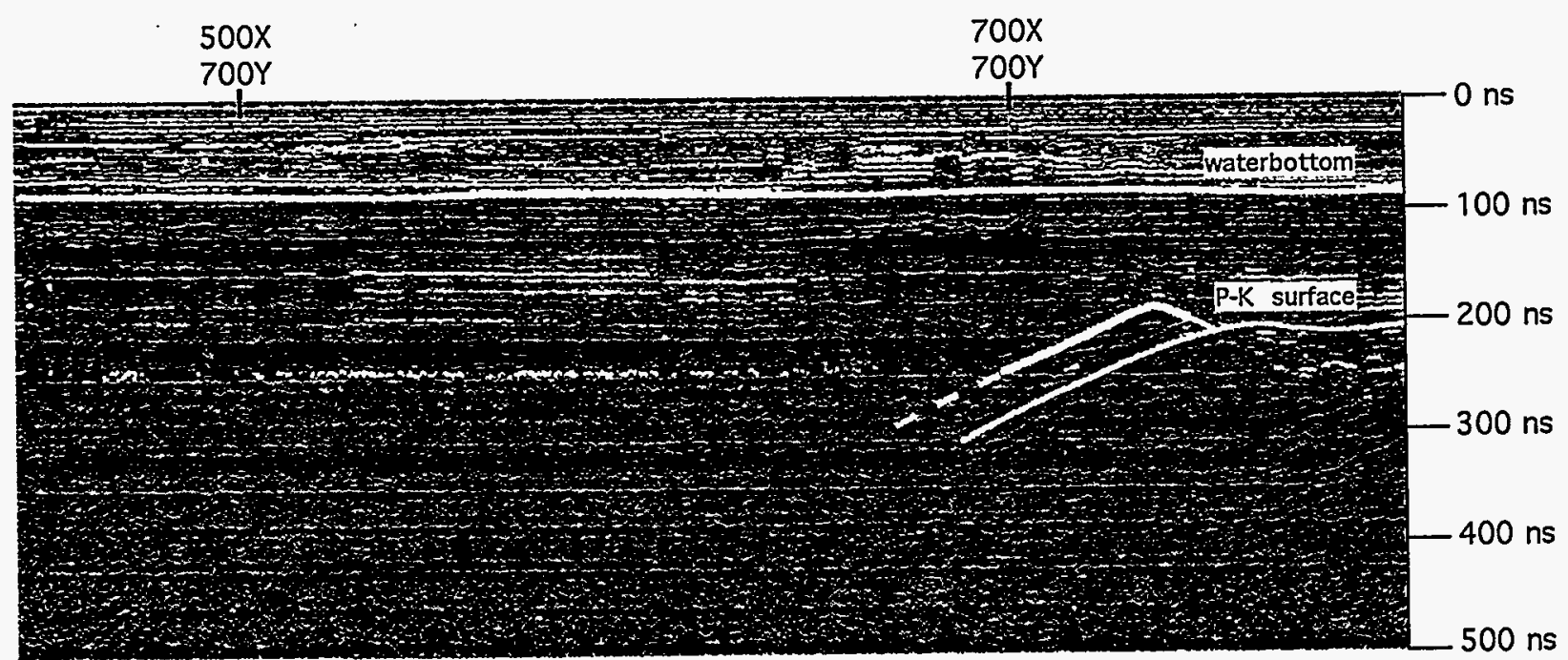

\section{B}

FIGURE 34 A: Area 3 GPR Profile; B: Area 3 GPR Profile with Interpretation 


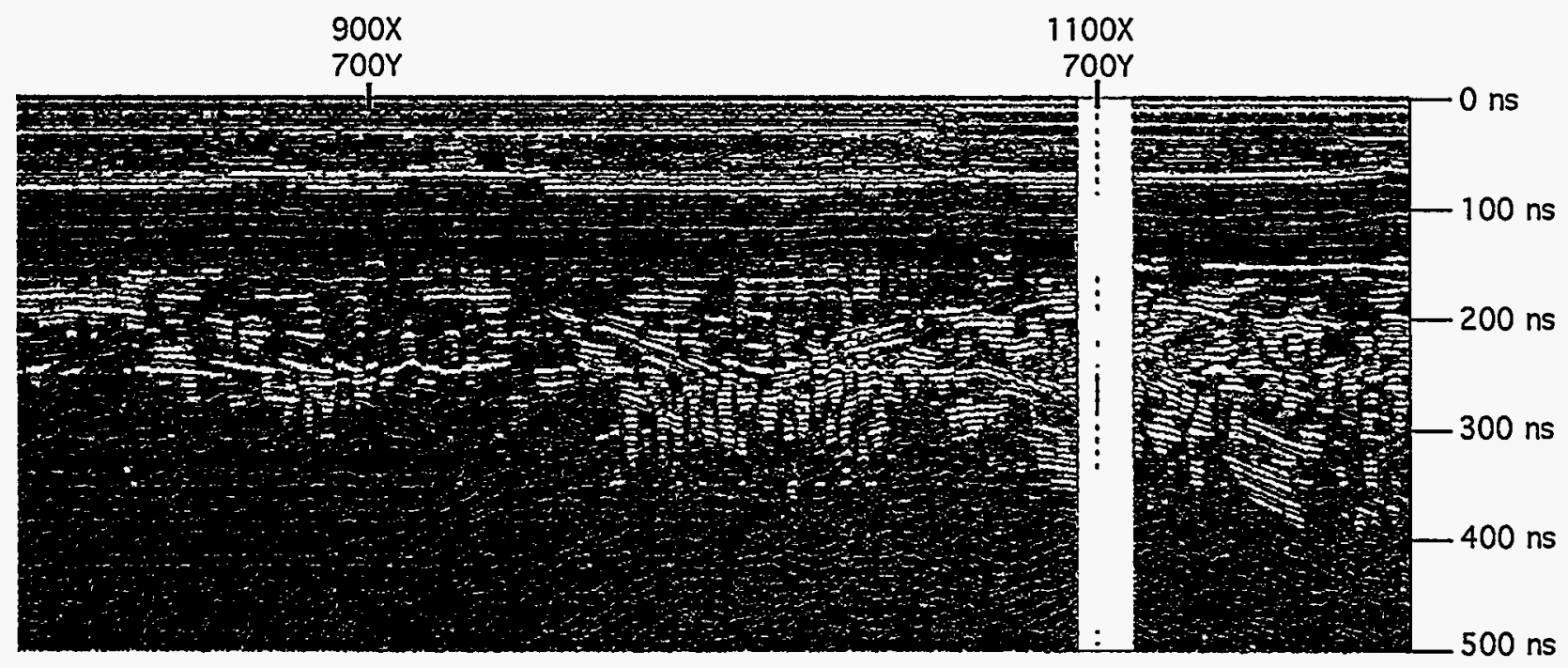

$35 \mathrm{~A}$

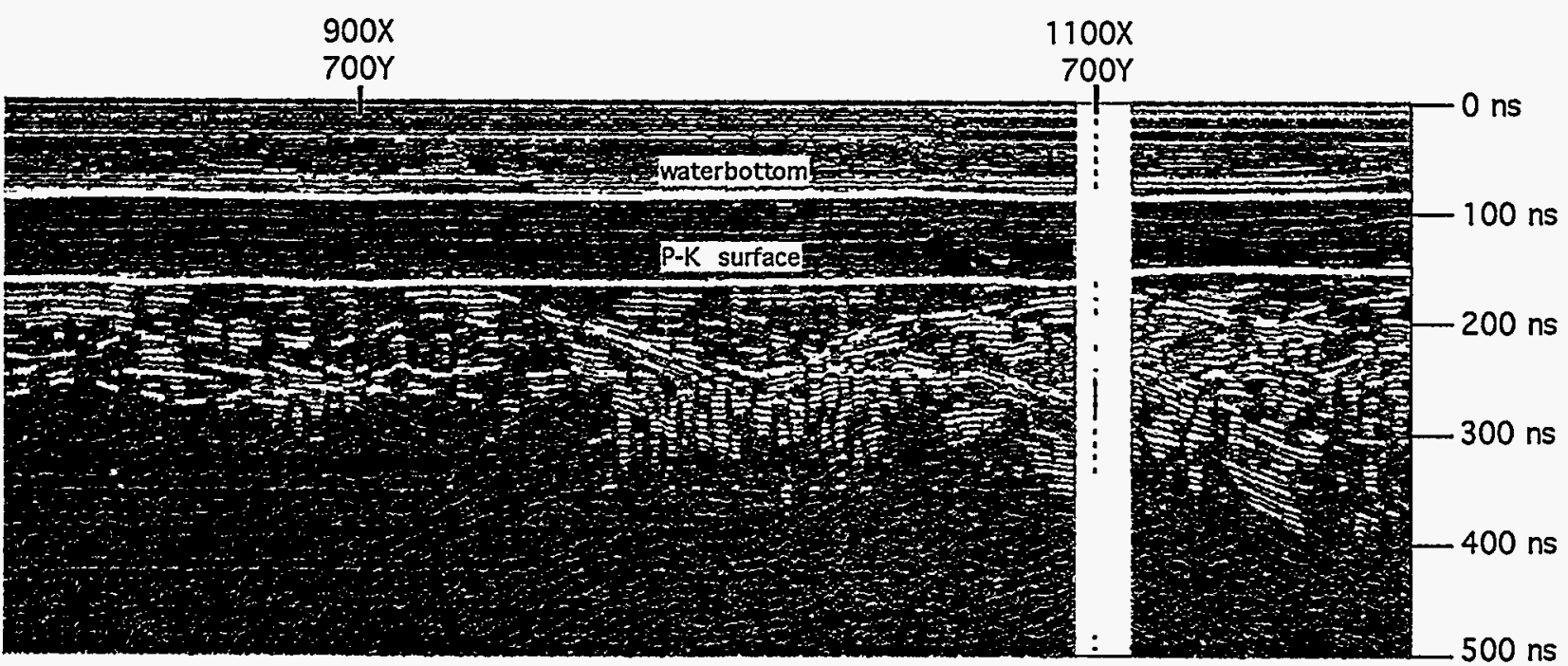

35B

FIGURE 35 A: Area 3 GPR Profile; B: Area 3 GPR Profile with Interpretation 


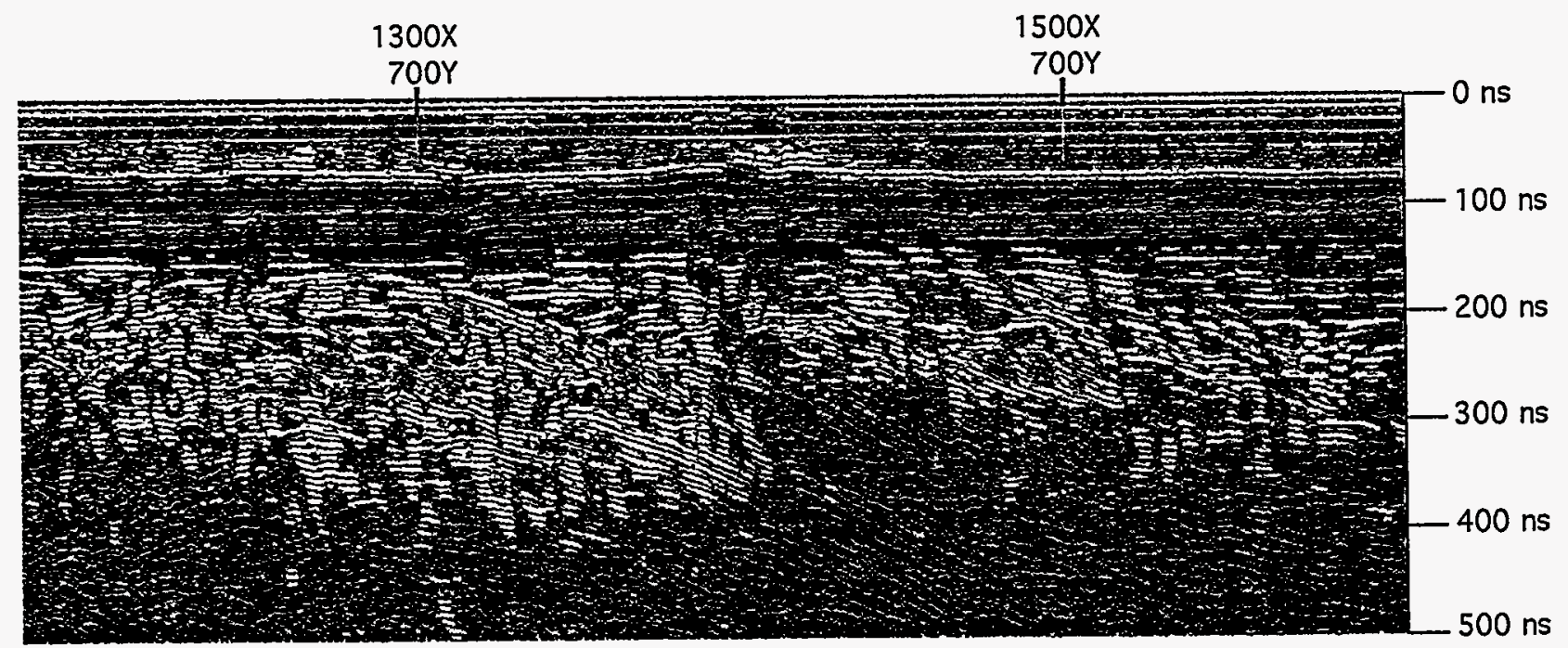

$36 \mathrm{~A}$

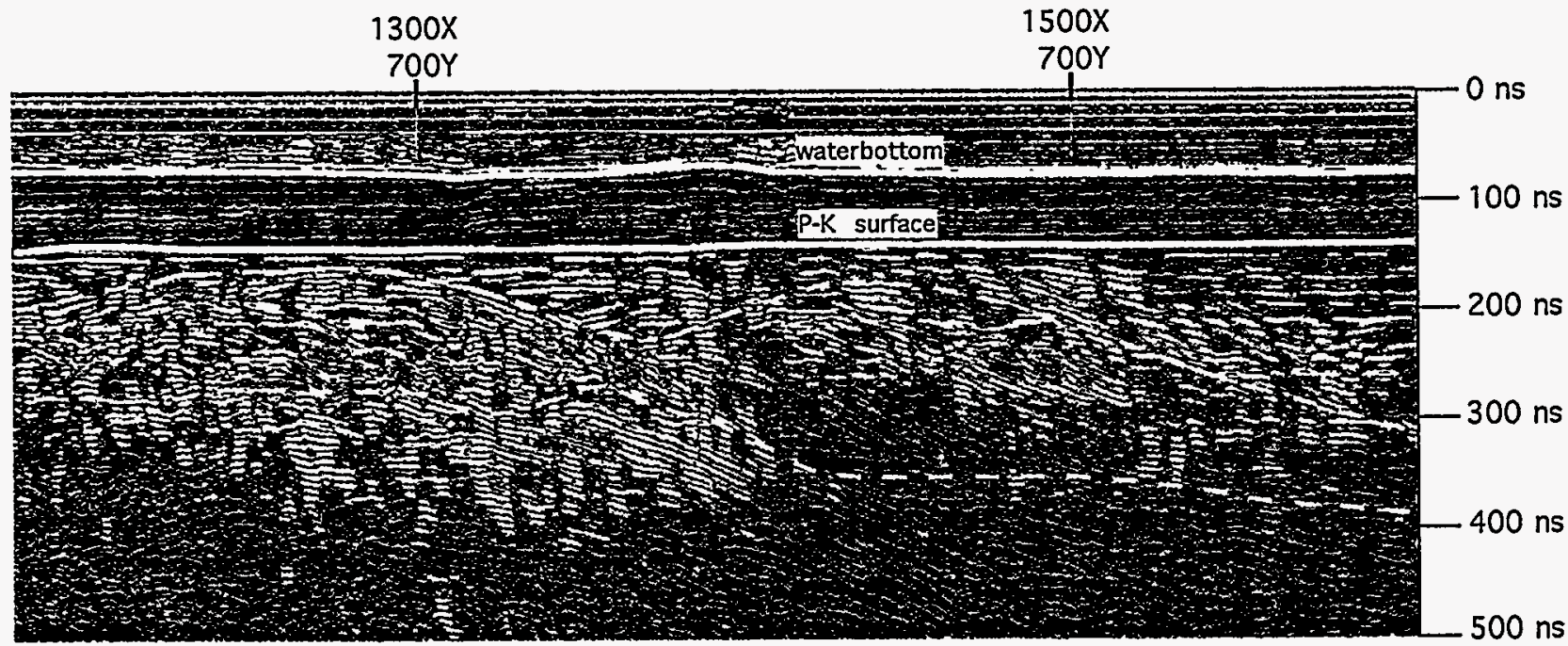

$36 \mathrm{~B}$

FIGURE 36 A: Area 3 GPR Profile; B: Area 3 GPR Profile with Interpretation 


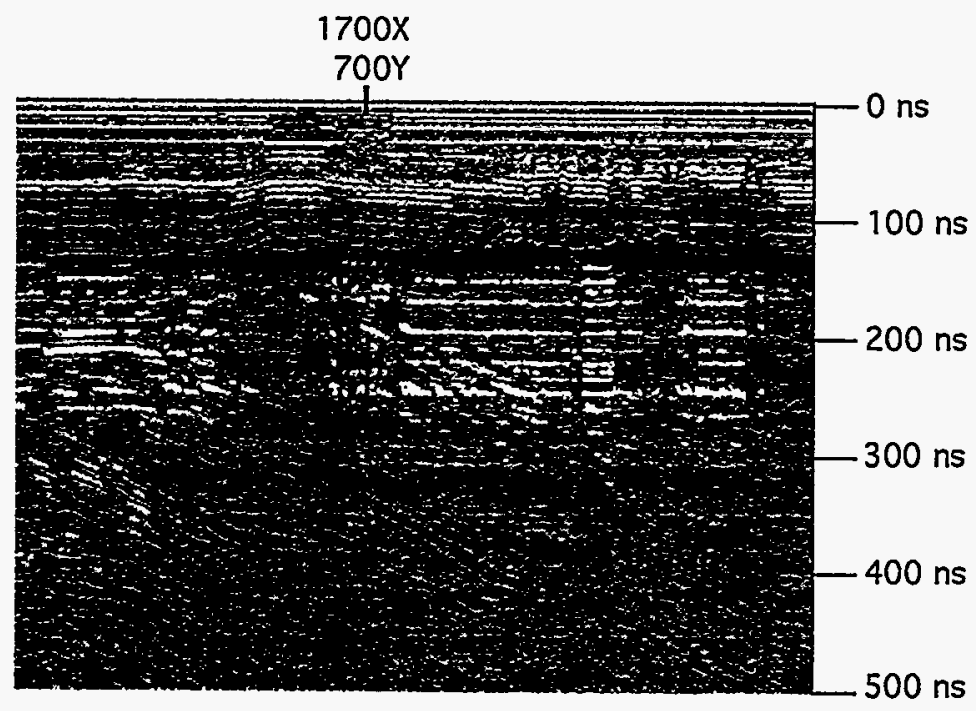

$37 \mathrm{~A}$

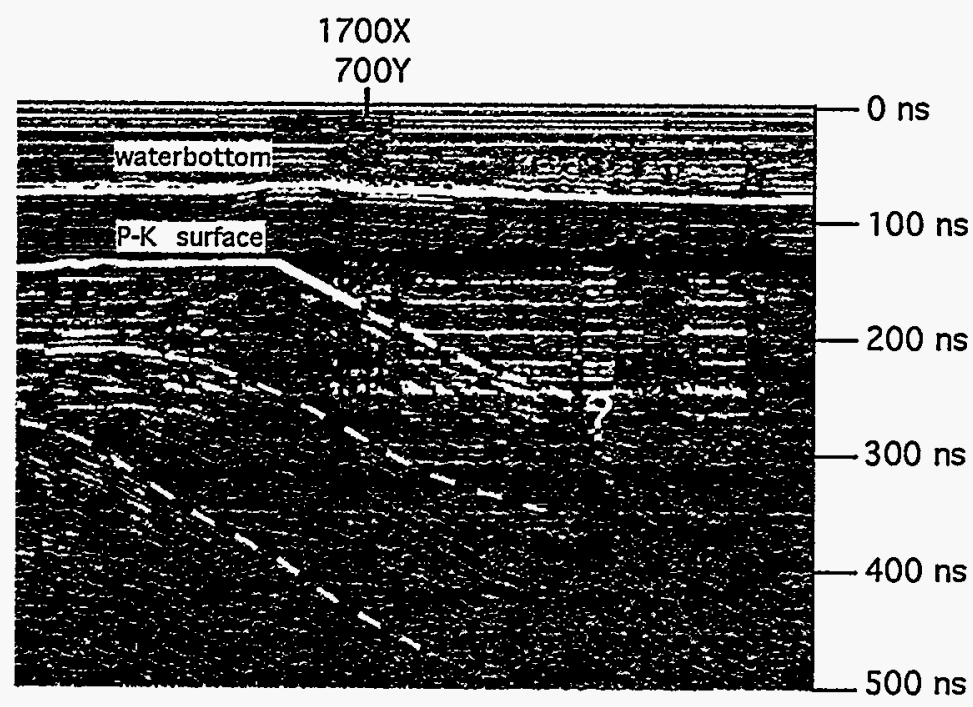

$37 B$

FIGURE 37 A: Area 3 GPR Profile; B: Area 3 GPR

Profile with Interpretation 


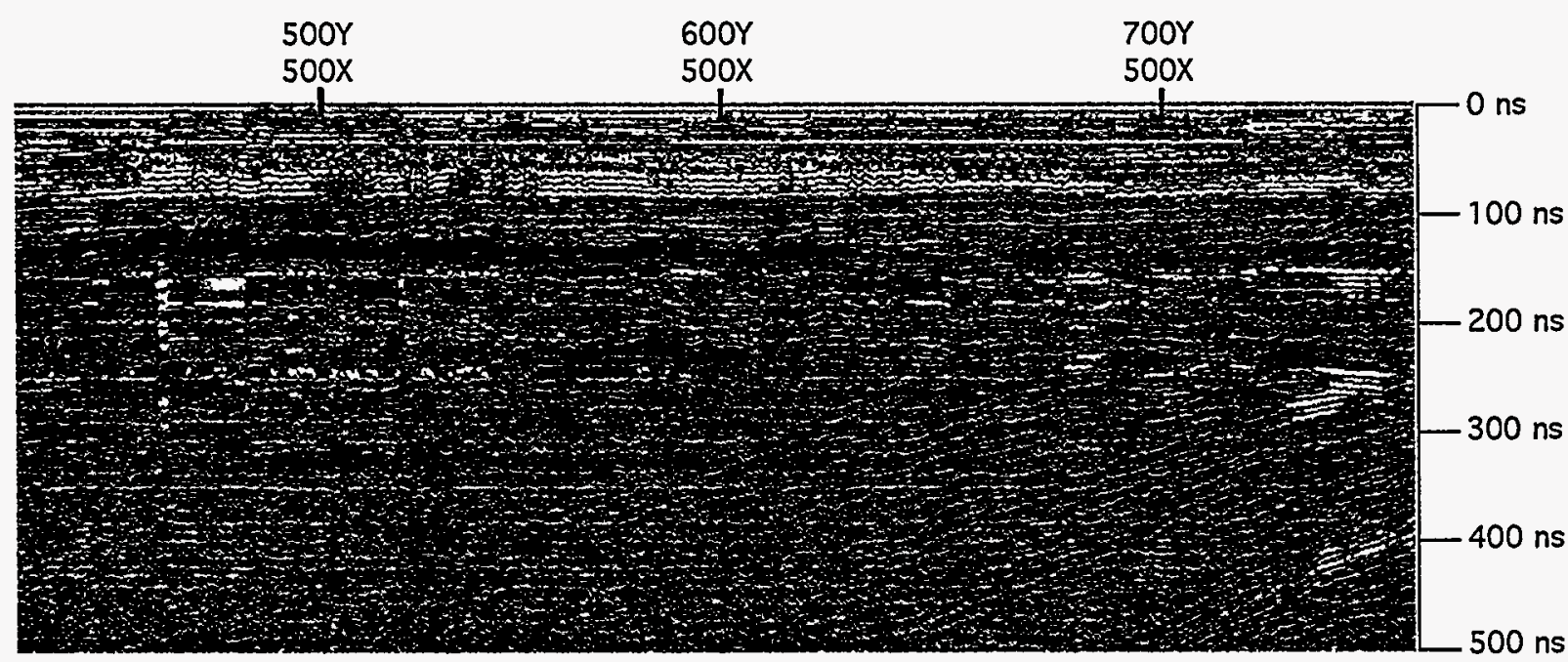

$38 \mathrm{~A}$

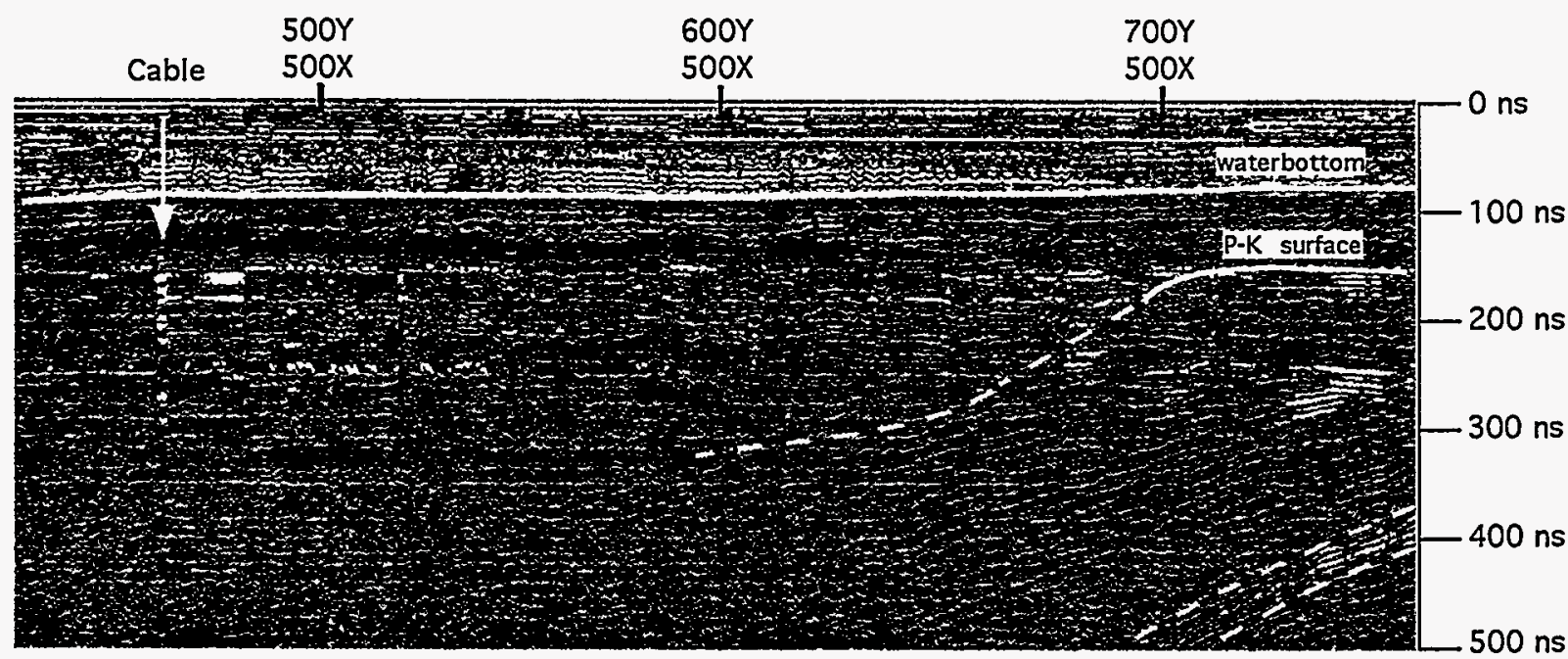

38B

FIGURE 38 A: Area 4 GPR Profile; B: Area 4 GPR Profile with Interpretation 


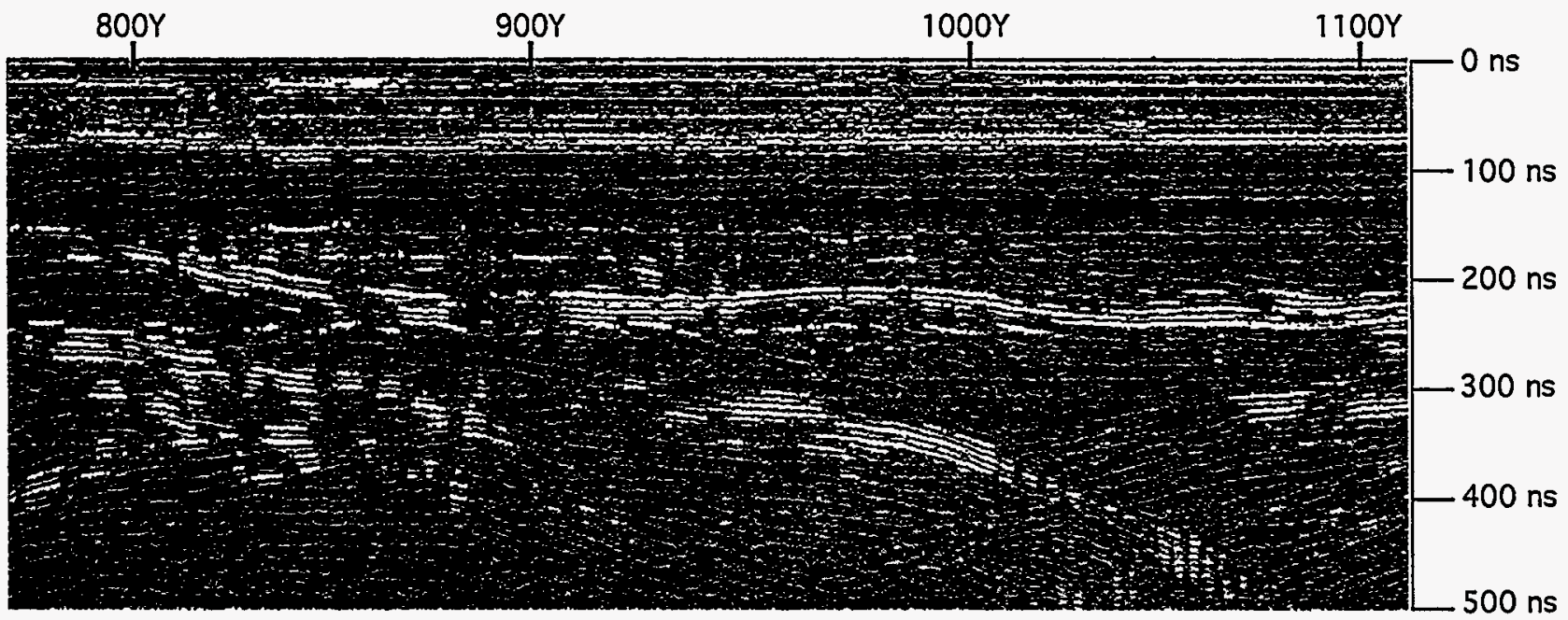

$39 \mathrm{~A}$

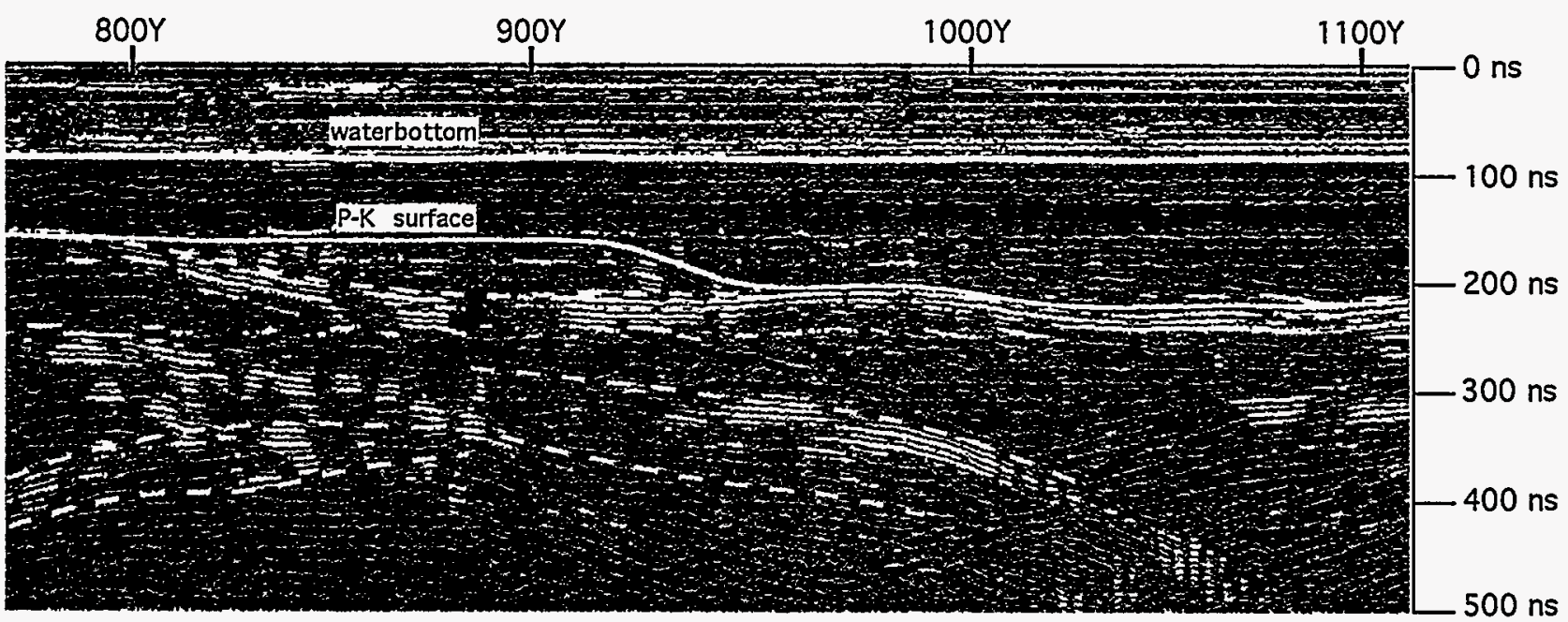

$39 B$

FIGURE 39 A: Area 4 GPR Profile; B: Area 4 GPR Profile with Interpretation 


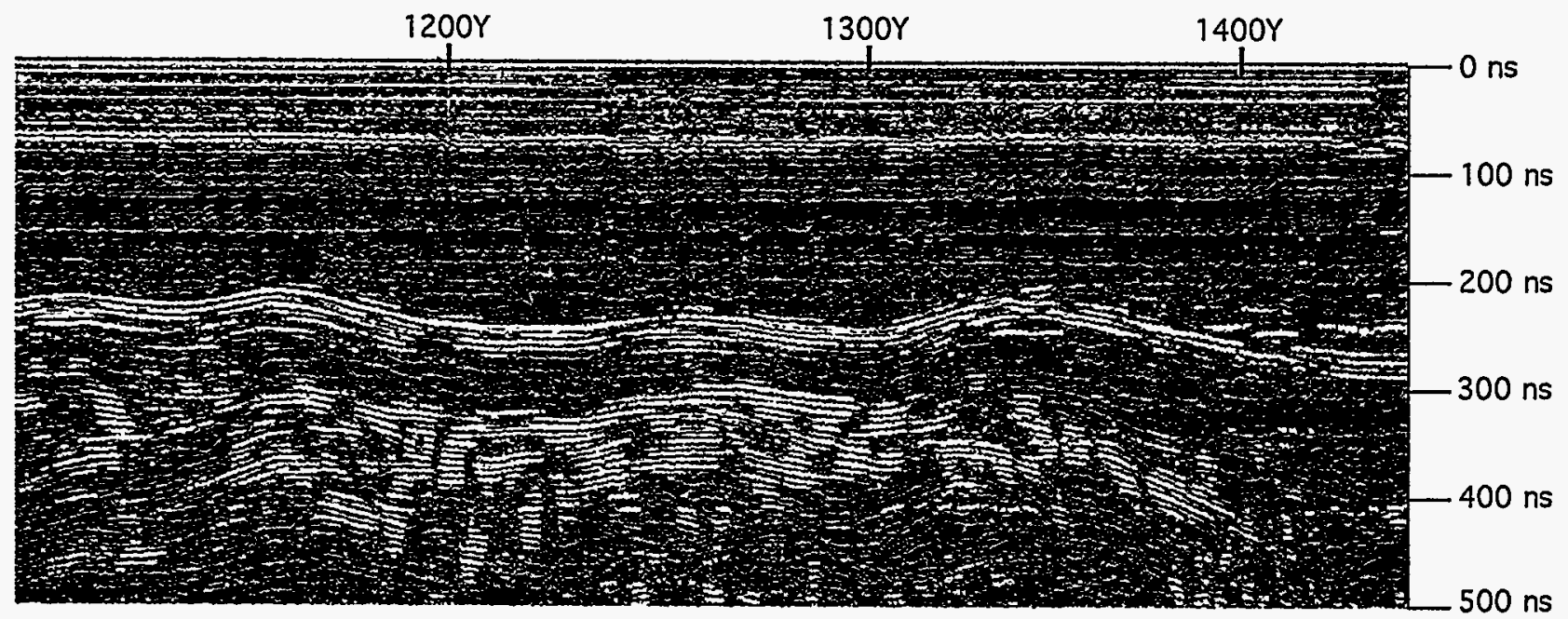

$40 \mathrm{~A}$

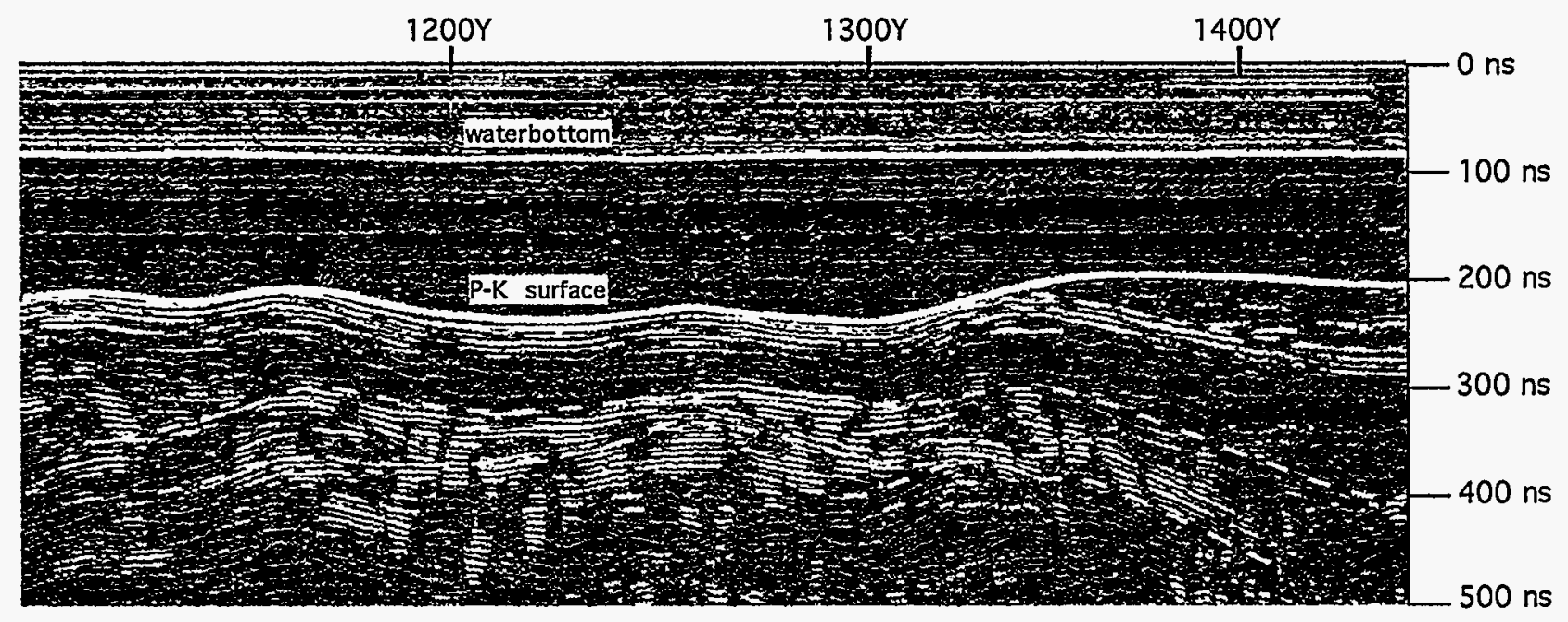

$40 \mathrm{~B}$

FIGURE 40 A: Area 4 GPR Profile; B: Area 4 GPR Profile with Interpretation 


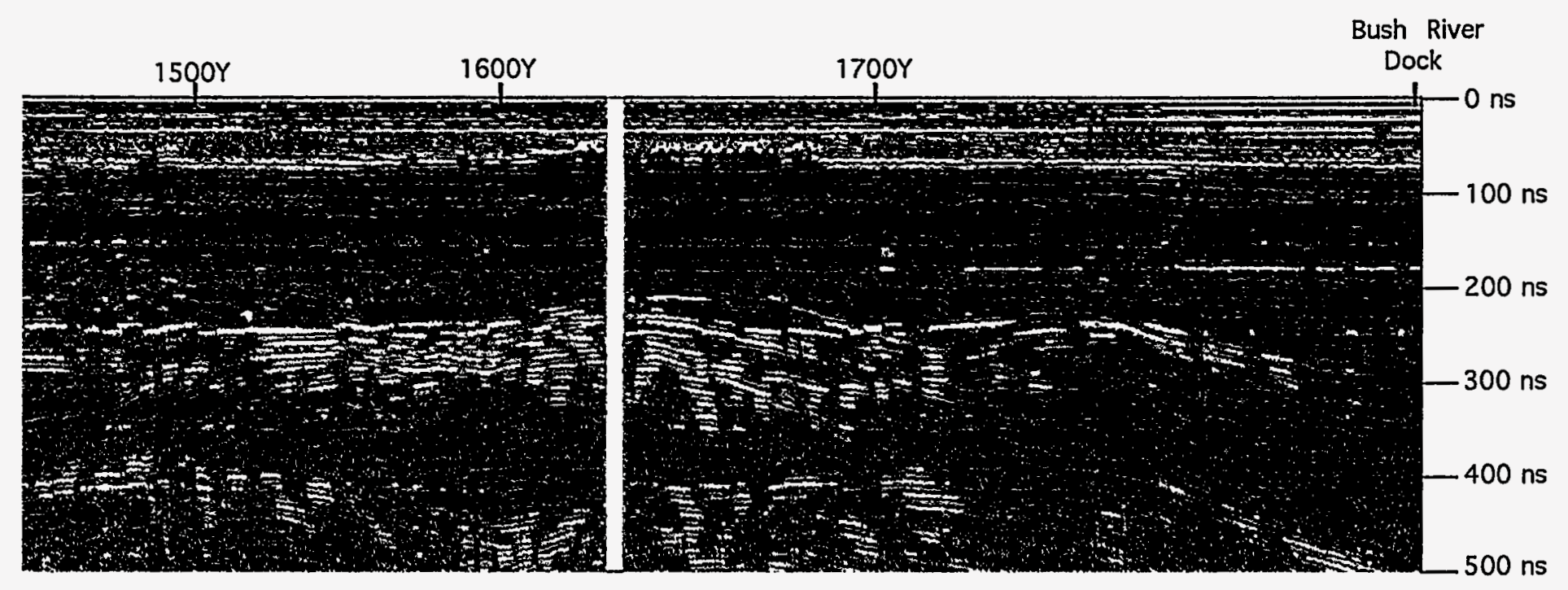

$41 \mathrm{~A}$

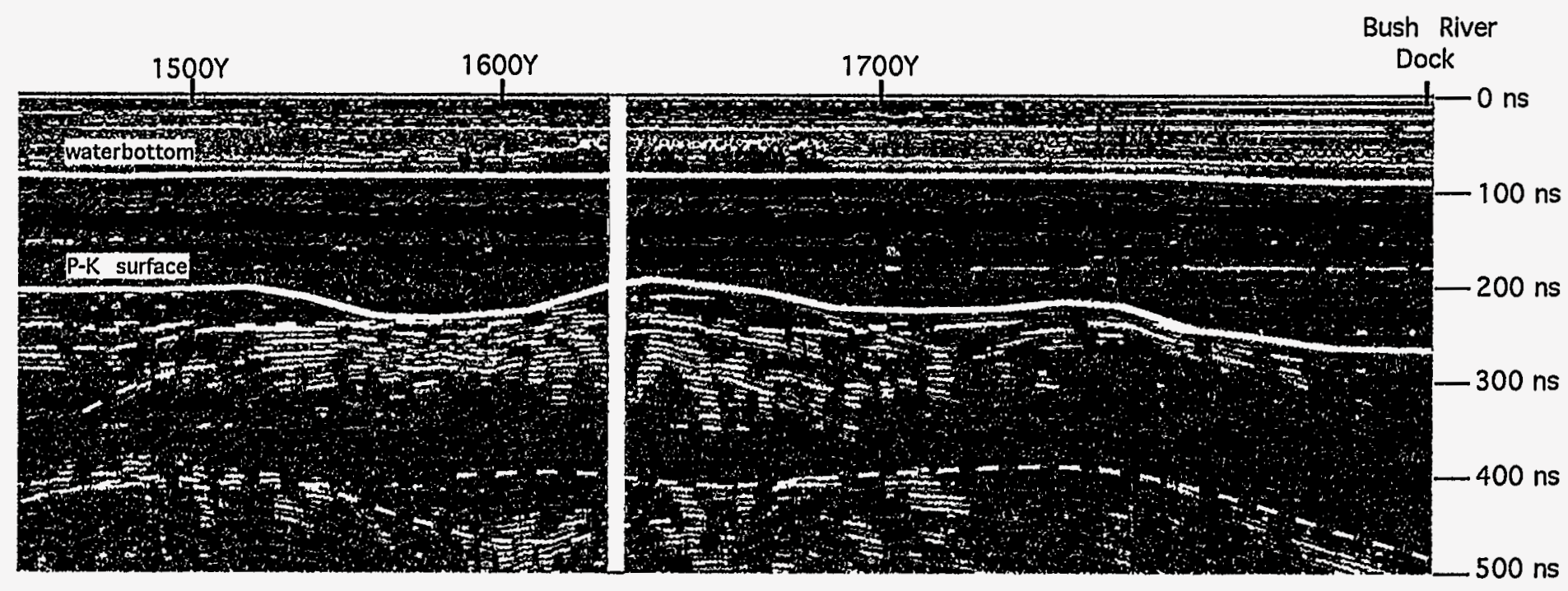

41B

FIGURE 41 A: Area 4 GPR Profile; B: Area 4 GPR Profile with Interpretation 


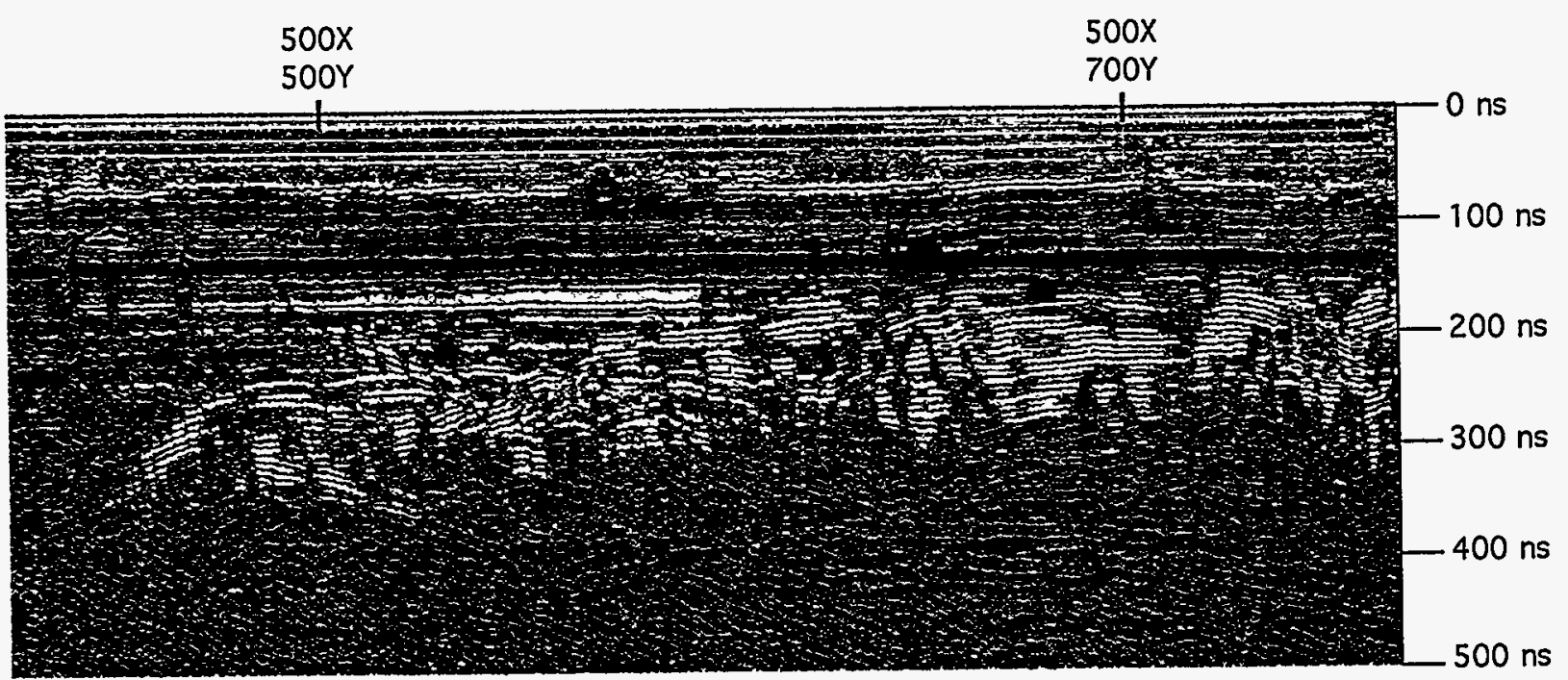

$42 \mathrm{~A}$

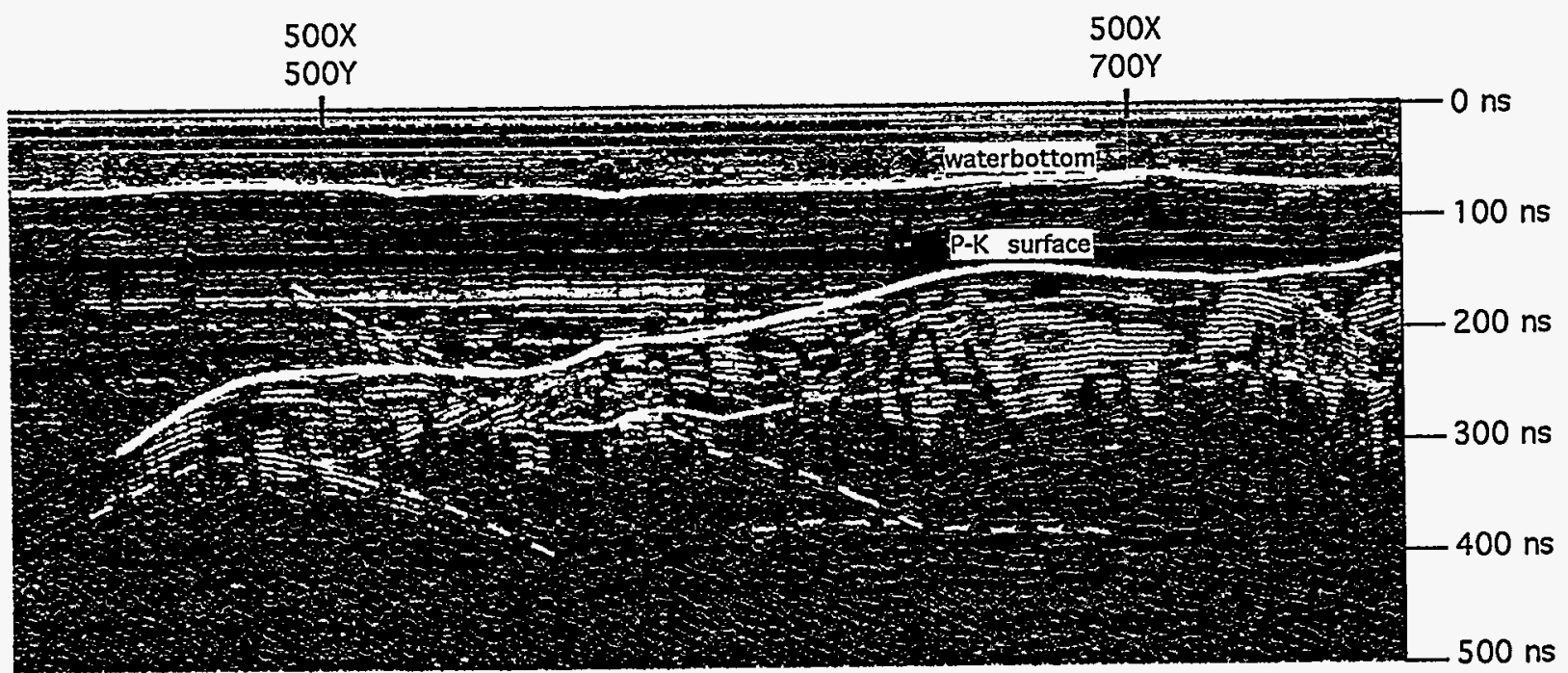

$42 B$

FIGURE 42 A: Area 5 GPR Profile; B: Area 5 GPR Profile with Interpretation 


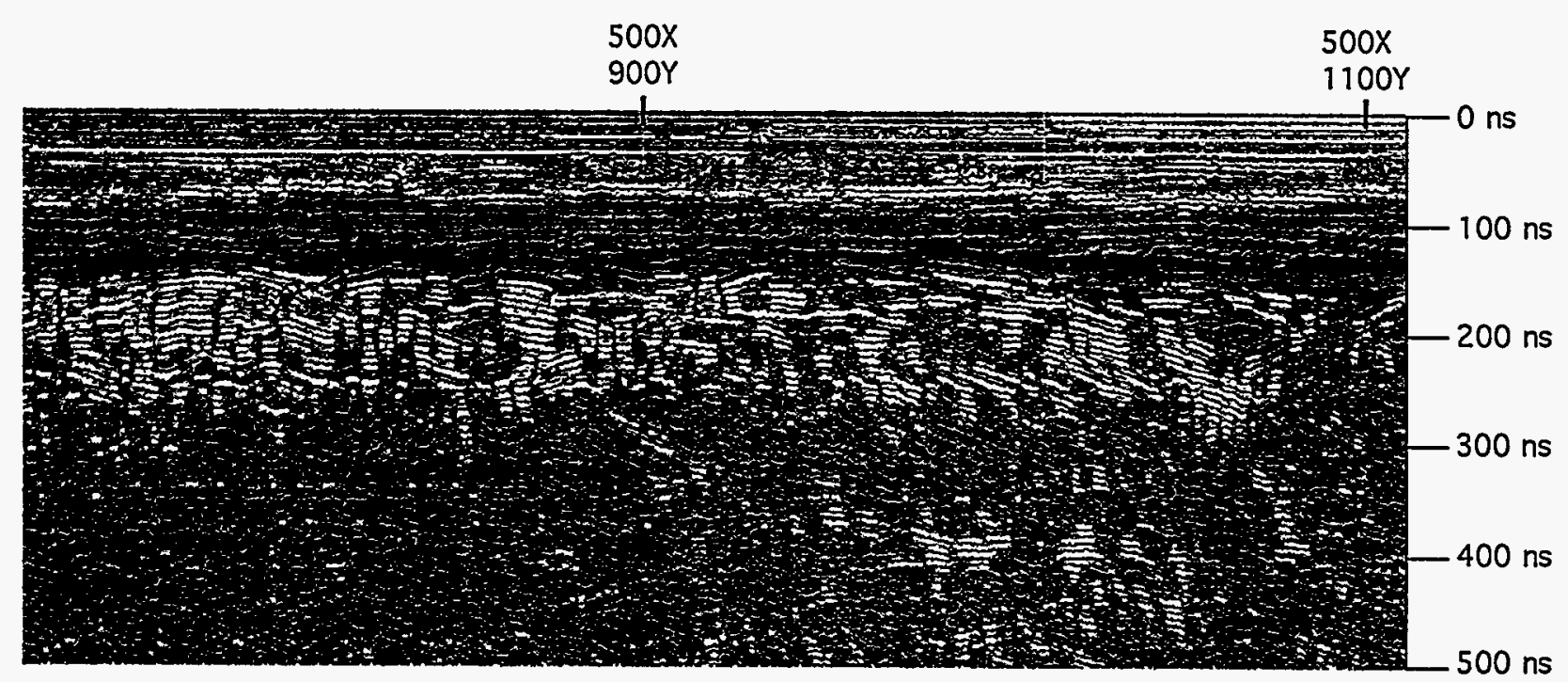

$43 A$

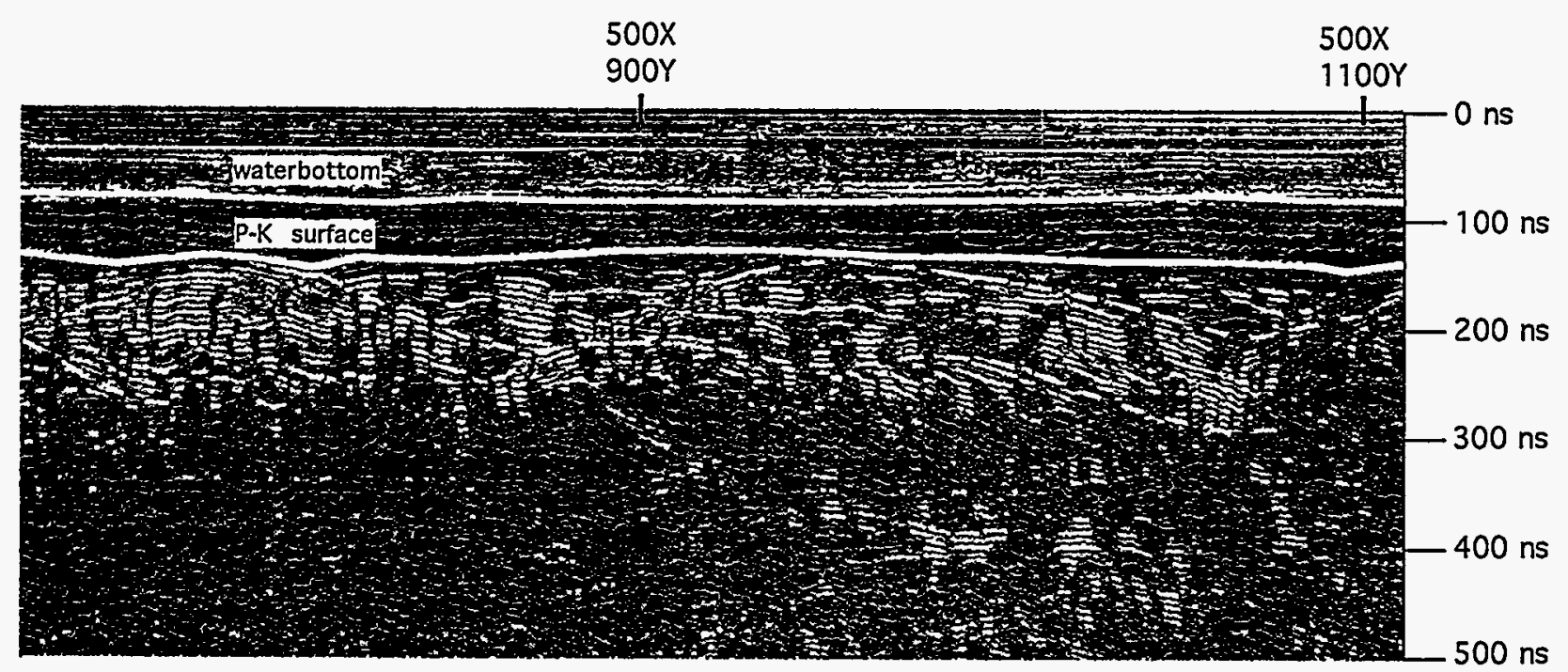

43B

FIGURE 43 A: Area 5 GPR Profile; B: Area 5 GPR Profile with Interpretation 


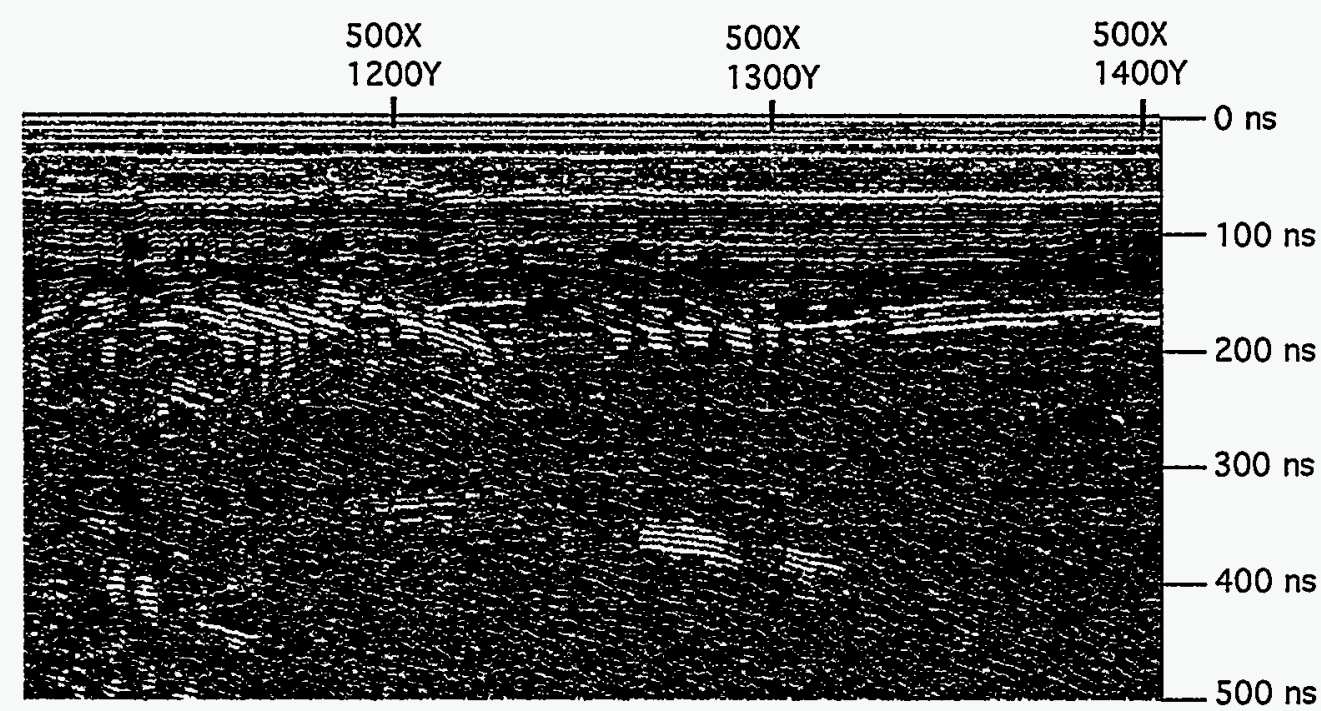

$44 \mathrm{~A}$

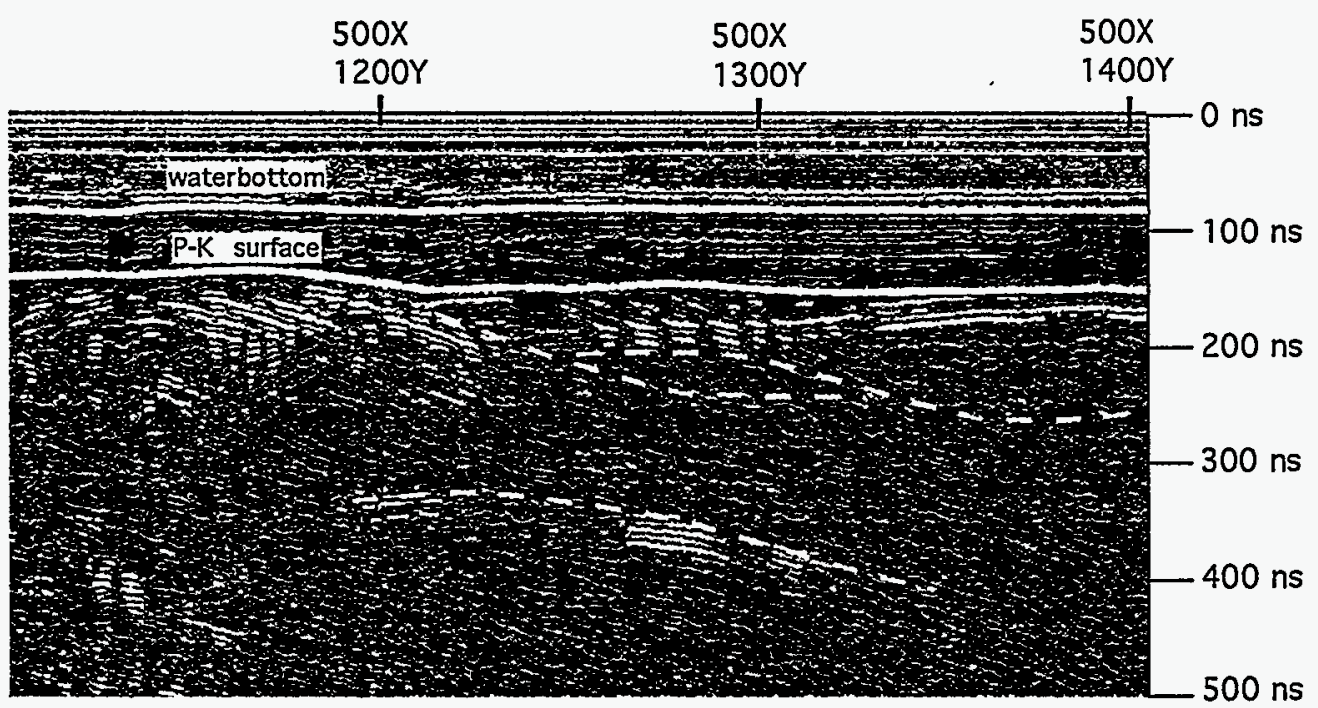

44B

FIGURE 44 A: Area 5 GPR Profile; B: Area 5 GPR Profile with. Interpretation 
540Y. This area is tentatively interpreted to result from a paleochannel cut during the Pleistocene; however, it may also be associated with past dredging around the dock. Thick sediments interpreted to be of Pleistocene-age represent the paleochannel fill. A wide, low-relief terrace is interpreted between grid values 500X, 540Y and 500X, 630Y. Evidence of a secondary channeling event within the Pleistocene fill may be present in the vicinity of grid value 500X, $575 \mathrm{Y}$. The base of the paleochannel could bottom out at $300 \mathrm{~ns}$, or it could be much deeper. The interpretation of a paleochannel in this area is consistent with the sag imaged at the northern terminus of Area 4. The interpretation of a paleochannel beneath the Bush River Dock is suspect because of gaps between the end of Area 4 GPR coverage and the start of Area 5 GPR coverage. It maybe more appropriate to call this a localized sag.

The P-K unconformity is interpreted to remain structurally high and the Pleistocene correspondingly thin between grid values $500 \mathrm{X}, 630 \mathrm{Y}$ and the end of the line at 500X, $1475 \mathrm{Y}$.

\subsection{Area 6}

Ground-penetrating radar in Area 6 (Figures 45-47) indicates the P-K unconformity is shallow and the Pleistocene is thin between grid values 500X, 500Y and 500X,600Y. In this area, immediately offshore from the RAD storage building (E2370), two anthropogenic objects are interpreted to be the generators of the flat-lying multiples in the vicinity of grid values $500 \mathrm{X}$, $585 \mathrm{Y}$ and 500X, 680Y, respectively.

To the north, between grid values $500 \mathrm{X}, 1100 \mathrm{Y}$ and $500 \mathrm{X}, 1560 \mathrm{Y}$, a broad, lowamplitude structural sag is seen at the level of the P-K unconformity. The Pleistocene atop this sag area is relatively thick. This area is designated a suspected paleochannel. 


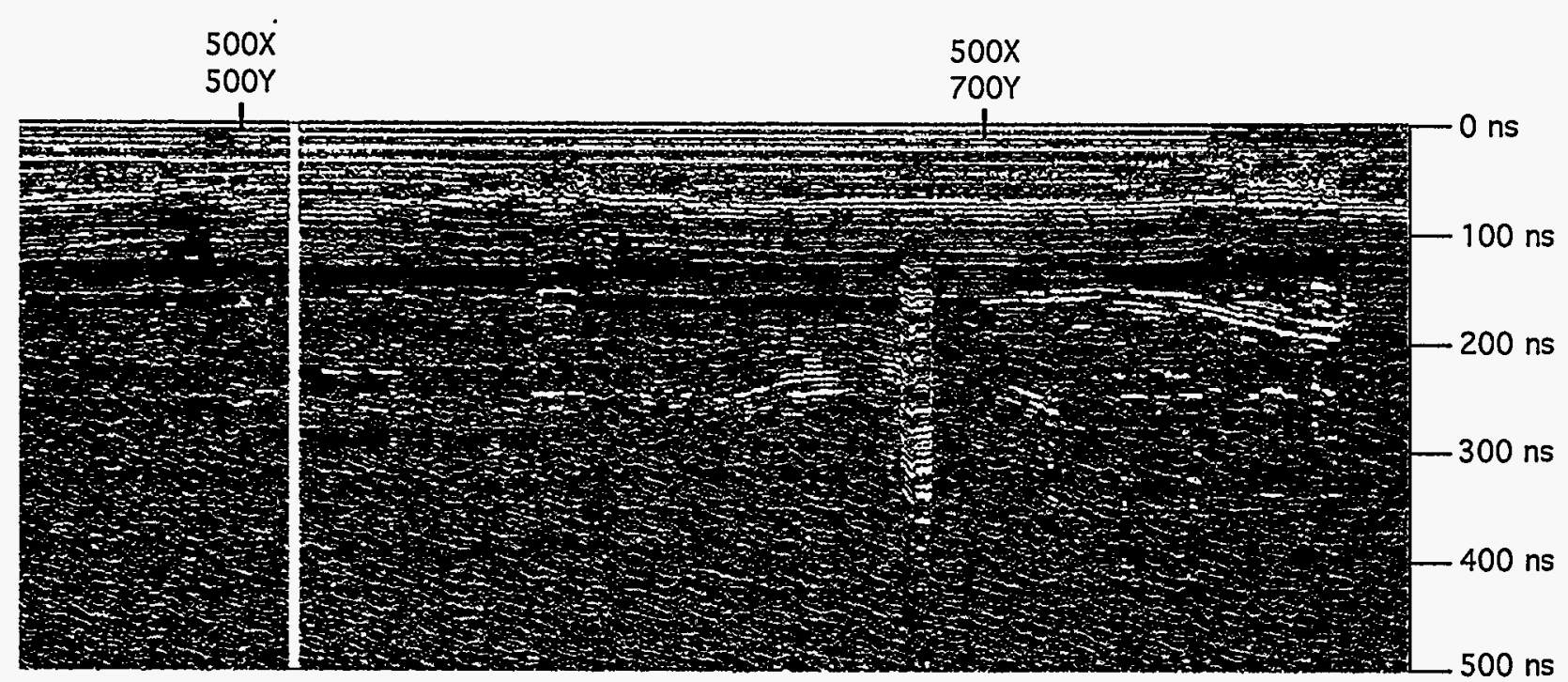

$45 \mathrm{~A}$

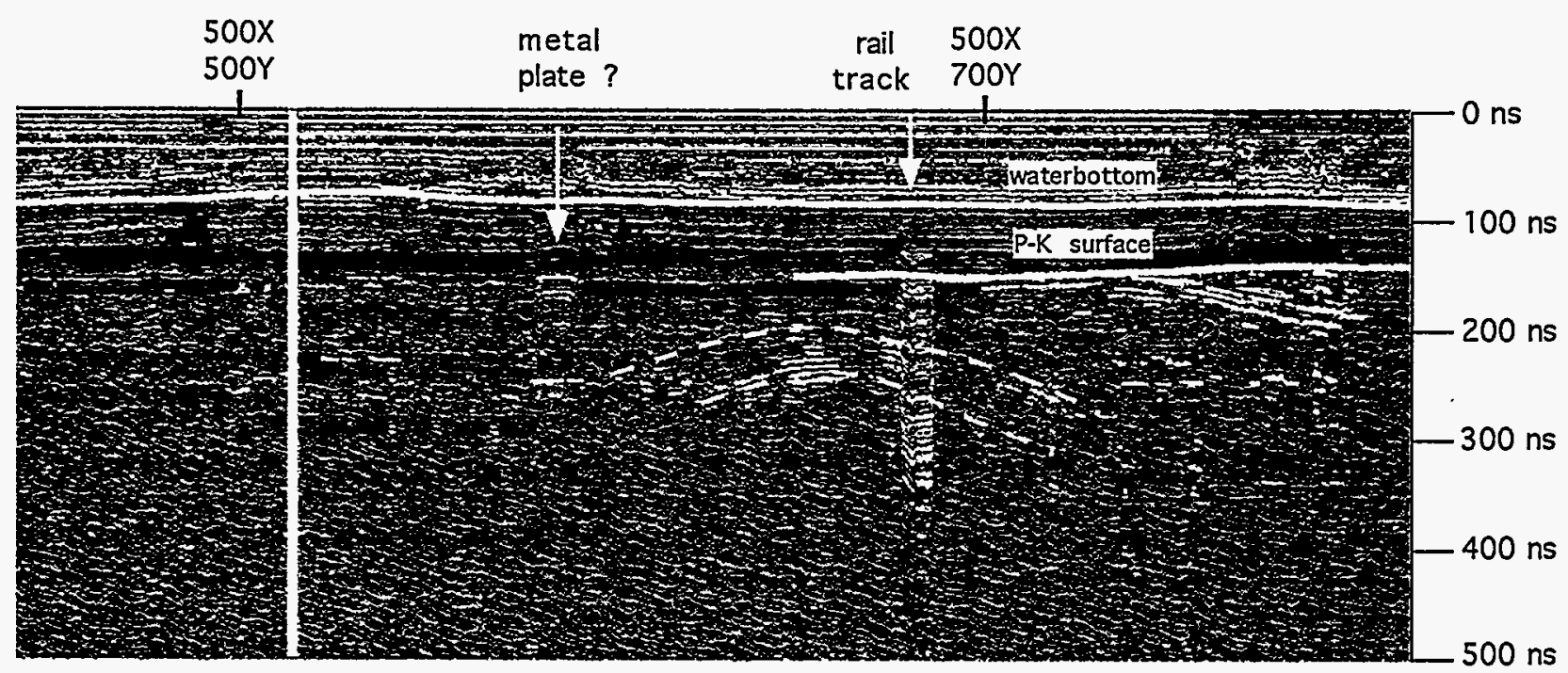

45B

FIGURE 45 A: Area 6 GPR Profile; B: Area 6 GPR Profile with Interpretation 


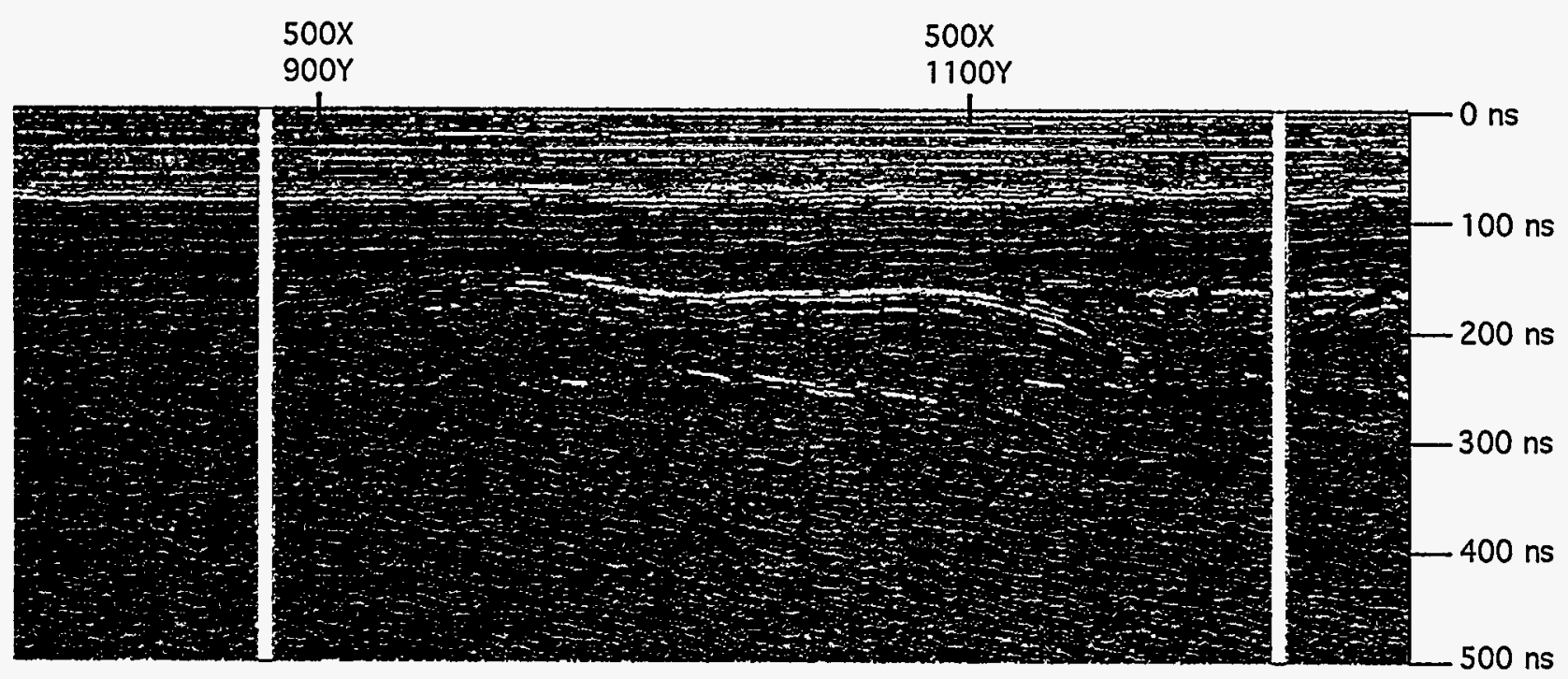

$46 \mathrm{~A}$

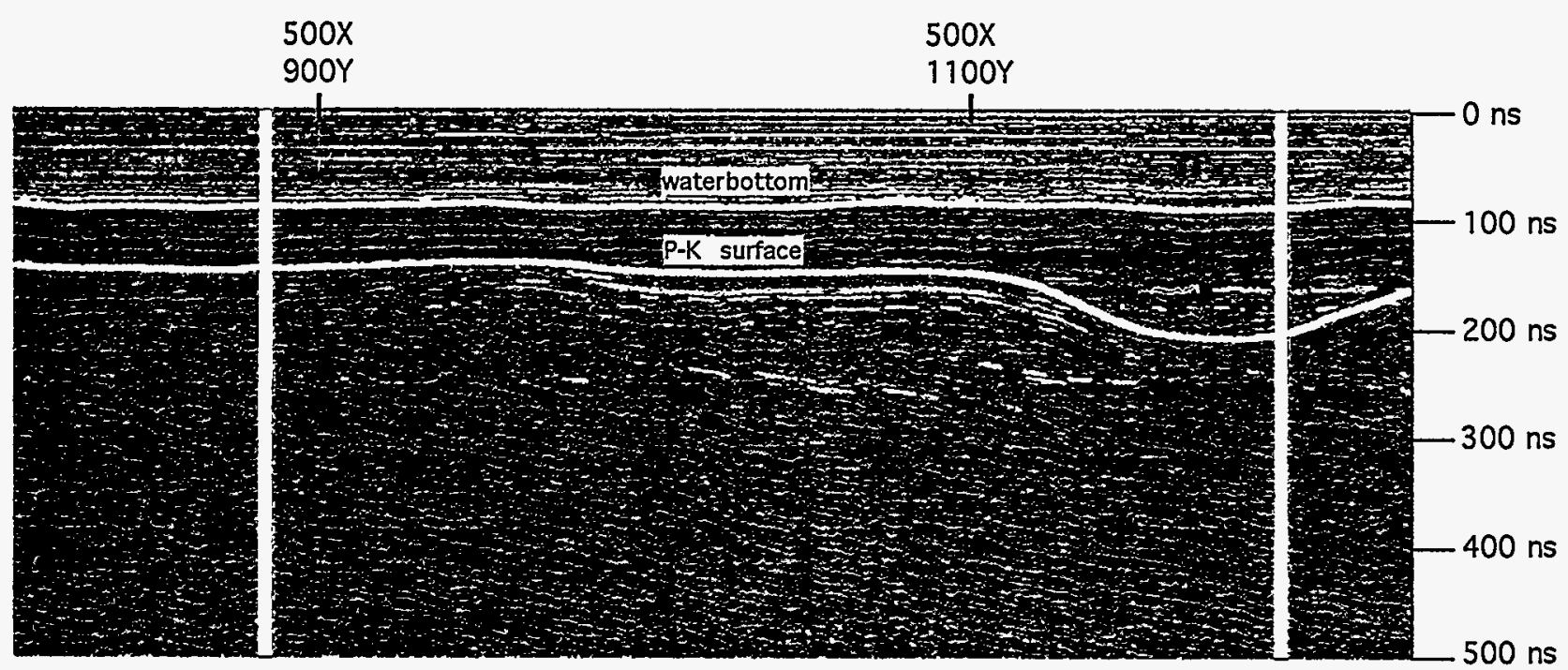

$46 B$

FIGURE 46 A: Area 6 GPR Profile; B: Area 6 GPR Profile with Interpretation 


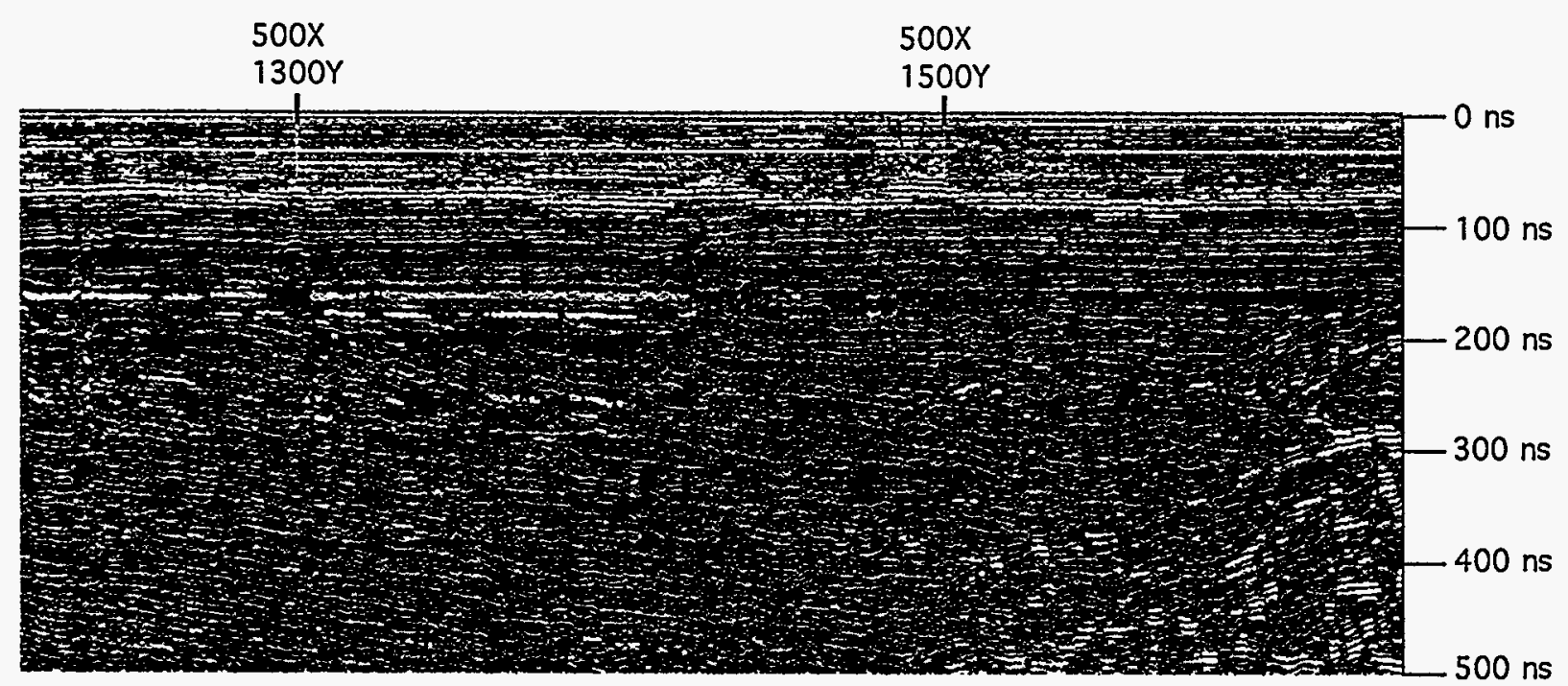

47A

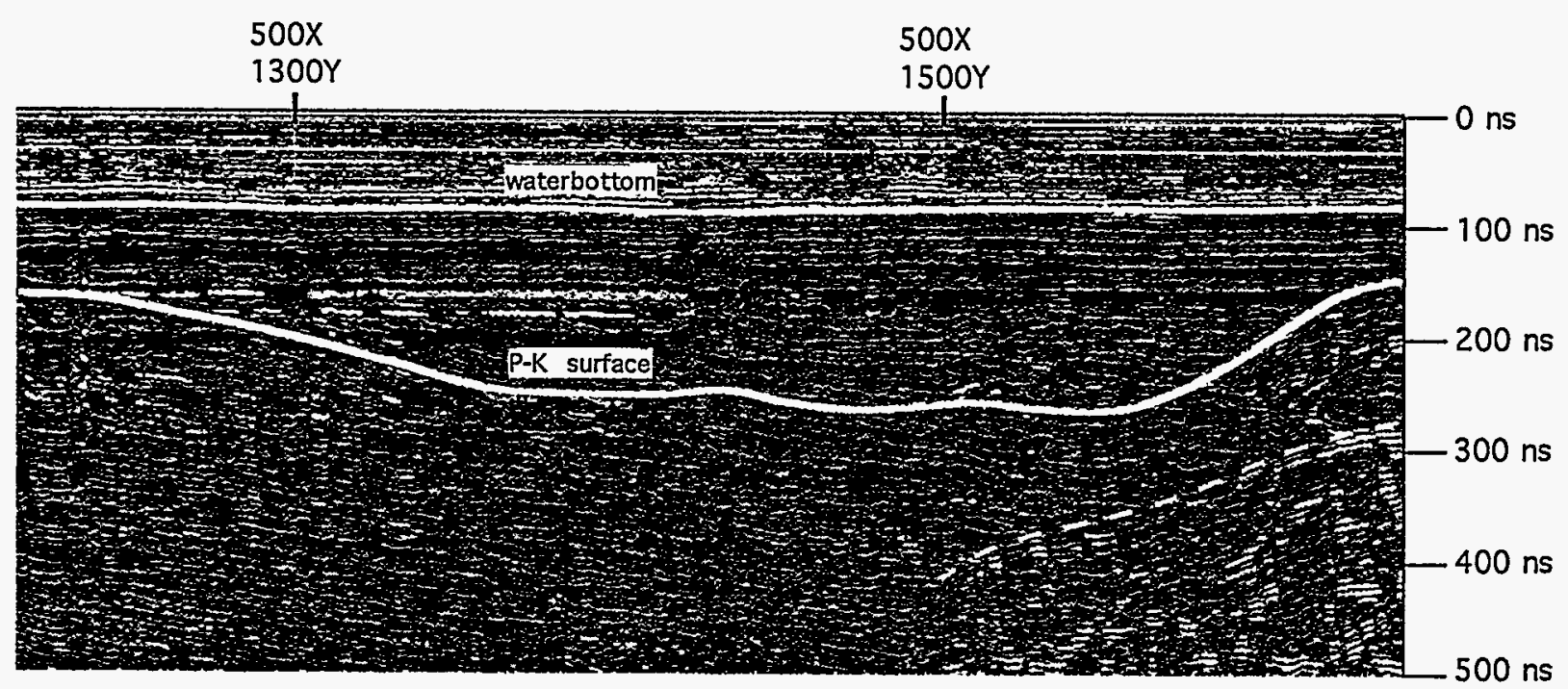

47B

FIGURE 47 A: Area 6 GPR Profile; B: Area 6 GPR Profile with Interpretation 


\section{Marine Seismic Reflection}

\subsection{Approach}

Offshore seismic-reflection records were acquired along various transects in the Gunpowder and Bush Rivers between July 8, 1994, and July 17, 1994. Of these, the July 11, 1994, record provided continuous coverage between the south side of Tapler Point and Eagle Point. The location of this line is shown in Figure 48.

Bubble Pulser seismic-reflection data were acquired in order to obtain a medium- to highresolution reflection record of stratigraphy to $1 / 8 \mathrm{~s}$ two-way time (TWT). The frequency of the sound source ranged from $365 \mathrm{~Hz}$ to $1,030 \mathrm{~Hz}$. The primary value of Bubble Pulser data in this area is for mapping the Top Cretaceous reflector, locally referred to as the PleistoceneCretaceous $(\mathrm{P}-\mathrm{K})$ unconformity. In areas where underlying Cretaceous reflectors are discordant with overlying Pleistocene reflectors, the $\mathrm{P}-\mathrm{K}$ unconformity is identified. In areas where both the Cretaceous and Pleistocene reflectors are concordant, identification of the P-K unconformity is less certain. Bubble Pulser data images the Top Cretaceous reflector as a continuous, mappable reflector, although minor undulations $( \pm 4 \mathrm{ft}$ ) in the Top Cretaceous surface are masked because of the large, multiple amplitudes propagated from overlying, flat Pleistocene strata.

The interpretation of stratigraphy on this seismic line follows techniques outlined in seismic stratigraphic analysis (Mitchum, Vail, and Thompson 1977). Only the Top Cretaceous (P-K) unconformity is mapped in this exercise (Figure 49). Areas are identified in which the Cretaceous layer is high and the Pleistocene layer is thin, as well as areas in which the Cretaceous layer is deep and the Pleistocene layer is thick. Areas in which Top Cretaceous reflectors are discordant with overlying Pleistocene strata are considered definitive picks, whereas areas in which these strata are characterized by concordance are considered interpretive picks. Mapping the Top Cretaceous surface, regionally, requires interpretation to connect picks of high confidence with those assigned lower confidence. However, as mentioned in the GPR section, without adequate palynological data, it is possible that the mapped reflector could be a HolocenePleistocene boundary or an intra-Pleistocene contact.

\subsection{Seismic Reflection Interpretations}

The Top Cretaceous is interpreted predominately as a high between Tapler Point and Eagle Point, with the exception of four minor, localized lows, which are described in the following text.

The first interpreted low (labeled 1a, Figure 49) is a broad feature located along the south shore of Tapler Point that exhibits a maximum depth of approximately 9.5 milliseconds (ms) 


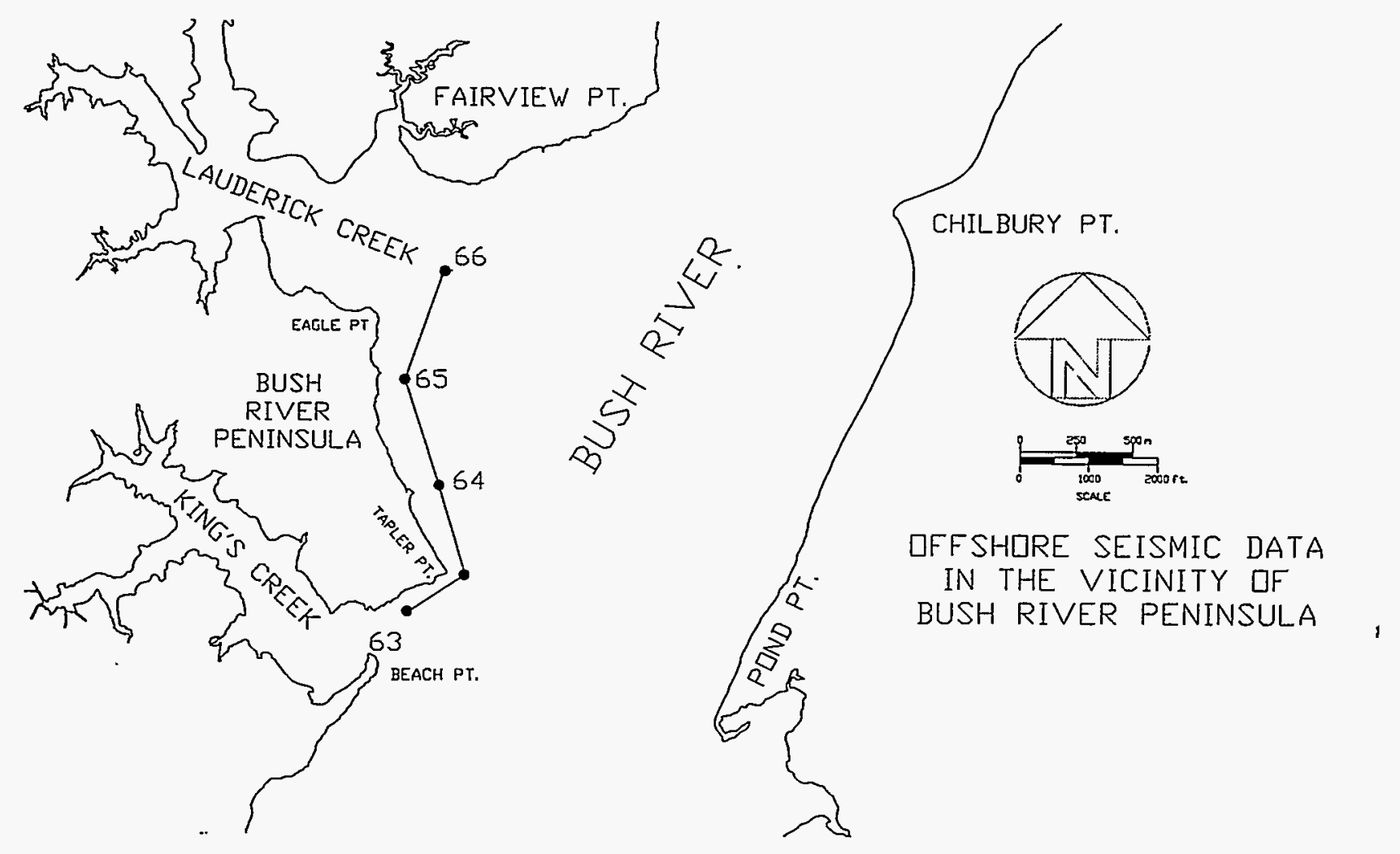

FIGURE 48 Location of Marine Seismic Profile

TWT, which can be converted to $23 \mathrm{ft}$ below MSL by using a velocity of $4,920 \mathrm{ft} / \mathrm{s}(1,500 \mathrm{~m} / \mathrm{s})$. This feature may result from Pleistocene erosion or channeling in an area where the Top Cretaceous was deep. This same feature is imaged again immediately north of the turn around Tapler Point (labeled 1b, Figure 49), but it appears more spatially restricted because of the orientation of this transect.

The second interpreted structural low (labeled 2, Figure 49) is mapped in the vicinity of the Bush River Dock, where Bubble Pulser data indicate a broad sag at the Top Cretaceous. The interpreted maximum depth of this feature is approximately $9.5 \mathrm{~ms}$ TWT, which can be converted to $23 \mathrm{ft}$ below MSL. This interpretation is largely unsupported by GPR and EM data because these data sets were discontinuous in the vicinity where seismic profiling indicates the sag is best developed. This feature may result from Pleistocene erosion, or channeling, in an area where the Top Cretaceous is deep. The breadth of this feature may suggest an orientation roughly parallel to the eastern shoreline of the BRP.

The third interpreted sag in the P-K unconformity (labeled 3, Figure 49) is located immediately south of Fix 65 . The maximum depth of this feature is approximately $10 \mathrm{~ms}$ TWT, which can be converted to $24.5 \mathrm{ft}$ below MSL. This low is not seen on GPR data acquired closer to shore. 


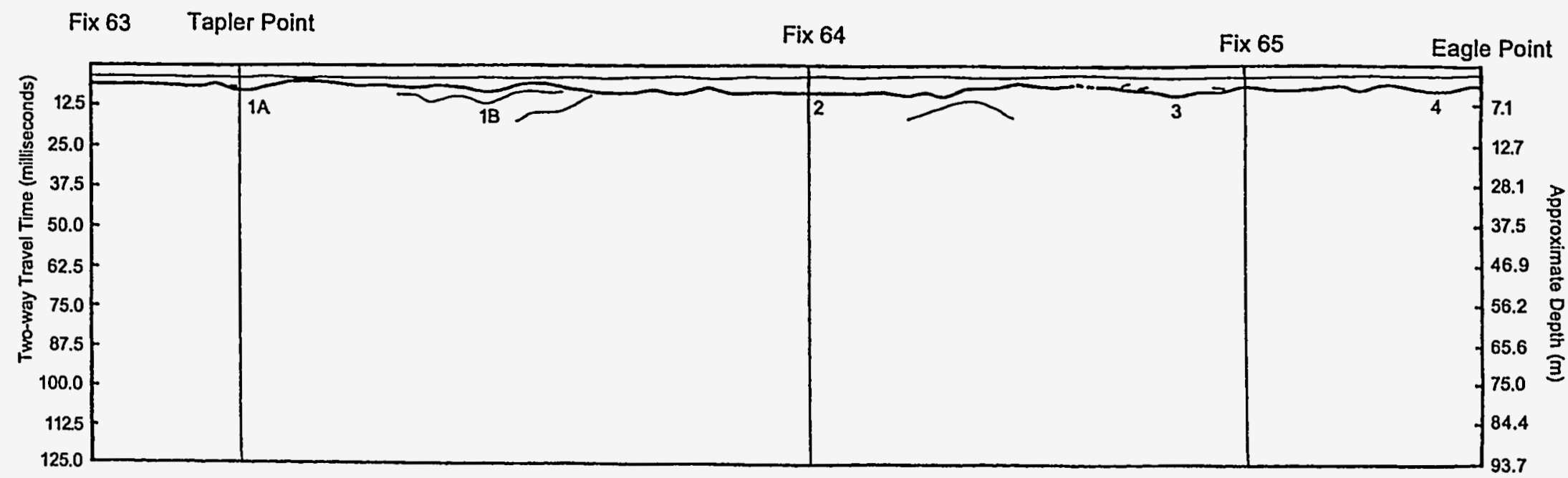

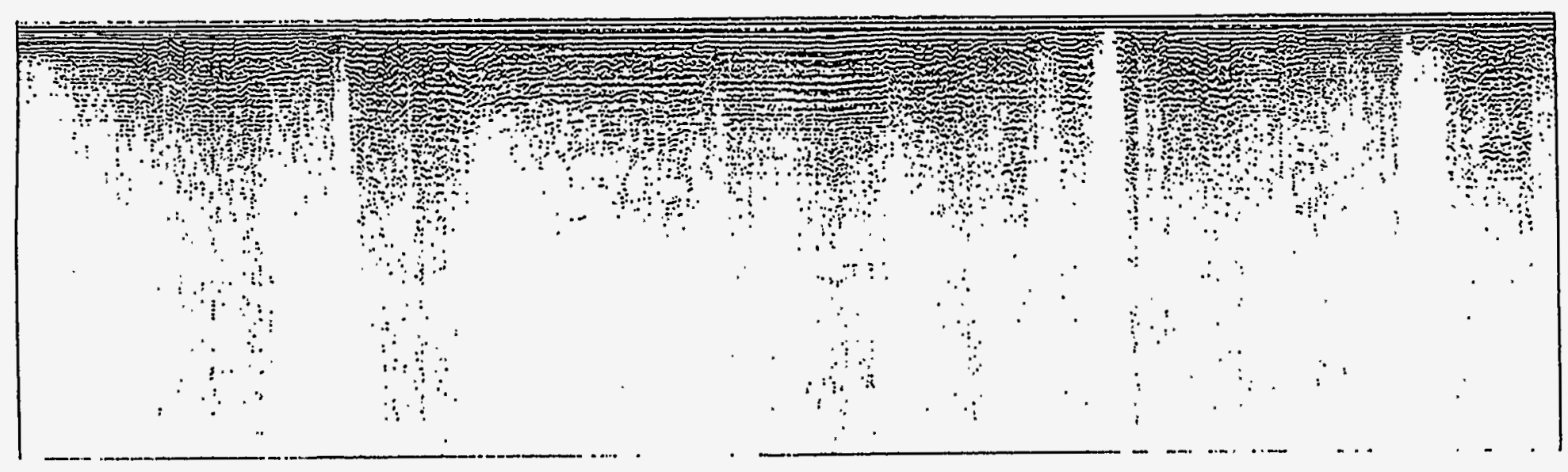

FIGURE 49 Marine Seismic Reflection Profile (Tapler Point - Eagle Point) 
The fourth interpreted structural low (labeled 4, Figure 49) is mapped offshore from the 22nd Street Landfill and south of Eagle Point. Bubble Pulser data indicated a minor sag at the level of the Top Cretaceous. Assuming the floor has been interpreted correctly, the maximum depth of this asymmetrical feature is approximately $8.5 \mathrm{~ms}$ TWT, which can be converted to $21 \mathrm{ft}$ below MSL. This low may result from the erosion of a spatially restricted Pleistocene paleochannel. Both the minor low and the broader low are corroborated on GPR data in Area 6.

The important issue that has been addressed in the previous seismic depth estimates is the expected scale of paleochannel features east of the BRP. The maximum depth measured in these three examples is approximately $25 \mathrm{ft}$. Previous researchers have mapped the dimensions of paleochannels in the valleys of the ancestral Susquehanna and have estimated that these paleochannels have incised between 90 and $150 \mathrm{ft}$ below present MSL (Colman et al. 1990; Colman and Mixon 1988; Benson 1995, personal communication). The paleochannels mentioned above represent either very late, perhaps basal, Holocene erosion by minor tributaries into the greater Bush River paleochannel complex or localized gullying features that anastamose into larger paleochannels offshore. 


\section{Discussion}

\subsection{Synthesis of Anthropogenic Anomalies}

Geophysical technologies, including magnetics, electromagnetics, side-scan sonar, and GPR, have been used in the environmental investigation of the waters surrounding the BRP. These geophysical techniques, combined with visual and other supporting evidence, have helped identify anomalies of anthropogenic origin.

\subsubsection{Area 1}

Area 1 encompasses the shoreline off the former Kings Creek Disposal Site and includes a larger embayment off of the 30th Street Landfill. The significant anthropogenic anomalies within Area 1 were only detected with the EM-31 and magnetometer. Two linear trends of anomalies in the northwestern end of the survey area are seen in both EM-31 and magnetics data (Figures 18 and 22). These linear trends are most likely sourced by waste debris where extensive buried munitions were subsequently discovered by U.S. Navy demolition experts. During field operations associated with this study, the Navy team extracted miscellaneous debris from this anomalous area. The majority of the anthropogenic anomalies are located along the shoreline, from both the former Chemical Munitions Disposal Site and 30th Street Landfill. These anomalies are only detected with the magnetometer and do not appear to extend more than $10-20 \mathrm{ft}$ offshore (Figure 18). Further offshore, there are also several isolated point-source magnetic anomalies of unknown origin. Side-scan sonar and GPR did not detect any significant anomalies of anthropogenic origin in Area 1.

\subsubsection{Area 2}

Area 2 begins at the southeast end of Area 1, continues toward the southeast in Kings Creek, and includes the offshore area surrounding CMBS-3. In the southeast corner of Area 2, near CMBS-3, a side-scan sonar anomaly might be associated with debris push-out or bank failure from erosion (Figure 9). There is no corresponding magnetic or conductivity anomaly associated with this feature. The only other detected anthropogenic anomalies are two singlepoint magnetic anomalies located over $100 \mathrm{ft}$ offshore (Figure 19). These are small iron-bearing objects of unknown origin.

\subsubsection{Area 3}

Area 3 extends 1,660 ft in an approximate east-west direction along the southern portion of the BRP to slightly beyond Tapler Point. Large magnetic anomalies were detected in both the 
western and eastern ends of Area 3, as were some scattered small-point anomalies. A large ferrous object(s) is present in the western end of the survey grid. The middle portion of Area 3 is devoid of magnetic anomalies, indicating the absence of ferromagnetic objects. Significant magnetic anomalies are present near the shore at Tapler Point. This section onshore has been designated as CMBS-2. Previous magnetic surveys performed onshore indicate this area contains materials that generate positive magnetic anomalies. Visible metallic debris is present at the surface (see Davies et al. 1995b). Unknown polygonal-shaped structures are also evident in the side-scan sonar data in this same general area, near Tapler Point (Figure 7). The assumed buried cable in the eastern end of Area 3 is both a magnetic and an EM-31 anomaly.

\subsubsection{Area 4}

Area 4 extends $1,330 \mathrm{ft}$ in a north-northwesterly direction along the eastern shore of the BRP from Tapler Point to the Bush River Dock. Large magnetic and EM-31 anomalies of anthropogenic origin were detected near Tapler Point and near the Bush River Dock. Two linear anomalies extending offshore to beyond the survey boundary are thought to represent underwater cables (Figures 21 and 25). One of these cables is also seen at the beginning of the GPR profile for Area 4. The EM-31 and magnetic anomalies at the northern end of the survey area are most likely associated with activities on the Bush River Dock. The origin of the numerous small-point magnetic anomalies in the middle of the survey is unknown. The side-scan sonar detected what is suspected to be a piling or footing (Figure 13) several hundred feet south of Bush River Dock and at least $200 \mathrm{ft}$ offshore.

\subsection{Paleochannel Synthesis}

The identification and delineation of Pleistocene paleochannels by nonintrusive, remotely sensed methods has been a focus of ANL's geophysical work at APG. Paleochannels are thought to be major fluid pathways in which contaminants, deposited onshore, can be transported offshore. Coarse clastics deposited at the base of each valley-fill depositional cycle are hydraulically conductive and can transport fluids laterally within the paleochannel pathways and

vertically when Pleistocene aquifers are juxtaposed against Cretaceous aquifers. Mapping Pleistocene paleochannels provides a first-order approximation for mapping the surficial aquifer confined therein. The geophysical basis for identifying and delineating Pleistocene paleochannels within each sub-area for this report is provided in the following discussion.

\subsubsection{Area 1}

GPR identified a paleochannel on the Area 1 transect between grid markers $1300 \mathrm{X}$ and the end of the line at $1700 \mathrm{X}$. Projecting the slope of the valley walls to a hypothetical floor yields a maximum time depth of approximately $510 \mathrm{~ns}$ at a grid location of approximately 1530X. Assuming an average two-way travel time (TWT) of $9 \mathrm{~ns} / \mathrm{ft}$ for paleochannel sediments, 
the valley floor is calculated at $56 \mathrm{ft}$ below MSL. The EM-31 map indicates the presence of a linear, offshore-trending positive conductivity anomaly (refer to Figure 22); a plot of the EM-31 anomaly in relation to the same GPR transect indicates that the EM anomaly is not coincident with the axis of the channel, but rather it plots toward the channel's western flank (Figure 50). The EM-31 only measures conductivities in the upper 18-20 ft of the paleochannel. Greater clay thicknesses along the western flank of the offshore paleochannel extension provide one explanation for the high-conductivity signature. Water depth appears greatest above areas where this paleochannel is well developed. Offshore vibracores should be taken across the Area 1 paleochannel to identify geologic controls governing this phenomenon.

Onshore EM data ties with the offshore data. EM-31 mapping, in the ANL onshore report (Davies et al. 1995a), defined a linear, high-conductivity anomaly spatially coincident with EM-31 linear anomalies identified in the offshore data set. GPR data acquired offshore imaged the paleochannel in its entirety, while the onshore GPR data imaged only small parts of a complex, bifurcating system.

The orientation of the Area 1 paleochannel is resolved by tying onshore to offshore data (Figure 51). This paleochannel flowed to the southwest and most likely joined the greater Kings Creek paleochannel. This paleochannel is manifest at mean sea level as an embayment in the vicinity of the 30th Street landfill, with an accompanying onshore wetland area dominated by Phragmites sp. reeds. This orientation classifies the Area 1 paleochannel as a subsequent valley, coursing along structural strike in easily erodible, subcropping Lower Cretaceous sediments.

\subsubsection{Area 2}

Two paleochannel features were identified in Area 2 data. Support for this interpretation comes from EM-31, GPR, well borings, and onshore physiographic expression. This interpretation is consistent with previous onshore work.

The first paleochannel identified is actually a continuation of the paleochannel identified at the south end of Area 1 data. Offshore GPR identifies the paleochannel's southeastern valley wall in the first $75 \mathrm{ft}$ of data (grid values $425 \mathrm{X}$ to $500 \mathrm{X}$ ). Interpretation of the EM-31 data does not indicate a positive bulk conductivity anomaly in this part of the paleochannel for reasons previously discussed. A minor erosional feature is recognized between grid values $670 \mathrm{X}$ and $1000 \mathrm{X}$.

The second paleochannel was identified in Area 2 GPR data between grid value $1320 \mathrm{X}$ and the end of the profile at grid value $1700 \mathrm{X}$. The northeast by southwest orientation of this line segment is essentially parallel to the northeast valley wall of this paleochannel, thus explaining the low, flat disposition of the P-K unconformity in this area. To the south, GPR coverage changes orientation to northwest by southeast and appears to profile across the valley, thus explaining the rapid change from dipping Lower Cretaceous reflectors into the valley to an 


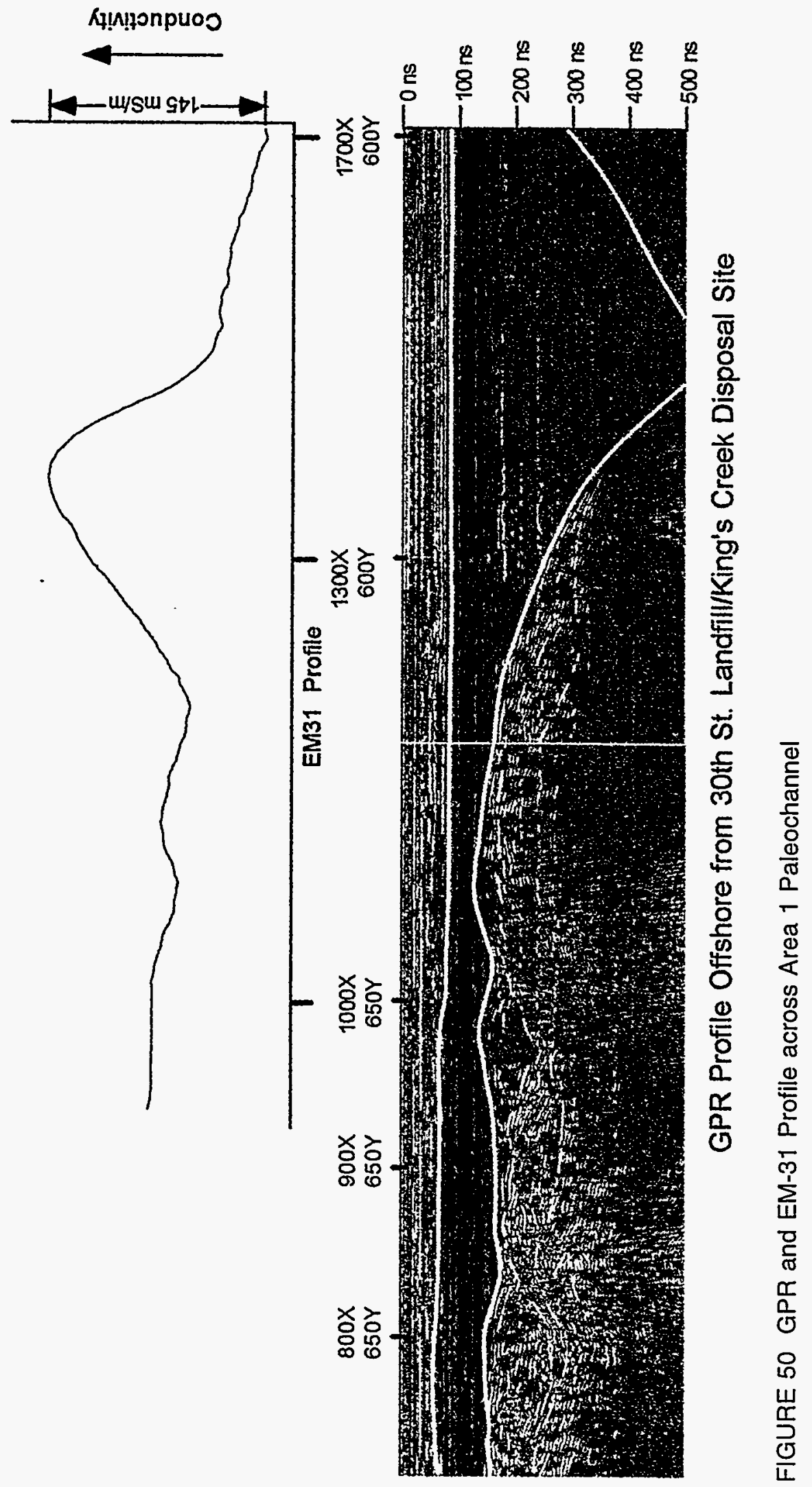




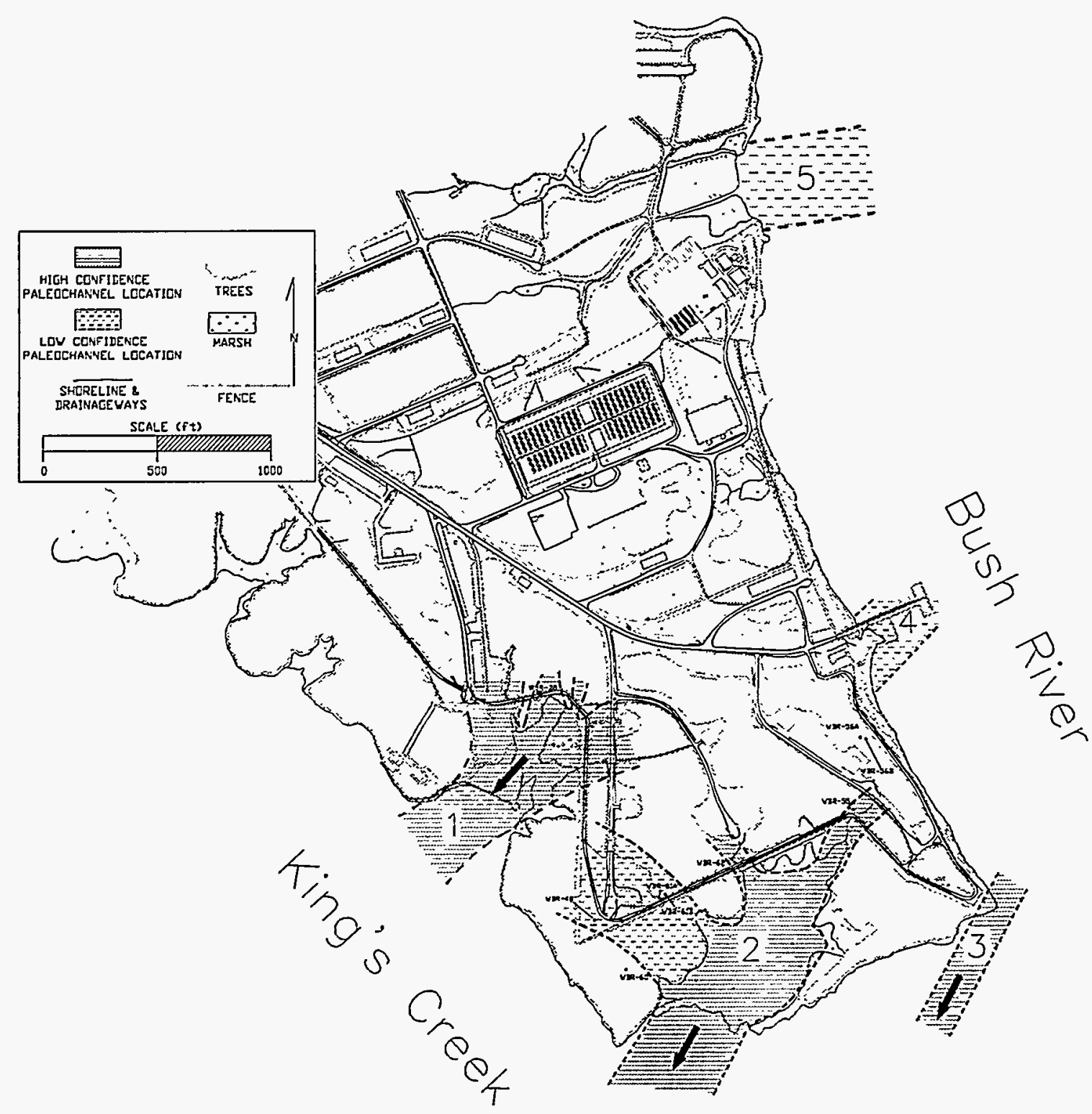

FIGURE 51 Locations of Paleochannels on the Basis of Geophysical Surveying

absence of Lower Cretaceous reflectors between grid values $1500 \mathrm{X}$ and $1700 \mathrm{X}$. The inability of GPR to image Lower Cretaceous reflectors in this paleochannel may be due to the presence of highly organic clays within the channel fill and/or a rapidly deepening Pleistocene section. Either or both reasons could account for this rapid attenuation of the primary signal. Like the Area 1 paleochannel, the Area 2 paleochannel is oriented northeast by southwest and occupies a subsequent stream course. By projecting the dip of the valley walls downward to the hypothetical valley floor, the estimated depth of this paleochannel is approximately $50-60 \mathrm{ft}$. EM-31 data identify a linear-trending high-conductivity feature spatially coincident with the mapped GPR feature. 


\subsubsection{Area 3}

A continuation of the paleochannel identified in Area 2 data is evident in Area 3 data between grid values $500 \mathrm{X}$ and $700 \mathrm{X}$. The southeastern valley wall of this paleochannel is seen around grid value $700 \mathrm{X}$. The slope of the valley wall appears low because of the angle at which the valley wall and the Area 3 GPR transect intersect.

A minor feeder channel may be present between grid values $1520 \mathrm{X}$ and $1630 \mathrm{X}$, depending on whether the wedge of sediment mapped between 150 and 250 ns is Pleistocene or Lower Cretaceous. Water depth is greater above the thick part of this feature than it is on the flank, thus suggesting that this may be a Pleistocene feature. The EM-31 map does not support this interpretation. On the basis of the available data set, this feature is not recognized as a paleochannel.

A paleochannel is recognized at the eastern termination of GPR Area 3, between grid value $1700 \mathrm{X}$ and the end of the line. The slope of the northwestern valley wall appears low because of the angle at which the GPR transect crosses this feature. EM-31 data are used to support the interpretation of a paleochannel here. EM-31 anomalies provide convincing evidence that the orientation of the paleochannel is similar to that of the two previously discussed paleochannels in the BRP (i.e., coursing towards the southwest) (Figure 51). A pattern of subsequent stream courses for these paleochannels appears to be the dominant trend. Unlike the previously discussed paleochannels, which displayed onshore wetlands, the orientation of this feature is tangent to the coastline and shows no such association.

Perhaps the most convincing argument for the presence of a paleochannel tangent to Tapler Point comes from a seismic profile (Figure 49). The Bubble Pulser record in the vicinity of Fix 63 (Figure 49) reveals a channelized low that attains a maximum depth of about $-19 \mathrm{ft}$ MSL.

\subsubsection{Area 4}

The southeastern valley wall of the paleochannel identified at the end of Area 3 data is evident between grid values $600 \mathrm{Y}$ and $700 \mathrm{Y}$ on the Area 4 line. The exact position of the valley wall is difficult to map because of the high multiple content, which is propagated downward by flat-lying Pleistocene stratigraphy. GPR data for areas 3 and 4 do not tie but instead are separated by approximately $250 \mathrm{ft}$. The paleochannel appears much wider than it actually is because the Area 4 GPR profile crosses the valley at an oblique angle. Water is slightly deeper in areas where this paleochannel reaches maximum development. Assuming the valley floor is imaged at position 500Y, the approximate depth is $-33 \mathrm{ft} \mathrm{MSL}$, a value that is determined on the basis of velocities of $18 \mathrm{~ns} / \mathrm{ft}$ for the water column and $9 \mathrm{~ns} / \mathrm{ft}$ for the Pleistocene. This feature is deeper than the $-19 \mathrm{ft}$ MSL feature obtained from the Area 3 seismic calculation. 
To the north, a paleochannel appears to be developing at the end of the line, between grid values 1750 Y and 1900Y. GPR and EM-31 data were terminated at this position because the Bush River Dock precluded continuous profiling farther north. Bubble Pulser results, however, indicate the maximum development of a broad Lower Cretaceous low in the vicinity of the dock. Measurements indicate the P-K unconformity may be as deep as $-27 \mathrm{ft}$ MSL beneath the dock. Uniboom data show a wedge of very recent muds occupying a sag in this area. A channelized low exists in this area, but the orientation of the channel is uncertain. It is mapped at this time like the other paleochannels (i.e., coursing down structural strike as a subsequent stream).

\subsubsection{Area 5}

Area 5 GPR imaged the northern valley floor and valley wall of the paleochannel identified at the end of Area 4 GPR. Maximum development occurred at grid value 450Y, at which a depth of $-28.6 \mathrm{ft}$ MSL was calculated by assuming $18 \mathrm{~ns} / \mathrm{ft}$ for water velocity and $9 \mathrm{~ns} / \mathrm{ft}$ for the velocity of Pleistocene sediments. Additional studies are needed to determine the orientation of this paleochannel, as discussed previously. Evidence of a channel cut or dredging activity is seen within the Pleistocene fill at position $500 \mathrm{Y}$. The location of DM2, a depthcalibrated tie to the A-A' cross section, is shown at position 545Y. The Lower Cretaceous remains structurally high for the remainder of the Area 5 GPR record.

Bubble Pulser seismic records reveal two areas immediately north of the Bush River Dock in which multiple generation Pleistocene channel fills are seen. Flat-lying valley fill reflectors, which terminate laterally into valley wall features, distinguish these sediments as Pleistocene. Multiples propagating downward from flat-lying acoustic boundaries and from concave-up valley reflectors create artifacts in these records that make the Pleistocene look thicker than it actually is.

\subsubsection{Area 6}

Area 6 GPR reveals two strong downward propagating, ringing multiples between grid values $60 \mathrm{Y}$ and $185 \mathrm{Y}$ (immediately offshore from the RAD storage site). Both features appear to be anthropogenic and both originate in the upper foot or two of Quaternary sediments. Neither magnetics nor EM-31 were collected in this area by ANL.

A broad, shallow, paleochannel was identified between grid value 600Y and the end of the line at approximately position $1100 \mathrm{Y}$. The maximum development of this paleochannel occurs at approximately position $990 \mathrm{Y}$, where a depth of $-22.5 \mathrm{ft}$ MSL was calculated. Evidence of multiple cut-and-fill episodes is seen within this larger channel-fill complex. Additional studies are needed to understand the complex stratigraphy of each channel fill, especially those transporting potential contaminants offshore. 
Bubble Pulser seismic records indicate a paleochannel complex immediately south of the 22nd Street landfill (south of Fix 65). The maximum depth of this feature is approximately $-26.0 \mathrm{ft}$. This seismic-calculated depth is consistent with the previous depth estimate from GPR. Uniboom results indicate an area with an additional surface mud layer immediately overlying the mapped paleochannel. The orientation of this feature is coincident with an onshore wetland dominated by Phragmites $s p$. reeds. On the basis of available data, this paleochannel appears to course toward the east-northeast, indicating a different orientation and flow direction than those of previously discussed paleochannels. 


\section{Summary and Conclusions}

In summary, geophysical evidence is present for five paleochannels in the vicinity of the $\mathrm{BRP}$ (Figure 51). High confidence is assigned to the orientation of three of these features.

The Area 1 paleochannel and the paleochannel in Areas 2 and 3 are southwest-flowing, major subsequent paleochannel courses, and each has incised to a depth greater than $-51 \mathrm{ft}$ MSL. Likewise, the Area 6 paleochannel is a subsequent stream course, but it flows toward the eastnortheast and has incised to approximately $-25 \mathrm{ft}$ MSL. High confidence is assigned to the mapped orientation of these paleochannels. The paleochannel mapped tangent to Tapler Point has incised to a depth of about $-33 \mathrm{ft} \mathrm{MSL}$. This paleochannel is interpreted to have a southwestflowing, subsequent orientation, but uncertainties dictate a moderate confidence in this interpretation. The paleochannel interpreted beneath the Bush River Dock has incised to a depth of about $-28 \mathrm{ft} \mathrm{MSL}$, but its orientation is unknown.

Drainage basins were spatially very restricted, and the localized erosion was essentially a gullying phenomenon. Anastomosing gullies formed a network by which upland terranes were drained, and these, in turn, joined more permanent courses offshore (e.g., the Bush River and Susquehanna River systems). Pleistocene sediments removed by paleochannels during sea level low stands were largely redistributed during highstands to fill these same preferred drainageways.

A more fundamental control governing the orientation of Pleistocene paleochannels deals with the substrate on which they are deposited. In the GPR-interpreted paleochannels presented in this report, internal reflectors within the underlying Lower Cretaceous do not appear to be terminated by the Pleistocene channeling event. Instead, the Pleistocene channels appear to preferentially occupy interlobate depositional fairways in the Lower Cretaceous, which have become low because of differential compaction or other processes not yet recognized. Lobate depositional fairways (e.g., distributary mouth bars) commonly form parallel to depositional and structural strike in the modern, prograding Mississippi Delta. Successively younger Lower Cretaceous members are evident on GPR records. In such a setting, it is not unreasonable to assume fairways would develop that directly reflect softer or more consolidation-prone substrate.

Additionally, the fact that multiple generations of Pleistocene channels tend to occupy the same fairway, as evidenced in GPR and seismic records, is testimony that subsidence is greater beneath thick sections of consolidation-prone sediments (i.e., Pleistocene channel fills) than in areas outside of them. This observation is supported by GPR records indicating a direct relationship between increased water depth and the thickest parts of channel fills.

The construction of a meaningful geological cross section in the vicinity of the BRP was the focus of a work session (April 19, 1995) hosted by Aberdeen Proving Ground. In attendance were representatives of General Physics Corporation, HAZWRAP, USGS, COE, and ANL. The most important conclusion that came from this session is that the geological framework regarding the depth of Pleistocene sediments is poorly understood, and the only deep wells that have been 
examined for diagnostic palynology differentiating Pleistocene sediments from underlying Lower Cretaceous sediments were the BR-1, BR-2, BR-3, BR-4, and BR-5 deep borings (Figures 1 and 3). All other interpretations, previously made on other wells, are suspect. In addition, the value of the offshore GPR data was seen as a data set of very high confidence for differentiating Pleistocene from Lower Cretaceous layers on the basis of reflector discordance and fundamentally different styles of deposition.

In light of these conclusions, a west-to-east cross section was constructed that ties the palynologically calibrated BR-5 boring and honors depth estimates from offshore GPR data in the line of the section (Figure 52, Cross Section $A-A^{\prime}$ ). The $A-A^{\prime}$ cross section is shown in Figure 53. The details of the important datums in this section are provided in the following discussion.

The BR-5 boring encountered the top of the Lower Cretaceous section (i.e., the P-K unconformity) at a structurally high elevation of $-2.5 \mathrm{ft} \mathrm{MSL}$, indicating that $17.5 \mathrm{ft}$ of Pleistocene deposits was encountered. Three additional datums were recognized within the Lower Cretaceous section: (1) a correlative shale datum (encountered at $-55.5 \mathrm{ft} \mathrm{MSL}$ ), (2) the top of the Canal Creek Aquifer (encountered at $-83.2 \mathrm{ft}$ MSL), and (3) the base of the Canal Creek Aquifer (encountered at $-154.0 \mathrm{ft} \mathrm{MSL}$ ). The great depth of the BR-5 boring (235 ft measured depth, $-219.8 \mathrm{ft} \mathrm{MSL}$ ) provided for the penetration of a stratigraphically deeper aquifer, locally called the Lower Confined Aquifer.

The $\mathrm{CC}-11 \mathrm{~B}$ boring was not sampled for diagnostic palynology. The $\mathrm{P}-\mathrm{K}$ unconformity, therefore, had to be determined by other means. The P-K unconformity, in this boring, was identified at $-35.5 \mathrm{ft}$ MSL on the basis of GPR, which indicated a paleochannel at least $40 \mathrm{ft}$ thick south of CC-11B. A gamma ray log indicated a fining upwards sand body with a scour base at $-35.5 \mathrm{ft}$ MSL. The greater thickness of Pleistocene sediments at $\mathrm{CC}-11 \mathrm{~B}$ represents a local aberration from thin values recorded on either side of the boring. Paleochannels in the vicinity of the BRP are spatially restricted and incise locally on the order of 50-65 ft. Two additional datums were recognized within the Lower Cretaceous section: (1) the correlative shale datum (encountered at $-57.0 \mathrm{ft} \mathrm{MSL}$ ) and (2) the top of the Canal Creek Aquifer (encountered at $-105.5 \mathrm{ft}$ MSL).

The USGS \#3 boring also was not sampled for diagnostic palynology. The P-K unconformity was identified at $14 \mathrm{ft}$ depth $(+7.0 \mathrm{ft} \mathrm{MSL})$ on the basis of a sample description $\log$, which indicated a sharp change from light brown silts and loam (typical of the Pleistocene) to varicolored clays and hematite-cemented sands and gravels (typical of the Lower Cretaceous). The other datums of interest were identified as follows: (1) the correlative shale datum (encountered at $-53.0 \mathrm{ft} \mathrm{MSL}$ ) and (2) the top of the Canal Creek Aquifer (encountered at $-112.0 \mathrm{ft}$ MSL).

The P-K unconformity is imaged by GPR at DM1 and DM2 (see Figures 54 and 55) in two locations along the line of the A-A' cross section. However, without adequate palynological 


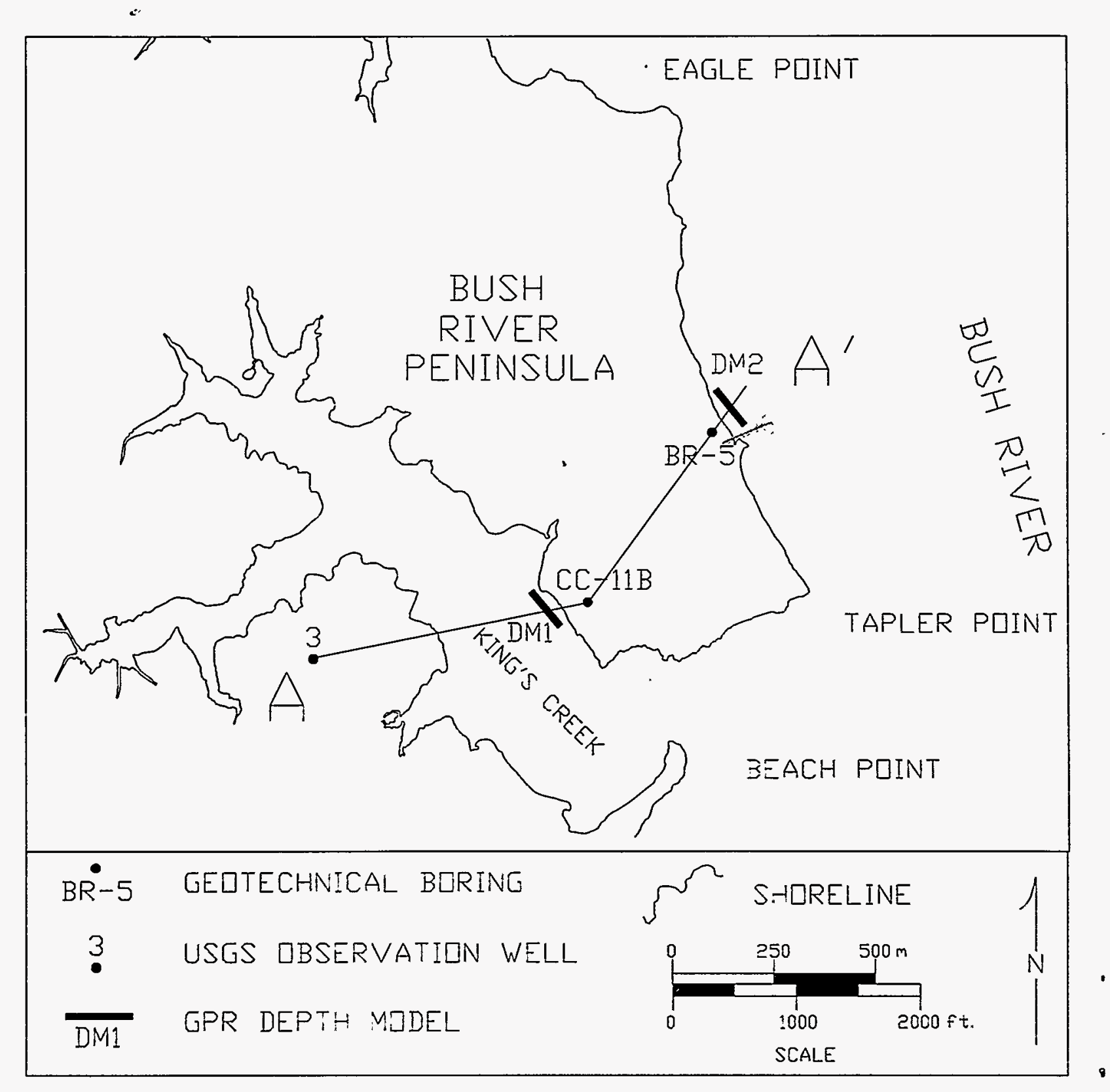

FIGURE 52 Locations of Cross Section A-A' 


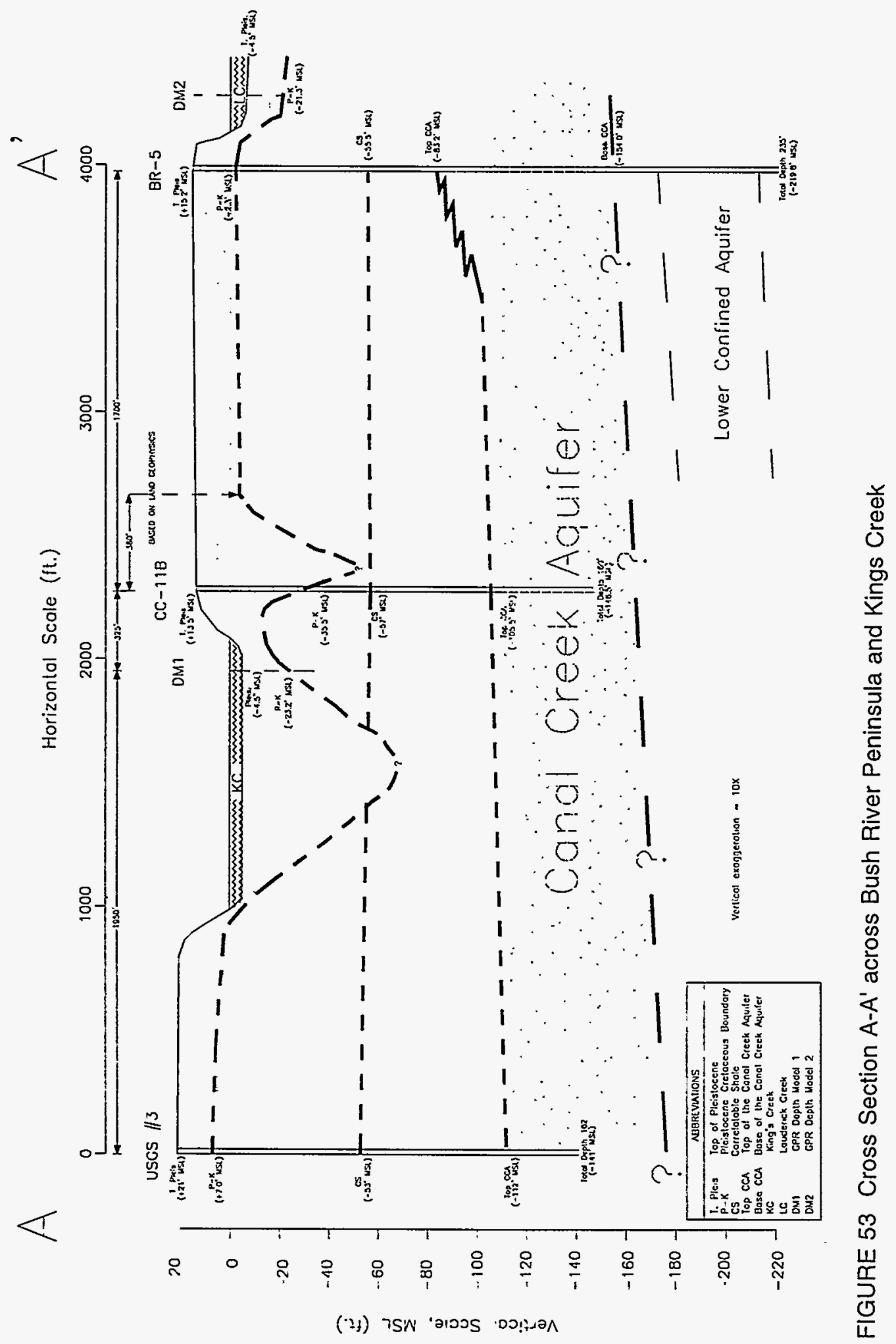




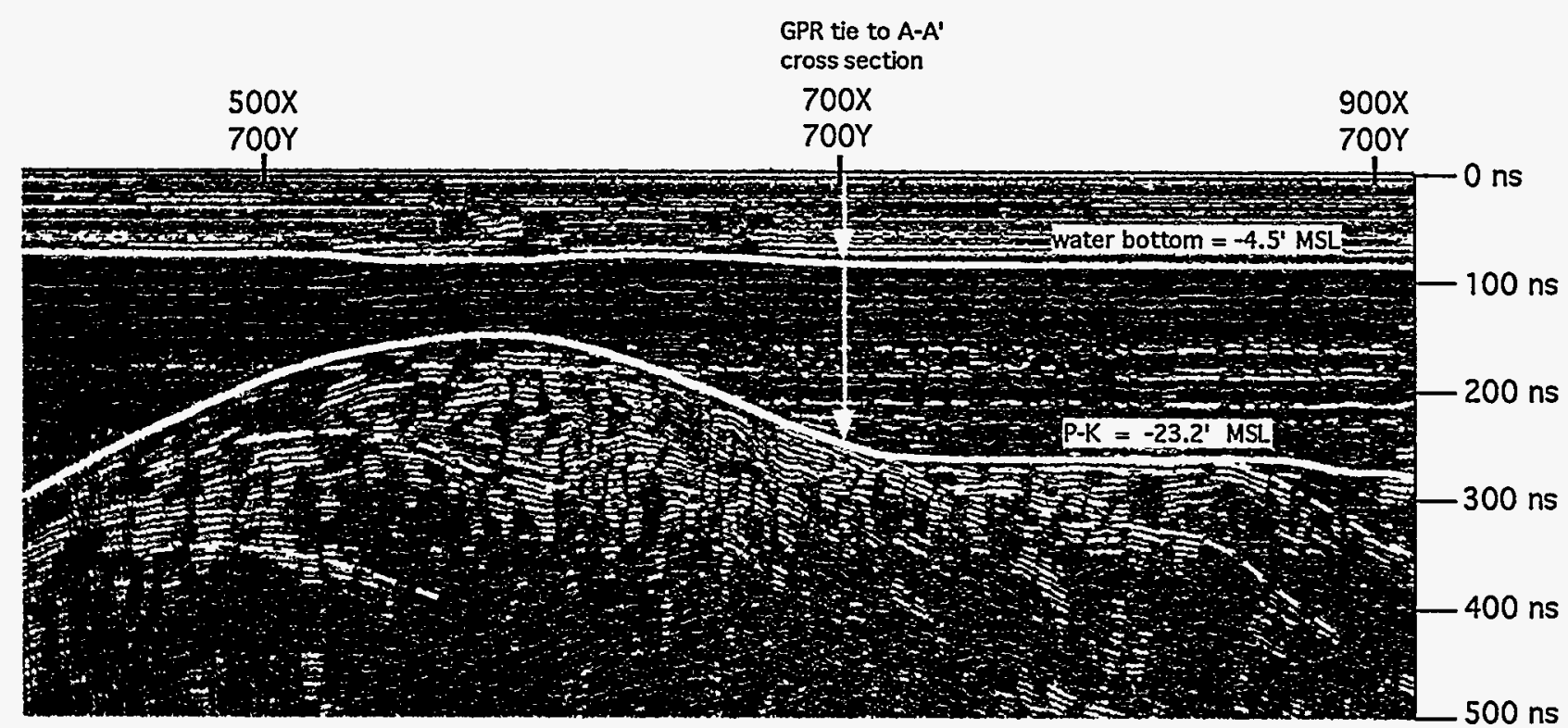

FIGURE 54 GPR Depth Model \#1

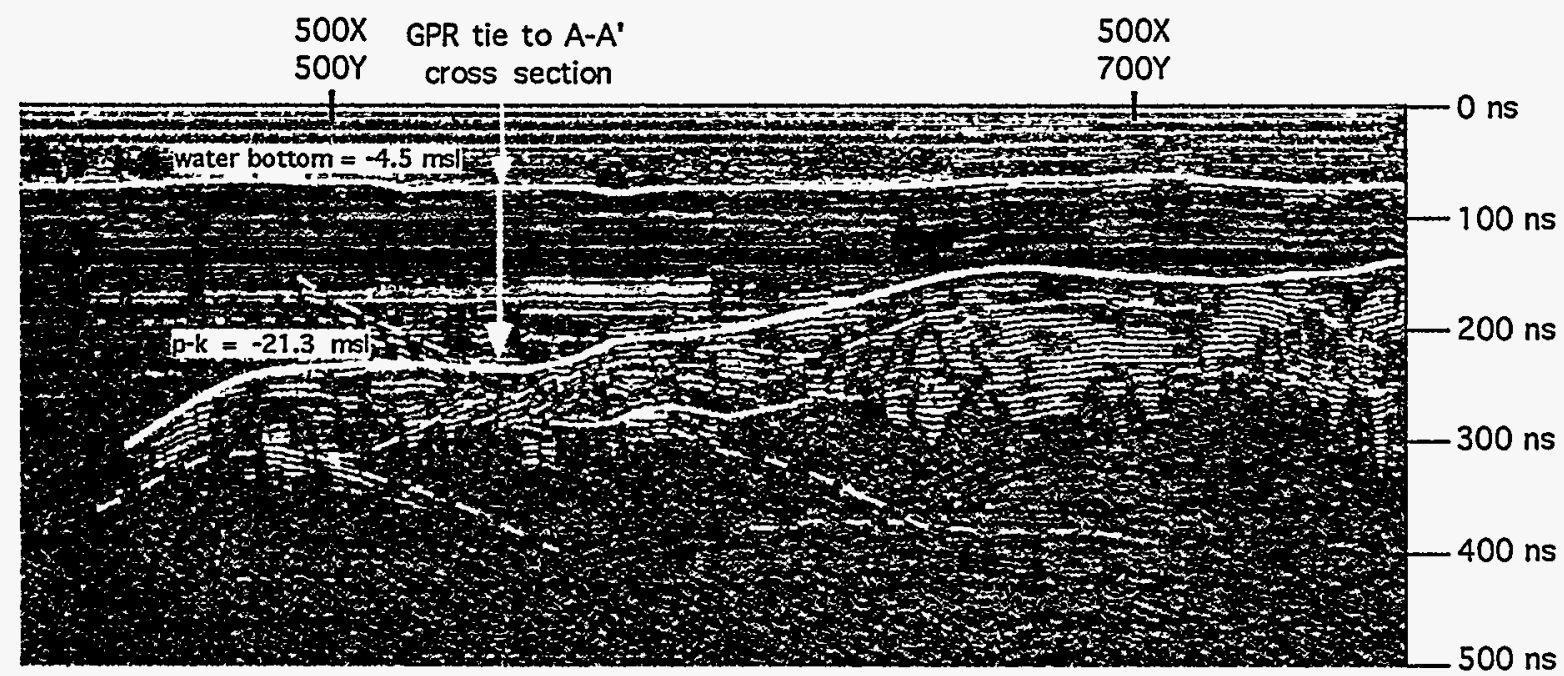

FIGURE 55 GPR Depth Model \#2

data, it is possible that the mapped reflector could be a Holocene-Pleistocene boundary or an intra-Pleistocene contact. DM1 refers to the GPR depth model, which constrains the P-K interpretation on the eastern side of Kings Creek (Figure 54). The water column at the A-A' tie position measures $81 \mathrm{~ns}$ in time thickness, TWT, which corresponds to a thickness of $4.5 \mathrm{ft}$ at a velocity of $18 \mathrm{~ns} / \mathrm{ft}$ TWT. Pleistocene sediments at this tie location measure $168 \mathrm{~ns}$ in time thickness, TWT, which corresponds to a thickness of $18.7 \mathrm{ft}$ at a velocity of $9 \mathrm{~ns} / \mathrm{ft}$ TWT. DM2 (Figure 55) refers to the GPR depth model, which constrains the P-K interpretation on the western shore of Bush River. The water column at the A-A' tie position measures 82 ns in time thickness, TWT, which corresponds to a thickness of $4.5 \mathrm{ft}$ at a velocity of $18 \mathrm{~ns} / \mathrm{ft}$ TWT. Pleistocene sediments at this location measure $150 \mathrm{~ns}$ in time thickness, which corresponds to a 
thickness of $16.7 \mathrm{ft}$ at a velocity of $9 \mathrm{~ns} / \mathrm{ft}$ TWT. These GPR depth models provide valuable depth constraints for such cross sections, especially in areas between well control.

Together, the datums defined in A-A' exhibit little or no slope (Figure 53). The upper $80 \mathrm{ft}$ of the Lower Cretaceous section is characterized by varicolored clays, silts, sands, and lignites. Pleistocene paleochannels have locally incised into this substrate, which is critical for modeling boundaries for fluid flow models at APG. More deeply incised paleochannels can be found east and south of the BRP, many of which are deep enough to incise into the Canal Creek Aquifer. 


\section{References}

Bennett, R.R., and R.R. Meyer, 1952, Geology and Ground-Water Resources of the Baltimore Area, Maryland Department of Geology, Mines, and Water Resources, Bulletin 4.

Colman, S.M., and R.B. Mixon, 1988, "The Record of Major Quaternary Sea-Level Fluctuations in a Large Coastal Plain Estuary, Chesapeake Bay, Eastern United States," Paleogeography, Paleoclimatology, and Palaeoecology, 68:99-116.

Colman, S.M., et al., 1990, "Ancient Channels of the Susquehanna River beneath Chesapeake Bay and the Delmarve Peninsula," The Geological Society of America Bulletin, 102:1268-1279.

Cordell, L., J.D. Philips, and R.H. Godsen, 1992, Potential Field Geophysical Software: Version 2, U.S. Geological Survey, open-file report 92-18.

Daniels, J.J., 1990, Fundamentals of Ground-Penetrating Radar, SoftEarth Associates.

Daniels, J.J., R. Roberts, and M. Vendl, 1995, "Ground-Penetrating Radar for the Detection of Liquid Contaminants," Journal of Applied Geophysics, 343:195-207.

Davies, B.E., et al., 1995a, Environmental Geophysics at Kings Creek Disposal Site and 30th Street Landfill, Aberdeen Proving Ground, Maryland, report ANL/ESD/TM-83, Argonne National Laboratory, Argonne, Ill.

Davies, B.E., et al., 1995b, Environmental Geophysics of the Bush River Peninsula, Aberdeen Proving Ground, Maryland, report ANL/ESD/TM-89, Argonne National Laboratory, Argonne, Ill.

Dingman, R.J., H.F. Ferguson, and R.O. Martin, 1956, The Water Resources of Baltimore and Harford Counties, Maryland Department of Geology, Mines, and Water Resources, Bulletin 17.

Hansen, H.J., 1978, Upper Cretaceous (Senonian) and Paleocene (Danian) Pinchouts on the South Flank of the Salisbury Embayment, Maryland, and their Relationship to Antecedent Basement Siructures, Maryland Geological Survey, Report No. 29.

Kehrin, R.T., et al., 1988, The Surficial Sediments of the Chesapeake Bay, Maryland - Physical Characteristics and Sediment Budget, Maryland Geological Survey, Report No. 48.

Lorah, M.M., and D.A. Vroblesky, 1989, Inorganic and Organic Ground-Water Chemistry in the Canal Creek Area of Aberdeen Proving Ground, Maryland, U.S. Geological Survey, WaterResources Investigations Report 89-4022. 
McGinnis, L.D., et al., 1994a, Environmental Geophysics at Beach Point, Aberdeen Proving Ground, Maryland, report ANL/ESD-23, Argonne National Laboratory, Argonne, Ill.

McGinnis, L.D., et al., 1994b, Environmental Geophysics of the Pilot Plant on the West Branch of Canal Creek, Aberdeen Proving Ground, Maryland, report ANL/ESD/TM-74, Argonne National Laboratory, Argonne, Ill.

Mitchum, R.M., P.R. Vail, and S. Thompson, 1977, "Seismic Stratigraphy and Global Changes of Sea Level, Part 2: The Depositional Sequence as a Basic Unit for Stratigraphic Analysis", in Seismic Stratigraphy - Applications to Hydrocarbon Exploration, publisher, editor C.E. Payton.

Nemeth, G., 1989, RCRA Facility Assessment Report, Edgewood Area, Aberdeen Proving Ground, Maryland, prepared for U.S. Army Material Command by Aberdeen Proving Ground, Test and Evaluation Command, Aberdeen Proving Ground, Md.

NOAA: National Oceanic Atmospheric Administration, 1992, Head of Chesapeake Bay, Maryland (Nautical Chart), U.S. Department of Commerce.

Oliveros, J.P., and D.A. Vroblesky, 1989, Hydrogeology of the Canal Creek Area, Aberdeen Proving Ground, Maryland, U.S. Geological Survey, Water-Resources Investigations Report 894021.

Otton, E.G., and R.J. Mandle, 1984, Hydrogeology of the Upper Chesapeake Bay Area, Maryland, with Emphasis on Aquifers in the Potomac Group, Maryland Geological Survey, Report No. 39.

Ryan, D.J., 1953, The Sediments of Chesapeake Bay, Maryland Department of Geology, Mines, and Water Resources, Bulletin 17.

Southwick, D.L., J.P. Owens, and J. Edwards, Jr., 1969, The Geology of Harford County, Maryland, Maryland Geological Survey.

Thompson, M.D., 1994, unpublished information.

Thurmond, V., 1993, North-South Stratigraphic Cross-Section of the Bush River Area, Corp. of Engineers-Baltimore District, Internal Document. 